Portland State University

PDXScholar

\title{
Archaeological Feature Identification Through Geochemical Analysis of Arctic Sediments from the Cape Krusenstern National Monument, Northwest Alaska
}

Patrick William Reed

Portland State University

Follow this and additional works at: https://pdxscholar.library.pdx.edu/open_access_etds

Part of the Anthropology Commons, and the Geochemistry Commons Let us know how access to this document benefits you.

\section{Recommended Citation}

Reed, Patrick William, "Archaeological Feature Identification Through Geochemical Analysis of Arctic Sediments from the Cape Krusenstern National Monument, Northwest Alaska" (2020). Dissertations and Theses. Paper 5437.

https://doi.org/10.15760/etd.7310

This Thesis is brought to you for free and open access. It has been accepted for inclusion in Dissertations and Theses by an authorized administrator of PDXScholar. Please contact us if we can make this document more accessible: pdxscholar@pdx.edu. 
Archaeological Feature Identification Through Geochemical Analysis of Arctic

Sediments from the Cape Krusenstern National Monument, Northwest Alaska

by

Patrick William Reed

A thesis submitted in partial fulfillment of the requirements for the degree of

Master of Science

in

Anthropology

Thesis Committee:

Shelby Anderson, Chair, Chair

Virginia Butler

Douglas Wilson

Robert Perkins

Eva Hulse

Portland State University

2020 
(C) 2020 Patrick William Reed 


\begin{abstract}
Identification and interpretation of archaeological phenomena is typically based on visual cues and the physical presence of "something archaeological," such as a diagnostic artifact, landscape modification, or structural element. Yet many archaeological features, i.e. the discrete archaeological deposits related to past human behavior, lack clear indicators of human activity that provides clues to the feature's origin. At the Cape Krusenstern beach ridge complex, located in northwest Alaska, ambiguous features, that could be natural or anthropogenic (vegetation anomalies), or are of unknown cultural function (indeterminate), comprise $60 \%$ of the identified features at the complex. These ambiguous features represent a large gap in our understanding and interpretations of the occupation history of Cape Krusenstern and the Arctic. The goal of this thesis was to identify anthropogenic features and interpret the original human behaviors that contributed to their formation, through soil geochemical analysis. I sought to identify 1) which features are natural and which are anthropogenic; and 2) what behaviors created the cultural features (e.g. occupation of houses or caching of marine versus terrestrial food resources). I used photometric phosphates spot tests and inductively coupled plasma mass spectrometry (ICPMS) to geochemically characterize bulk sediment samples from ambiguous features. I then used a variety of statistics, including principal component and discriminant function analysis to identify patterning in elemental compositional data. I compared results to geochemical expectations for different types of cultural features based on prior research and my own analysis of cultural and non-cultural control samples.
\end{abstract}


Analysis indicated that a single feature is natural, and the other tested features are anthropogenic features. However, the analysis did not aid in definitely identifying specific human behaviors (i.e. house/occupation versus storage activities) that could have created the ambiguous anthropogenic features. Broadly, food storage features showed slightly greater enrichment levels and less overall variation than house/occupation feature samples. In addition, food storage features showed very low variation between one another for several elements ( $\mathrm{Cr}, \mathrm{Al}, \mathrm{Ni}, \mathrm{K}, \mathrm{Co}, \mathrm{Mg}$, and $-\mathrm{Fe})$. My analysis did indicate that between 10 to 13 of the tested ambiguous (or indeterminate) features may be house features, and between four and 15 may be some form of storage feature. Analysis to identify caching of marine versus terrestrial resources, using the ratios of $\mathrm{Ba} / \mathrm{Ca}, \mathrm{Sr} / \mathrm{Ca}$ and $\mathrm{Ba} / \mathrm{Sr}$, suggest that potentially six features may have held marine resources, while the remaining either held terrestrial resources or had their contents emptied prior to abandonment.

Overall this thesis indicates that there are likely more house ( 7.9 to $10.2 \%$ increase) and food storage features (1.5 to $5.2 \%$ increase) present at the Cape Krusenstern beach ridge complex than previously thought. Increasing the number of house and food storage features suggests that the occupation history at the complex is potentially more intense than previously established. These results also suggest that geochemical analysis has potential use for feature identification at a broader landscape scale than previously performed in other archaeological applications of soil geochemistry. Last, this thesis shows there is potential in using previously collected bulk samples to gain in-depth information that can guide future work at the complex 


\section{Acknowledgments}

I could not have finished this thesis without the support of an innumerable amount of people. First and foremost, I must thank my advisor Dr. Anderson for taking a chance on a young archeologist back in 2008. I cannot say thank you enough for all the opportunities and direction you have provided to me. Secondly, to my committee, your guidance and thoughtful comments were very helpful in making this happen and I am grateful for the time and input you provided. I must also thank the Alaskan Anthropological Association for awarding me the Stefanie Ludwig Memorial Graduate Scholarship, and Portland State university Anthropology Department for awarding me the Thomas M. Newman Fund which provided the funding that allowed me to do this analysis.

There are far too many people to explicitly name here a few I feel need to be mentioned include; Shelby Navone, thank you so much for sorting through all that dirt with me! Thank you to Alexandra Franco at the PSU Trace Element Analytical Laboratory for helping with the ICP analysis. Tony thanks for occasionally pulling me away and getting me out on a river-one day we will actually catch a fish. Thank you to the guys at the Ross Island Grocery you kept me well caffeinated and provided a great place to focus and write most of this thesis.

To my family there is no amount of gratitude I can express for your encouragement. You all have helped make this. And lastly, my wife Michelle without your love and support I could not have done this. It was not easy, and I still don't know why we decided to do the grad school thing at the same time, but WE DID IT! 


\section{Table of Contents}

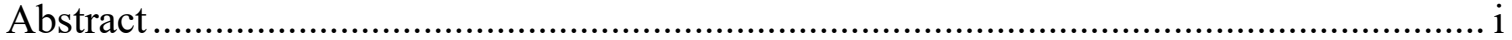

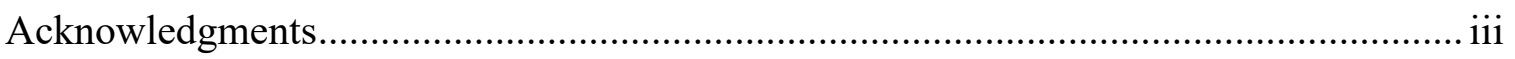

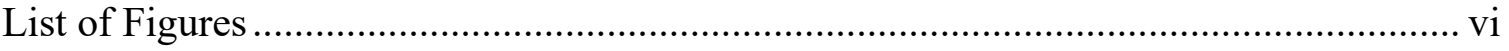

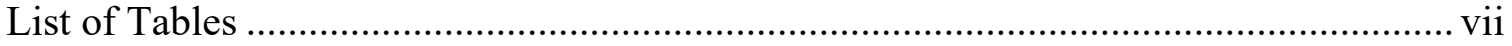

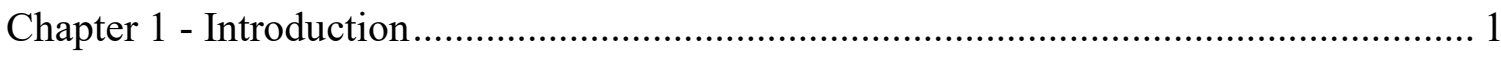

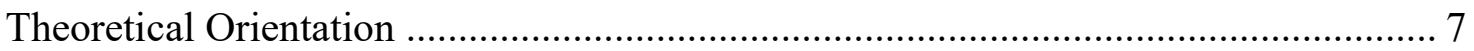

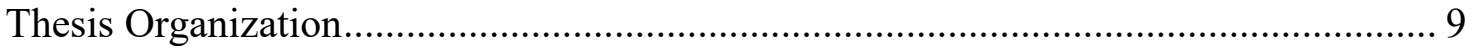

Chapter 2 - Background ............................................................................................. 11

Cape Krusenstern Beach Ridge Complex Development............................................... 11

Current Interpretation of Coastal Hunter-Gatherer Settlement Patterns in Northwest

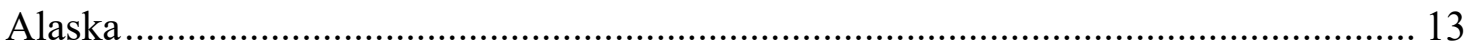

Cape Krusenstern Features and Population Dynamics .............................................. 14

Thule Sites: Houses, Storage Features, and Activity Areas........................................ 16

Geochemical Analysis of Soils in Arctic or Subarctic Settings as a Tool for

Identification of Archaeological Features .................................................................. 19

Geochemical Analysis of Soils as a Tool for Identification of Marine and Terrestrial

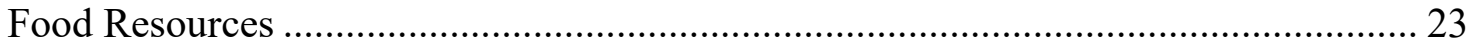

Non-Human Influences and Natural Process on Sediment Elemental Concentrations 25

Limitations of Geochemical Analysis and Identifying Features and Function............. 26

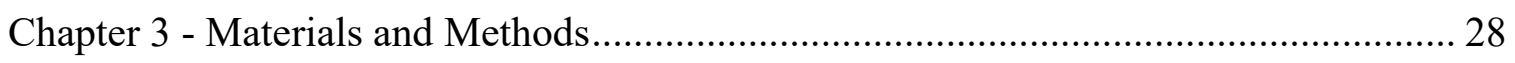

Hypothesis and Expectations ........................................................................... 28

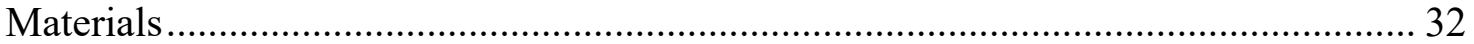

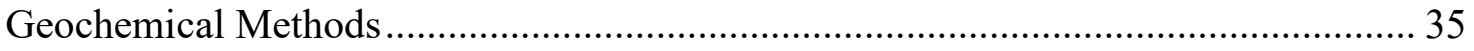

Phase I Method: Photometric Spot Tests .................................................................. 36

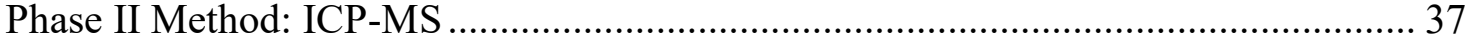

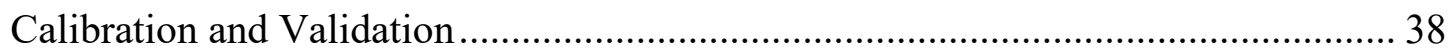

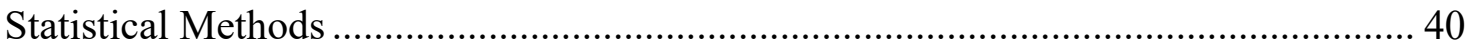

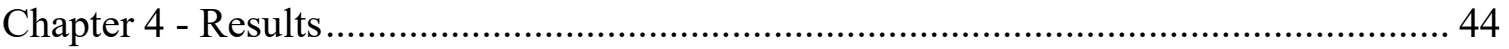


Phase I: Photometric Spot Test Results................................................................... 44

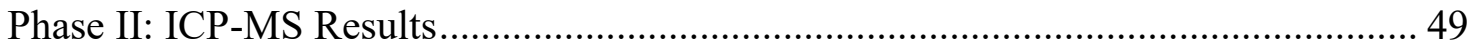

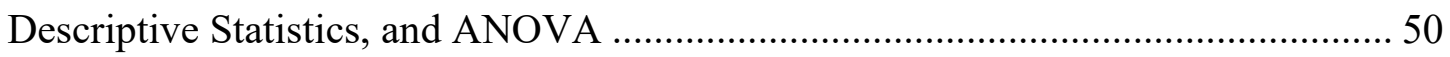

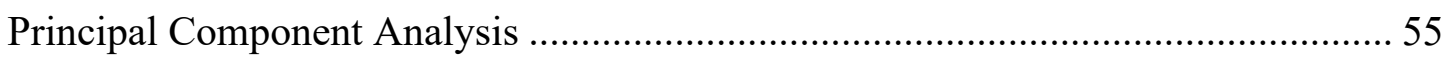

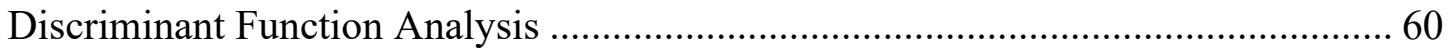

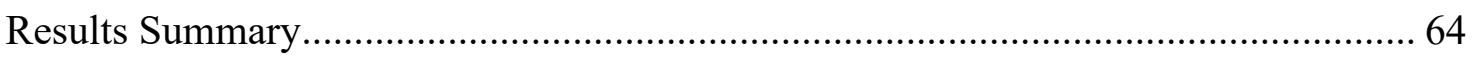

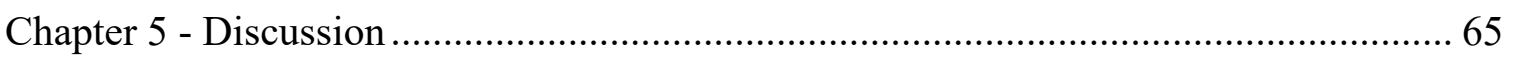

Hypothesis 1: The Vegetation Anomaly is a Natural or Cultural Feature .................... 65

Hypothesis 2: The Indeterminate Features are House or Food Storage Features ......... 68

Hypothesis $2 \mathrm{a}$ and 2b: The Indeterminate Features are Houses or Food Storage

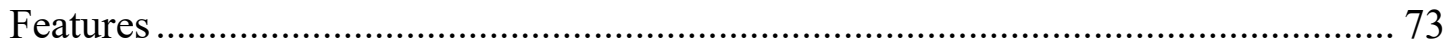

Hypothesis 3: Food Storage Features Represent Different Contents ............................ 78

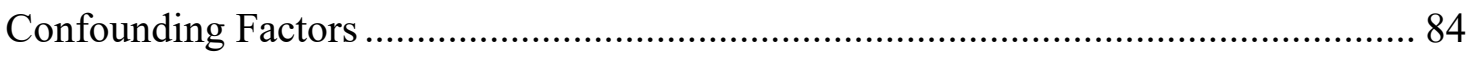

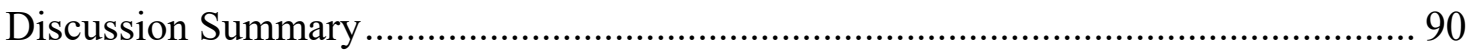

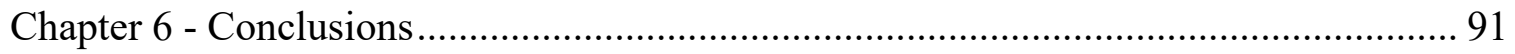

Implications for Regional Research and Study of Thule Subsistence Practices ........... 93

Implications for Method Application ...................................................................... 95

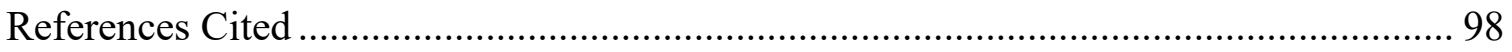

Appendix A Phase One: Photometric Phosphates Reactions ………………………..... 108

Appendix B Phase Two: ICP-MS Element Concentration Data. ..................................... 117 


\section{List of Figures}

Figure 1-1. Cape Krusenstern National Monument beach ridge complex....................... 2

Figure 1-2. Overview photographs of representative features..................................... 5

Figure 3-1. Sample and feature locations by feature class......................................... 34

Figure 4-1. Bulk sediment phosphate sample reactions............................................ 45

Figure 4-2. Bulk sediment phosphate sample reactions by arbitrary $10 \mathrm{~cm}$ level........... 46

Figure 4-3. Box plots of mean concentration data for all analyte elements. ................... 53

Figure 4-4. Biplots of first principal component factor scores vs (a) PC2, (b) PC-3, (c)

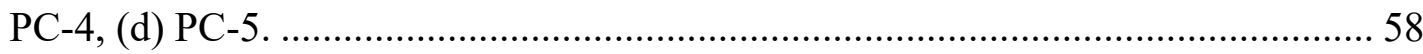

Figure 4-5. Biplot of second and third principal component factor scores..................... 59

Figure 4-6. Canonical discriminant function analyses biplots..................................... 63

Figure 5-1. Proposed groupings of cultural features from DFAc. ................................ 77

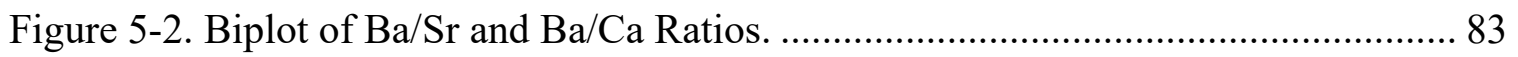




\section{List of Tables}

Table 1-1. Frequency of Features by Class and Ridge Segment at Cape Krusenstern ....... 4

Table 1-2. Feature Classifications Used in Survey of Cape Krusenstern .......................... 6

Table 2-1. Human Activities and Inferred Elemental Expressions in Arctic Soil ........... 22

Table 3-1. Hypotheses, Expectations, and Analytical Methods .................................... 29

Table 3-2. Features and Samples used in Analysis ...................................................... 33

Table 4-1. Features and quantity of samples included in Phase 2 ICP-MS analysis ....... 49

Table 4-2. Elements and Feature Classes with Statistically Significant Variation determined by ANOVA and Post-hoc T-Tests ................................................. 52

Table 4-3. Principal Components, Loading Elements and Observed Feature Class

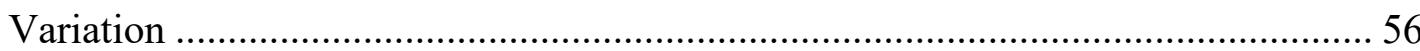

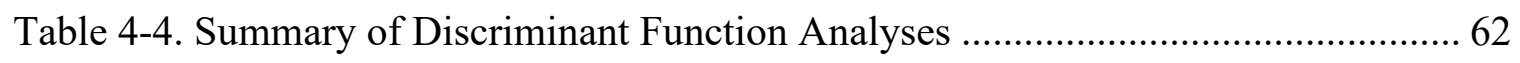

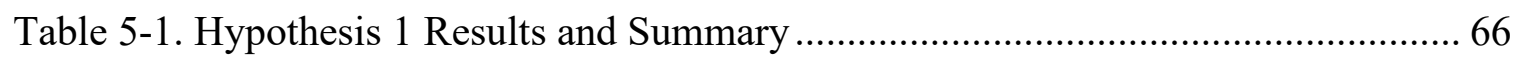

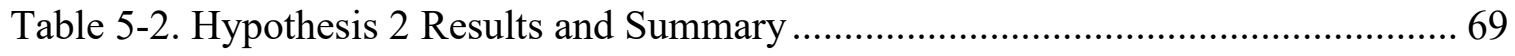

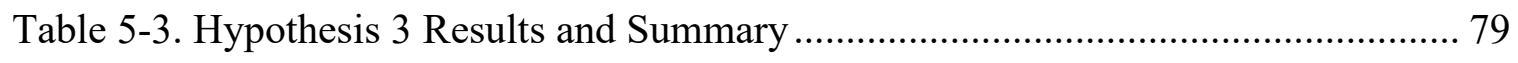

Table 5-4. Ba/Ca and $\mathrm{Sr} / \mathrm{Ca}$ Ratios for Feature Classes ............................................ 82 


\section{Chapter 1 - Introduction}

Identification and interpretation of archaeological phenomena is typically based on visual cues and the physical presence of "something archaeological," such as a diagnostic artifact, landscape modification, or structural element. Yet many archaeological features, i.e. the discrete archaeological deposits related to an past human behavior, lack clear indicators of human activity and may not have a characteristic form that provides clues to the feature's origin. Often, archaeologists cannot reliably identify archaeological features with traditional archaeological survey techniques that are limited to the length of a shovel and constrained by the nature of the substrate. Feature identification is further confounded by the decay of organic materials and other post-depositional processes (Stein and Farrand 2001; Wood and Johnson 1978). This makes it difficult to understand the nature of the past activities that created the archaeological record (Schiffer 1975, 1976, 1987). So how do we identify anthropogenic features and interpret the past when no clear cultural indicators are present?

The goal of this thesis is to identify anthropogenic features and interpret the original human behaviors that contributed to feature formation at Cape Krusenstern (Figure 1-1) through soil geochemical analysis. I aim to identify 1) which features are natural and which

are anthropogenic; and 2) what behaviors created the cultural features (e.g. occupation of houses or caching of marine versus terrestrial food resources). Geochemical analysis of sediments and soils is used in a variety of archaeological settings to aid in the identification of archaeological features and activity areas (Knudson et al. 2004; Knudson and Frink 2010; Middleton and Price 1996; Misarti 2007). Geochemical analysis has significant 
potential in the Arctic, where frozen soils are likely to preserve ancient fats, proteins, and other chemical evidence of human activities (Butler 2008; Pastor et al. 2016). Geochemical analysis could identify more archaeological feature types, particularly features containing minimal artifacts, and provide new information about feature formation processes. In Northwest Alaska, geochemical analysis of features could provide more information about on-site activities, subsistence practices, and settlement patterns.

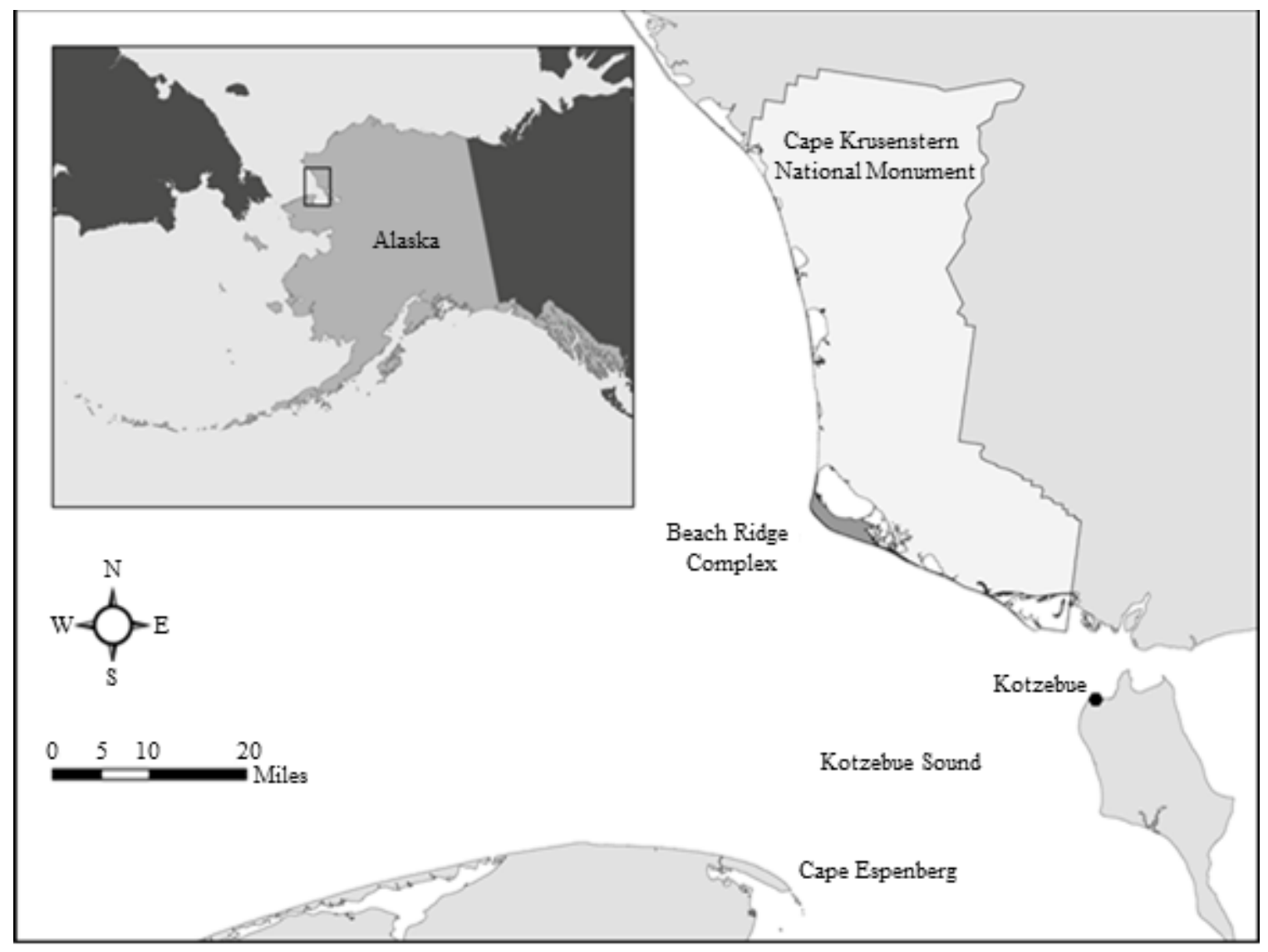

Figure 1-1. Cape Krusenstern National Monument beach ridge complex. 
The Cape Krusenstern National Monument beach ridge complex (hereafter referred to as The Complex) is a series of low-lying beach ridges that contains evidence of nearly continuous human occupation since the formation of the landform between 5,000 to 6,000 years ago (Anderson et al. 2018; Mason and Jordan 1993). Recent research at the Complex is challenging interpretations of regional settlement patterns that use the presence and quantity of semi-subterranean houses and food storage features as the basis for population estimates and indicators of increased sedentism and intensification of resource use (Anderson and Freeburg 2014; Anderson et al 2019; Dumond 1975; Giddings and Anderson 1986; Mason 1998). Radiocarbon sequences tied to the interpretation of feature classes indicate a more intensive and continuous occupation than previously thought (Anderson and Freeburg 2013, 2014; Freeburg and Anderson 2012; Anderson et al. 2018). For example, during the Thule period (Approx. 1200-500 years ago), there is a dramatic increase in the number of archaeological features at the site complex (Table 1-1: Beach Segment I and II) (Anderson and Freeburg 2013, 2014; Freeburg and Anderson 2012). Sixty percent of identified features (identified through pedestrian surface, subsurface and test excavations) at the site complex appear cultural in origin based on their shape (e.g. depressions or mounds), but investigators were unable to unequivocally classify the features as either cultural or natural in origin from surface characteristics and due to a lack of clear cultural indicators (Figure 1-2). These ambiguous features were classified as vegetation anomalies (vegetation anomalies $14.8 \%, \mathrm{n}=240$ ), which are regularly shaped, or circular, highly vegetated depressions (approx. 0.5 meters below ground surface) or mounds. No cultural materials were present at the surface or observed during subsurface 
testing. If these vegetation anomalies are anthropogenic, occupation of Cape Krusenstern over the last 2000 years is much more intensive than previously thought.

A second category of features, called 'indeterminate' features, are clearly cultural in origin but ambiguous enough in size, shape, or constituent artifact materials that their original cultural function (e.g. as houses or food storage) is not clear ( $\mathrm{n}=971$; indeterminate $45.2 \%, \mathrm{n}=731$ ). These features are typically isolated depressions that contain surface or sub-surface artifacts but could not be classified as house or food storage features because they lack discernible structural elements (e.g. tunnel, side-rooms, or food storage structure) and/or do not fit the size/area expectations of houses or storage features (Table 1-2). It is likely that the indeterminate features represent additional house or food storage features.

Table 1-1. Frequency of Features by Class and Ridge Segment at Cape Krusenstern

Beach Ridge Segment

(Upper Limiting Date Cal. BP)

\begin{tabular}{|c|c|c|c|c|c|c|c|c|}
\hline & Feature Class & $\begin{array}{c}\mathbf{I} \\
(1310)\end{array}$ & $\begin{array}{c}\text { II } \\
(2310)\end{array}$ & $\begin{array}{c}\text { III } \\
(2780)\end{array}$ & $\begin{array}{c}\text { IV } \\
(3210)\end{array}$ & $\begin{array}{c}\mathbf{V} \\
(3380)\end{array}$ & $\begin{array}{c}\text { VI } \\
(4420)\end{array}$ & Total \\
\hline \multirow{8}{*}{ 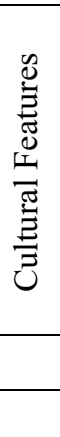 } & Hearth & 1 & 15 & 13 & 33 & 31 & 8 & 101 \\
\hline & House & 35 & 92 & 9 & 12 & 0 & 0 & 148 \\
\hline & Surface Scatter & 12 & 18 & 19 & 34 & 15 & 5 & 103 \\
\hline & Burial & 4 & 5 & 2 & 0 & 0 & 0 & 11 \\
\hline & Food Storage Features & 95 & 176 & 7 & 3 & 1 & 1 & 283 \\
\hline & Indeterminate Features & 168 & 401 & 110 & 16 & 19 & 17 & 731 \\
\hline & Vegetation Anomalies & 65 & 156 & 16 & 2 & 1 & 0 & 240 \\
\hline & Total & 380 & 863 & 176 & 100 & 67 & 31 & 1617 \\
\hline
\end{tabular}




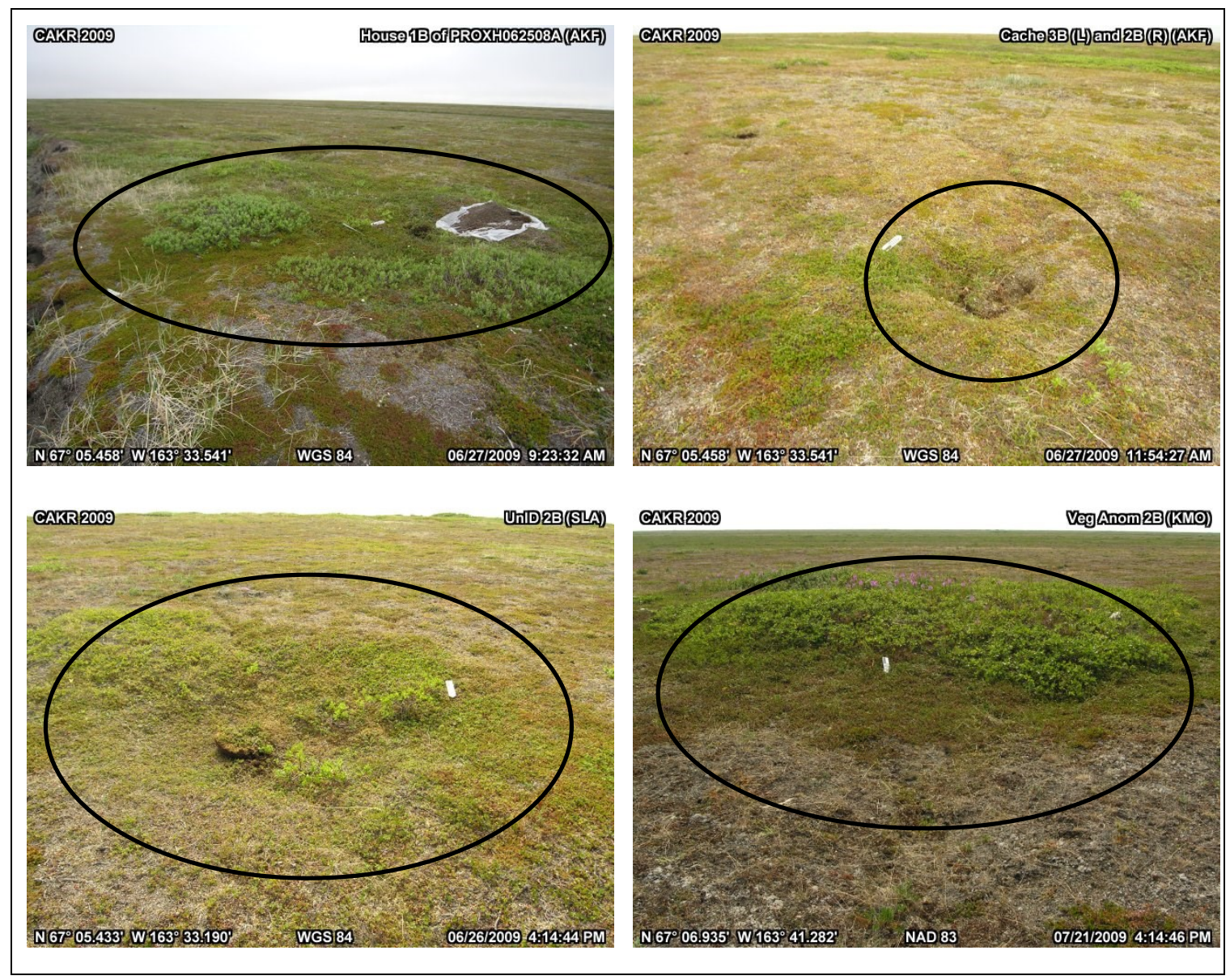

Figure 1-2. Overview photographs of representative features; house (top left), food storage feature (top right), indeterminate (bottom left) features, vegetation anomaly (bottom right).

Interpretation of the Complex's occupation history requires accurate identification of archaeological features, their original function, and better understanding of feature formation processes. The large proportion of unclassified indeterminate features and vegetation anomalies at Cape Krusenstern represents a gap in our understanding of the history and lives of those that inhabited the beach ridge complex. 
Table 1-2. Feature Classifications Used in Survey of Cape Krusenstern

\section{Feature/Sample Class Feature Description}

\begin{tabular}{ll}
\hline Control & $\begin{array}{l}\text { Samples taken from natural areas. Measurements reflect the natural geologic } \\
\text { background of the beach ridge complex. }\end{array}$ \\
\hline Vegetation Anomaly & $\begin{array}{l}\text { Vegetated areas greater than } 5 \mathrm{~m}^{2} \text { that are different than the surrounding } \\
\text { vegetation, with regular shape/appearance. May have a slight or deep } \\
\text { depression, or mound, within the vegetated area }(\sim 1 \mathrm{~m} \text { in depth or height }) . \text { Have } \\
\text { the appearance of cultural features, but no cultural materials are found during } \\
\text { subsurface testing. }\end{array}$
\end{tabular}

\begin{tabular}{ll}
\hline House & $\begin{array}{l}\text { Large surface depressions, greater than } 4 \mathrm{~m}^{2} \text {, that may have the following } \\
\text { features: multiple rooms, tunnel(s), and or associated features such as cache } \\
\text { pits, surface scatters, or vertical posts. }\end{array}$ \\
\hline Food Storage Features & $\begin{array}{l}\text { Small surface depressions, less than } 4 \mathrm{~m}^{2} \text { (when unexcavated), that may be } \\
\text { circular or square in shape, and are associated with a house feature or other } \\
\text { features. }\end{array}$ \\
\hline Indeterminate Features & $\begin{array}{l}\text { Surface or subsurface features that contain cultural materials but do not fit in } \\
\text { any of the other feature categories. These are often isolated features, not found } \\
\text { in association with houses, activity areas, or other cultural features. They could } \\
\text { be the remains of a single house, a storage features associated with more } \\
\text { ephemeral occupations. }\end{array}$
\end{tabular}

*Descriptions adapted from Freeburg and Anderson 2012: Appendix 1

This thesis investigates the archaeological nature of the numerous indeterminate features and vegetation anomalies observed at the Cape Krusenstern site complex through multi-elemental geochemical sediment analysis. My research questions are as follows: 1) Are the vegetation anomalies at the site complex anthropogenic or natural features? And: 2) What behaviors created the indeterminate cultural features? My analysis occurred in two phases. In Phase I, I use photometric phosphates analysis to identify if soil phosphates are enriched from cultural occupations. All available bulk soil samples $(n=151)$ from features on the first three beach ridge segments analyzed to 1) determine if vegetation anomaly is more likely natural or anthropogenic features, and 2) to aid in selection of samples with the most potential to contain archaeological residues created by past human activities. In Phase II, samples tested in Phase I, along with samples from representative house and food 
storage features, were subjected to further geochemical testing. The purpose of Phase II was threefold: (1) to collect and identify elemental concentrations and significant patterning present in the Cape Krusenstern samples, (2) to establish distinctions between cultural feature classes, and (3) to identify the range of human activities that created the indeterminate features by reclassifying them as house or food storage features. The behaviors that formed the features were identified using multi-elemental analysis. This

process involved comparing soil signatures from archaeological features of known/interpreted function (e.g. houses and food storage features) to the soil composition of the indeterminate features.

\section{Theoretical Orientation}

In this research, I drew on behavioral archaeological theory, particularly as it is implemented in geoarchaeological research. Behavioral archaeology examines the relationships between humans, their environments, and the processes that created the archaeological materials we observe in the archaeological record (Schiffer 1972, 1975, 1976; 1987). In this case, the archaeological materials are invisible anthropogenic inputs into sediments and soils. Behavioral archaeology complements middle range theory building, linking human behaviors to the archaeological record. Behavioral archaeology hinges on the concept that what is seen in the archaeological record is not a direct reflection of the past. The archaeological record is instead the result of a series of both human (ctransforms) and natural events (n-transforms) acting on an object, feature, or cultural material as it transfers from its original use (systemic context) to the archaeological context (the archaeological record) (Schiffer 1972, 1975, 1976 1987). These transforms describe a 
variety of ways the original context, use, function, or association of an item can be misinterpreted as it is observed in the archaeological record (Schiffer 1972, 1975, 1976, 1987). This includes past behaviors such as purposeful discard, cleanout events, and raw material or object recycling. Additionally, natural post-depositional processes such as erosion, feature collapse, and freeze-thaw cycles, as well as cultural processes such as artifact collecting, and later site reoccupation and use may obscure how archaeological materials are interpreted (Schiffer 1972, 1975, 1976, 1987).

I used behavioral archaeological theory to conduct middle range research. I undertook geochemical analysis of soil residues to address questions about human behaviors (e.g. food caching, domestic/house occupation) and the effect of natural processes (e.g. decay of organic materials) on the archaeological record. My results have implications for the reconstruction of local and regional occupation history over the last 2500 years. While the total number of features I analyzed is small, elucidation of the archaeological nature of these features advances our understanding of the occupation intensity at the site complex. In addition, I explored the application of a method that has seen only limited application in Arctic settings in a new and meaningful way. Multielemental geochemical analysis in archaeological studies has generally been performed at a smaller scale, at the site or individual features level. These smaller scale studies focus on identifying spatial patterning within archaeological features or sites, identification of site boundaries, prospection to guide archaeological excavations, or to link specific past human behaviors to elemental signatures (Rapp and Hill 2006:122-124: see also Couture et al. 2016 and Knudsen et al. 2010). My analysis differs by using geochemistry as a method for feature identification at a larger landscape scale. Identifying what these features are at Cape 
Krusenstern features could illuminate past subsistence and settlement patterns and aid in understanding past human behaviors and site formation processes.

\section{Thesis Organization}

This thesis is organized into six chapters and three appendices. The appendices present tables of background data as well as data resulting from the presorting and geochemical analysis of the bulk sediment samples.

In Chapter 2, I review the geographic and prehistoric cultural context of Northwest Alaska, focusing on previous studies of coastal settlement and subsistence practices in northern Alaska and at Cape Krusenstern. I also review the use of soil geochemical studies in archaeological research with a focus on prior studies that use multi-elemental soil geochemistry to identify archaeological activity areas and features.

In Chapter 3, I present my hypotheses and expectations and introduce the analyzed materials. I outline bulk soil sample preparation and acid digestion methods before discussing the photometric spot test and ICP-MS multi-elemental composition methods in greater depth. I conclude the chapter with a discussion of the statistical methods used to compare and interpret geochemical data.

In Chapter 4, I present the results of both phases of my analysis. I highlight the differences between control, vegetation anomaly, indeterminate feature samples, and known feature categories before assessing the potential of reclassifying the vegetation anomaly and indeterminate features. 
In Chapter 5, I discuss the results of the analysis. In Chapter 6, I present the conclusion of my research project, discuss the implications for use of ICP-MS and geochemical multi-elemental methods, and suggest lines of further research. 


\section{Chapter 2 - Background}

In this chapter I review the setting of the Cape Krusenstern beach ridge complex as well as the regional prehistoric cultural context of Northwest Alaska. I focus on coastal settlement and subsistence practices of the Thule period, including the use of house and food storage features. I briefly present the historical development of soil geochemical studies in archaeological research and examine recent use of multi-elemental plasma spectrometry methods in Arctic and high latitude settings. This serves as a base for using geochemistry as a tool to identify archaeological features, elucidate the original function, and illuminate the past activities that created the Cape Krusenstern features in relation to the theoretical framework of this research project.

\section{Cape Krusenstern Beach Ridge Complex Development}

Cape Krusenstern National Monument is a coastal plain with scattered brackish lagoons and drainages backed by bluffs and upland tussock tundra hills. The shoreline that forms the western and southern boundary of the Monument runs along the Chukchi Sea and forms the northern entrance to Kotzebue Bay. The beach ridge complex of Cape Krusenstern is located at the southern end of the National Monument (Figure 1-1).

The Complex is one of the oldest and most extensive beach ridge systems of the region, forming shortly after eustatic sea levels stabilized in the Chukchi Sea approximately 5000 to 6000 years ago (Anderson et al. 2018; Mason and Jordan 1993, 2002). The beach

ridge complex is a progradational beach system comprised of sand and sandstone, chert and limestone gravels sourced from the erosion of bedrock cliffs and bluffs along the shore north of the complex (Hopkins 1977). These deposits were subsequently reworked by 
longshore currents and mixed with near shelf sediments, a process that incorporated marine shell material into the sediment. As sea levels dropped, the continued seaward formation of new younger beaches at the active shoreline led to the initial development of barrier islands and spit landforms, which eventually evolved into the beach ridge complex (Anderson et al. 2018; Hopkins 1977). The more than 100 beach ridges at the Complex serve as horizontal stratigraphy linking the development of the Complex to past human occupations and environmental conditions (Anderson et al. 2018; Anderson and Freeburg 2013, 2014; Freeburg and Anderson 2012). The oldest beach ridges, and the oldest human occupations, are located on the north side of the Complex, while younger ridges and occupations are found closer to the modern shoreline. The beach ridge segments serve as a proxy for past coastal processes and provide a temporal framework for human occupation of the Complex. Early development of the beach ridge complex appears to have been relatively rapid and consistent between 5000 and 3000 cal. BP. This is indicated by the broad form and low elevation of ridges on segments IV and V, suggesting a period of relatively stable climate; sediment supply to the complex was potentially low during this period. After $2100 \mathrm{cal}$. BP numerous truncations and orientation shifts in the beach ridges suggest a period of increased climatic variability (Anderson et al. 2018; Mason and Ludwig 1990; Mason et al. 1995). The younger beach ridges are smaller in width, with more variable form, and have a higher maximum elevation. The difference in ridge form may be indicative of increased sediment loads and more intensive coastal processes during the later periods (Anderson et al. 2018). 


\section{Current Interpretation of Coastal Hunter-Gatherer Settlement Patterns in Northwest}

Alaska

Early research at Cape Krusenstern, conducted by J. Louis Giddings and Douglas D. Anderson, established that people occupied the Complex shortly after its formation and continued to utilize the area into the present day (Giddings and Anderson 1986). The earliest preserved human use of Arctic Alaskan coastal areas (4500 BP to $2800 \mathrm{BP}$ ) was limited to seasonal use by small, highly mobile groups, with a broad subsistence base. More intensive use of coastal environments, derived from the presence of higher investment semi-subterranean house features and larger settlements, is evident in northern Alaska starting around 2800 BP. Beginning approximately 2000 years ago, dramatic increases in population, settlement size, and the number of semi-subterranean houses, plus the expansion of social complexity, are apparent around the region(Anderson 1984; Anderson and Freeburg 2014; Anderson et al. 2018; Freeburg and Anderson 2012; Giddings and Anderson 1986; Mason 1998). Around 1350 BP, the Birnirk people, predecessors to the Thule peoples, appear along the coasts of the northern Arctic from the Bering Strait to the North Slope. The presence of whale bone in faunal assemblages (i.e. its use in house structures and other cultural materials) is interpreted as evidence of whaling during this period (Mason 2000; Mason and Barber 2003). The development of the Thule from the Birnirk occurred sometime between 1200-950 years BP (Anderson 1984; Giddings and Anderson 1986; Mason 2000). As Thule culture developed, Thule people spread rapidly across the North American Arctic, bringing with them a specialized maritime hunting technology (e.g. multicomponent harpoons) and an increased focus on marine resource use (Anderson 1984; Giddings and Anderson 1986). Considerable variability in technology, 
subsistence practices, and social complexity is represented in larger multi-family houses and community structures occurring throughout this period (Anderson 1984; Giddings and Anderson 1986).

\section{Cape Krusenstern Features and Population Dynamics}

At Cape Krusenstern, there is an increase in anthropogenic archaeological features during the period between $1750 \mathrm{BP}$ and $1150 \mathrm{BP}$, including semi-subterranean houses and food storage features. This increase in the number of features suggests intensified occupation, population increases, and specialized food processing and storage activities at the beach ridge complex (Anderson and Freeburg 2013, 2014; Anderson et. al 2018; Freeburg and Anderson 2012). The Thule period is marked by three major declines in population: approximately $1250-1000 \mathrm{BP}, 850-750 \mathrm{BP}$, and $750-450 \mathrm{BP}$. These declines

are identified by a relative lack and or lower quantity of features dating to those periods (Table 1-1) (see Figure 8: Anderson et al. 2019; Anderson and Freeburg 2014; Anderson et al. 2018; Freeburg and Anderson 2012; Giddings and Anderson 1986). Giddings and Anderson (1986) note that Thule peoples continued a semi-sedentary lifestyle and shifted their subsistence practices from marine mammal hunting to more intensive fishing. Some researchers have attributed these decreases in settlement sizes and occupational intensity to the dispersion of Thule peoples around the coast and migrations into the interior as responses to increasing population pressures and resource competition (Gerlach and Mason 1992; Mason 1998; Mason and Barber 2003). Starting 500 years ago, the archaeological record indicates a continued decrease in settlement size and further dispersion of 
occupations into previously unoccupied areas of the coast and interior river valleys (Anderson et al. 2019; Junge 2017).

In Northwest Alaska, the presence and quantities of semi-subterranean houses and food storage features are used as the basis of population estimates and indicators of increased sedentism and intensification of resource use ( Anderson and Freeburg 2014; Anderson et al 2019; Dumond 1975; Giddings and Anderson 1986; Mason 1998); this is similar to hunter-gatherer practices in other parts of the world (.e.g Ames 1994). Measures of occupation intensity have relied on the density of archaeological features, such as house and storage features, to establish estimates of population. House features in particular, paired with ethnographically informed assumptions about the number of occupants per house (Burch 1984:316-317, 1998:20), are used as general baselines for population estimates (e.g. Mason 1998). Additionally, archaeological features such as storage features and evidence of resource caching and marine resource use are linked in many cases to the development of larger populations, increased sedentism, technological complexity, and in some cases, the emergence of social complexity (Ames 1994; Anderson and Freeburg 2014; Erlandson 2001; Fitzhugh 2003).

While feature counts are a primary source of archaeological information, using them to estimate population can be problematic for numerous reasons (Chamberlain 2006:126-132). Namely, it is hard to say without extensive supporting excavations and analysis such as radiocarbon dating whether a house or series of houses was occupied at the same time, consecutively by a single family returning yearly, or concurrently by several families (Hassan 1978; Ropper 1979). Additionally, the use of storage feature quantities alone is problematic as many storage features may be associated with a specific/singular 
occupation. This is compounded by the fact that multiple storage feature types (i.e. for different resources) were likely in use at a single time. Therefore, it is important that archaeologists understand the context of feature types present in the archaeological record (Chamberlain 2006: 126-132; Schiffer 1976). Geochemistry can provide information regarding archaeological feature types in order to develop the context necessary to accurately interpret their function, as well as guide future research to date them and identify similar features. The identification of more features and their function can provide additional information to better understand the cause of declines in population at the Complex.

\section{Thule Sites: Houses, Storage Features, and Activity Areas}

Arctic semi-subterranean house structures have been well documented both ethnographically and archaeologically since the early $20^{\text {th }}$ century. Houses are highly variable in form at a regional level. Construction materials and internal arrangement are tied to distinct cultural groups and periods, as well as representing social practices or institutions (e.g. whaling crews, increasing social complexity), and/or different functional or seasonal uses of houses (Darwent et al. 2013; Dussault 2014; Giddings and Anderson 1986; McGhee 1984; Norman et al. 2017; Park 1988). Regional work including at the Complex and Cape Espenberg, located southwest of the Complex across Kotzebue Sound (Figure 1-1), has helped shed light on the internal arrangement and use of space in semisubterranean houses and, more specifically, those of the Thule house (Braymer-Hayes 2018; Norman et al. 2017; Norman 2018). The following discussion serves to describe the 
form and variety of activities performed in Arctic semi-subterranean houses, storage features, and activity areas that may be reflected in geochemical residues.

The typical Thule winter house form consists of a single main room where most daily activities would have taken place. The main room is accessed and protected from the outside by way of a long sunken entrance tunnel that served as a cold trap. Separate rooms or alcoves, often thought to be cooking rooms or kitchen areas, are common features, especially in later Thule houses. Kitchen areas are generally well defined by midden deposits associated with burnt marine mammal oils, crushed bone, and charcoal. Internal central hearths were not a common feature of early Thule houses, in which lighting and heat primarily came from the use of local ceramic or soapstone oil lamps (Norman et al. 2017; Park 1988, 1999). The sides of many houses contain elevated split log benches along the internal walls of the main room. These benches often functioned as sleeping platforms, lamp stands, as well as occasional internal storage. Structural architecture of the houses is primarily driftwood log posts and/or whale bone, and floors are formed from split wood logs (Alix 2005, 2016). The use of both skins and sods as insulating layers to form the major exterior wall and roof segments has been reported (Alix 2005, 2016; Park 1988, 1999).

Layers of cultural deposits have been found in the areas of tunnels, suggesting the deposition of internal cleaning episodes (Norman et al. 2017; Park 1988, 1999). Cemented sediments are often observed below the floorboards and less often reported at various places around the perimeter of the main room. The cementation is believed to be caused by the conglomeration of sediments by marine mammal oils, either from spillage of oil lamps 
or, as has been suggested, as potentially intentional in some areas, likely serving as a means of sealing the sediments of the perimeter (Norman et al. 2017; Norman 2018; Park 1988).

As discussed previously, Thule culture is characterized as having a highly adept maritime focused subsistence, with technology adapted for intensive hunting of marine mammals, the associated environmental conditions, and high group mobility. The highly specialized marine mammal hunting technology (e.g. composite harpoons, skin boats and skin floats) allowed people to take larger game, providing greater quantities of resources (Giddings and Anderson 1986; Mason and Barber 2003). This necessitated methods of processing and food dispersion to save food for later use without spoiling (Giddings and Anderson 1986; Park 1988; Sheehan 1995). Ethnographically, the use of external cache pits (here, food storage features) on the coast is generally tied to seal and marine mammal products after harvesting and processing. Often the primary harvest and processing of large marine mammals occurred in spring and summer on active beaches with only flesh, blubber, skin, and limited bones being taken to inshore locations for hang drying and preservation for winter consumption (Giddings and Anderson 1986:319; Park; 1988; 1999). Blubber was often placed in seal skin bags, or pokes, and dried meats were similarly stored in skin bags and placed in stone or dug out pit caches (Burch 1998:53; Park 1988, 1999).

The construction of cache pits has seen relatively limited research in Arctic studies. This is likely due to their simple construction which can lack architectural elements. Ethnographically, caches are constructed as stone or wood dug-out pits, and often lined with vegetation such as seaweeds and capped by rocks or log covers to prevent predator scavenging (Burch 1998:53, 73, 298; Entwistle 2007; Park 1988, 1999). Above-ground 
wood built caches are also noted at village locations (Burch 1998:185). The location of the pits in relation to living structures has also seen limited research in archaeology, though ethnographic accounts indicate caches would be placed near the site of processing (similar to interior terrestrial mammal meat processing) or adjacent to village and house locations (Park 1988, 1999). However, evidence of processing or temporary storage of foods taken in winter, either on the ice or when covered by snow, would not likely preserve. Geochemical analysis of soil residues may elucidate the subsistence practices of the Thule people in relation to the development and use of food resource storage pits.

\section{Geochemical Analysis of Soils in Arctic or Subarctic Settings as a Tool for Identification of Archaeological Features}

Above I discuss Thule house construction, subsistence, and resource caching as discrete archaeological features that may be found in the archaeological record and are suggestive of past human behaviors. However, decomposition and use may obscure or remove the visible traces of these features and activities from the archaeological record. These past behaviors have implications for how these features may be expressed in the geochemical archaeological record.

Soil geochemistry has been utilized as a tool in archaeological investigation since the early $20^{\text {th }}$ century (See Arrhenius 1929; 1962; and 1954: Lorch 1939). Early research observed increased levels of calcium $(\mathrm{Ca})$, carbon $(\mathrm{C})$, nitrogen $(\mathrm{N})$, and phosphorus $(\mathrm{P})$ in soils as indicators of past human presence at those locations. These elements are tied to the human deposition and decomposition of organic materials and refuse such as $\mathrm{Ca}$ from bone and shell, $\mathrm{C}$ from charcoal and general decomposition of organic materials for $\mathrm{N}$ and $\mathrm{P}$. 
Phosphate analysis became the dominant method, as anthropogenic or organic P is recognized as being easily separated from naturally occurring soil phosphorous (Barba 2007; Eidt 1977; Heizer and Cook 1965; Lutz 1951; Middleton and Price 1996; Rypkema et al. 2007). Numerous test methods exist for in-field and laboratory geochemical elemental analysis. However, many are purely qualitative, possess limited precision, focus on single elements and minerals, or are primarily utilized to guide archaeological prospection and excavations (Eidt 1977; Holliday and Gartner 2007; Middleton and Price 1996). With the advent of mass spectrometry (the sorting of ions of elements based on their mass to charge ratio), the field of archaeological geochemistry has turned to using multiple elements as indicators of human presence. Inductively coupled plasma mass spectrometry (ICP-MS) and inductively coupled plasma atomic emission spectrometry (ICP-AES) are the most common methods for soil geochemical analysis because they can analyze multiple elements and provide reliable quantitative data for analysis at a relatively low cost. Research utilizing multi-element analytical methods is increasing in the region and improving our understanding of how anthropogenic activities influence soils.

Numerous archaeological and ethnoarchaeological geochemical analyses have established that geochemical analysis works well in Arctic soil depositional environments (Buonasera et al. 2015; Couture et al. 2016; Hoffman 2002; Knudson et al. 2004; Knudson and Frink 2010; Lutz 1951). More specifically, many studies have provided information about potential sources of elemental soil inputs (Butler 2008; Goffer 2007; Heizer and Cook 1965; Misarti 2007; Oonk et al 2009; Wells 2004a). These studies established that in addition to $\mathrm{P}$ and $\mathrm{Ca}$, other elements including sodium $(\mathrm{Na})$, potassium $(\mathrm{K})$, aluminum $(\mathrm{Al})$, manganese $(\mathrm{Mn})$, magnesium $(\mathrm{Mg})$, barium $(\mathrm{Ba})$, strontium $(\mathrm{Sr})$, titanium $(\mathrm{Ti})$, zinc $(\mathrm{Zn})$, 
and iron $(\mathrm{Fe})$ often appear in either elevated or depleted concentrations as a result of specific human activities (Table 2-1). In particular, Misarti et al. (2011) found significant distinctions between anthropogenic sediments and natural sediments in the concentrations of $\mathrm{Fe}, \mathrm{Ti}, \mathrm{P}, \mathrm{Sr}$, and $\mathrm{Zn}$ levels from two Aleutian Islands archaeological sites. Statistical analysis of the element concentrations showed house pits and midden deposits were easily distinguished from each other and from other "on site" soils (Misarti et al. 2011).

Geochemical analysis has great potential to identify the types of signatures that may characterize Arctic house features. Couture et al. (2016) used soil geochemical analysis and micromorphology to study spatial patterning of $18^{\text {th }}$ century Inuit houses in northern Labrador. The elemental enrichment patterning indicated the influence of past behaviors and activities on specific locations within houses (Table 2-1). Specifically, floors and entrance tunnels showed similar enrichments of the same elements and compounds $(\mathrm{P}, \mathrm{Sr}$, and $\mathrm{CaO}$ ), while sleeping platforms had unique signatures with additional enrichment of organic $\mathrm{Ba}$ and $\mathrm{Na}_{2} \mathrm{O}$. Marine mammal oil lamp maintenance was tied to the enrichment of $\mathrm{S}$ and $\mathrm{Zn}$ present on lamp stands or alcoves. Overall, this study shows the potential of identifying internal spatial patterning from geochemical analysis. Statistically, however, the distinctions were generally only clear in two of the houses. The incongruence seen between houses may be indicate depositional processes in the systemic context, such as the mixing of deposits from different areas from multiple cleaning events. 
Table 2-1. Human Activities and Inferred Elemental Expressions in Arctic Soil

Human Activities

Elevated Elements

General waste, decomposition

\begin{tabular}{|c|c|c|}
\hline Bone and organic matter & $\mathrm{P}, \mathrm{N}, \mathrm{Mg}, \mathrm{Na}, \mathrm{Ca}$ & $\mathrm{Fe}, \mathrm{Mn}$ \\
\hline Fish bone and bird bone & $\mathrm{Na}, \mathrm{Ca}, \mathrm{Mg}$ & \\
\hline Marine organic materials & $\mathrm{Sr}, \mathrm{Zn}$ & $\mathrm{Ba}$ \\
\hline Dung & $\mathrm{Ca}$ & $\mathrm{Cr}, \mathrm{Al}, \mathrm{Pb}$ \\
\hline Heating of rocks & $\mathrm{Na}, \mathrm{Ca}, \mathrm{Mg}$ & \\
\hline Waste, and wood ash & $\mathrm{K}, \mathrm{Mg}$ & \\
\hline Marine shell & $\mathrm{Ca}, \mathrm{P}$ & \\
\hline \multicolumn{3}{|l|}{ House features: } \\
\hline Entrance tunnel & $\mathrm{P}, \mathrm{Ca}$, and $\mathrm{Sr}$ & \\
\hline Floor & $\mathrm{Ca}, \mathrm{P}, \mathrm{S}, \mathrm{Sr}, \mathrm{Zn}, \mathrm{Cu}, \mathrm{Pb}$ & \\
\hline Sleeping platform & $\mathrm{Ba}, \mathrm{Na}, \mathrm{K}$ & Ti, Fe, Mn, Mg, V \\
\hline Lamp stand & $\mathrm{Ba}, \mathrm{S}, \mathrm{Zn}$ & $\mathrm{Fe}, \mathrm{V}$ \\
\hline Caches & $\mathrm{Cu}, \mathrm{Pb}$ & \\
\hline Kitchen areas & $\mathrm{Na}, \mathrm{K}, \mathrm{P}, \mathrm{Ca}, \mathrm{Mg}$ & Low metals \\
\hline Food preparation & $\mathrm{Ca}, \mathrm{Sr}$ & \\
\hline Ovens & $\mathrm{Ba}, \mathrm{Fe}, \mathrm{Na}$ & \\
\hline Hearths (internal \& external) & $\mathrm{P}, \mathrm{K}, \mathrm{Al}, \mathrm{Mg}, \mathrm{Ti}$ & \\
\hline \multicolumn{3}{|l|}{ Other Areas: } \\
\hline Fish processing & $\mathrm{P}, \mathrm{Ca}, \mathrm{K}, \mathrm{Mg}, \mathrm{Na}$ & \\
\hline Kiln areas & $\mathrm{P}, \mathrm{Ca}, \mathrm{K}, \mathrm{Mg}$ & \\
\hline Lithic production/natural soils & Fe, Ti, Al, & \\
\hline
\end{tabular}

Compiled from Knudson 2004, 2001; adapted from Couture et al. 2016; Misarti et al. 2011; Villagran et al. 2013.

Similar to houses, the construction and use of food storage features for caching, and food processing areas provides clues to their probable geochemical expression. The research of Kelly Knudson, Liam Frink, and others $(2004 ; 2010)$ to identify the geochemical signatures of anthropogenic activities and food processing can inform us on the possible elements that may be elevated by the type of food resource being processed or 
stored. Using ICP-AES, they found elevated levels of $\mathrm{Ca}, \mathrm{P}, \mathrm{Na}$, and $\mathrm{Sr}$ in soils from inside the boundaries of known fish drying racks. The elevated elements are attributed to the decay of bones and accumulated oily drippings in the soil over the use life of the drying rack (Knudson et al. 2004). Additional ethnoarchaeological contexts of herring processing camps and activity areas on Nelson Island in western Alaska were analyzed using ICP-MS (Knudson and Frink 2010). The analysis indicated similar elevation levels of $\mathrm{Na}, \mathrm{Mg}, \mathrm{Mn}$, $\mathrm{Al}, \mathrm{P}, \mathrm{K}, \mathrm{Fe}$, cobalt $(\mathrm{Co})$, copper $(\mathrm{Cu})$, and lead $(\mathrm{Pb})$ in the tested features. Ratios of $\mathrm{Ba} / \mathrm{Ca}$ and $\mathrm{Sr} / \mathrm{Ca}$ concentrations are noted as depleted in fish processing areas (Knudson and Frink 2010; Knudson et al. 2004). These element ratios are used as indicators for marine influence on archaeological soils (Burton and Price 1990; 1999; Knudson et al. 2004; Knudson and Frink 2010). Ratios of these elements are inversely tied to trophic levels, decreasing as trophic levels increase (Burton and Price 1999; Knudson and Frink 2010). Maschner et al. (2010:71-77) had similar results with multi-elemental geochemical analysis on soils from two archaeological sites along the Sapsuk River in western Alaska. Couture et al. (2016) similarly found that caches were enriched in $\mathrm{Cu}$ and $\mathrm{Pb}$.

\section{Geochemical Analysis of Soils as a Tool for Identification of Marine and Terrestrial Food Resources}

Work outside of Alaskan archaeology has also contributed to our interpretations of the elemental inputs that various animal types have on archaeological soils and sediments. Villigran et al. (2013) conducted multi-elemental geochemical analysis alongside micromorphological and fatty acid analysis of sediments from two sealing structures in Antarctica. The authors found elevated levels of $\mathrm{P}_{2} \mathrm{O}_{5}, \mathrm{CaO}, \mathrm{Zn}$, and $\mathrm{Cl}$ and depleted levels 
of $\mathrm{SiO}, \mathrm{Al}_{2} \mathrm{O}_{3}$, and $\mathrm{Fe}_{2} \mathrm{O}_{3}$ in a combustion feature. The elevated values are attributed to the presence of seal remains, including burnt seal bone and charred material, as $\mathrm{Cl}$ is elevated in seal soft tissue. Villigran et al.'s (2013) interpretations of soil element and mineral composition were informed by food and nutritional sciences research showing that the blubber and meat of Greenlandic harp (Pagophilus, or Phoca, groenlandica) and hooded seals (Cystophora cristata) have high values of dietary minerals (e.g. major elements $\mathrm{Ca}$, $\mathrm{P}, \mathrm{K}, \mathrm{Na}$, and $\mathrm{Mg}$; and trace elements $\mathrm{S}, \mathrm{Fe}, \mathrm{Cl}, \mathrm{Co}, \mathrm{Cu}, \mathrm{Zn}, \mathrm{Mn}$, molybdenum (Mo), iodine (I), and selenium (Se)), though $\mathrm{Ca}$ and Fe are particularly high (Synowiecki 1993; Brunborg et al. 2006). Similar values of $\mathrm{Ca}, \mathrm{Fe}, \mathrm{Zn}$, and $\mathrm{Mg}$ are found in other marine mammal species important to western Arctic Alaskan diets, such as bearded seals (Erignathus barbatus), ringed seals (Pusa hispida), and walrus (Odobenus rosmarus) (Kuhnlein et al. 2002). Additionally, beluga (Delphinapterus leucas) and narwhal (Monodon monoceros) show little elemental distinction between each other and from other marine mammals. However, high Se values are observed in raw beluga and narwhal muktuk, as well as walrus meat (Kuhnlein et al. 2002). Villagran's study also found elevated levels of sulfur (S) in samples associated with fur and skin materials in the sediment matrix. This is corroborated by Gillespie and Frenkel (1974), who indicated that seal fur keratin is high in S compounds. Villigran et al. (2013) also noted high Fe levels in sediments with high fatty acid content which is interpreted as a signature for seal blood (Brunborg et al. 2006; Shahidi and Synowiecki 1993; Yamamotto, 1987). This research suggests that $\mathrm{Cl}, \mathrm{S}$, and $\mathrm{Fe}$ may serve as indicators for food storage feature contents as these are where items such as seal skin pokes may have been stored. Additionally, as marine mammal skin use was ubiquitous across the Arctic (Burch 1998), the signature 
could potentially be linked to other aspects of archaeological features such as roof coverings or bedding materials in houses.

While there is considerable nutritional research on seals, less information is available for other important food sources, such as terrestrial mammals. A study by Butler et al. (2013) showed elevated concentrations of $\mathrm{K}_{2} \mathrm{O}, \mathrm{MgO}, \mathrm{Fe}_{2} \mathrm{O}_{3}, \mathrm{Sr}, \mathrm{Sc}, \mathrm{Y}, \mathrm{Ca}, \mathrm{Ni}$, and $\mathrm{Pb}$ in areas where open air animal processing is thought to have occurred. This research from the central Canadian Arctic is corroborated by the use of fourier transform infrared spectroscopy (FTIR), which showed the presence of trans-fats associated with ruminant tissues, interpreted to be caribou, preserved in the sediments. Kuhnlein et al.'s (2002) arctic dietary research also included many Arctic terrestrial mammals (see Table 3 in Kuhnlein et al. 2002:554-557). The authors showed that mineral compositions in terrestrial mammals are generally low (except in $\mathrm{P}, \mathrm{Mn}$, and $\mathrm{K}$, which are similar to other animals) when compared to marine mammals.

\section{Non-Human Influences and Natural Process on Sediment Elemental Concentrations}

There is considerable research that establishes humans as the agent of elemental enrichment in sediments as a result of the deposition and decomposition of organic materials, including bodily wastes (Burton and Price 1990; Couture et al. 2016; Lutz 1951; Misarti 2007). However, there is little research to establish if a distinction between human and non-human enrichment is possible. That is, do animals (such as Arctic fox \{Vulpes lagopus $\}$ ) create different soil signatures than humans, and can this be used to identify anthropogenic versus natural features on the landscape? This question is of interest in the Arctic where sediment accumulation and soil formation are slow, and animals like the 
Arctic fox and ground squirrel (Spermophilus parryii), which build dens, can create features on the landscape that mound and have high vegetative potential like those of past human occupations.

Some researchers, such as Misarti et al. (2011), cite sediment and plant nutritional research that suggests that the presence of fox on landscapes results in significant decreases in $\mathrm{N}$ and $\mathrm{P}$ availability in natural soils (Croll et al. 2005; Maron et al. 2006), though Misarti's results did not actually show the predicted decrease in $\mathrm{N}$ and $\mathrm{P}$. The assumption made by the cited research (Croll et al. 2005; Maron et al. 2006) is reliant upon a multitrophic level relationship between fox predation and marine birds, whose excrement is the major supply of the soil nutrients. Unfortunately, this is not a direct measure of fox influence on landscapes, and presumably a human presence on a landscape could have the same effect. Gharajehdaghipour et al. (2016) specifically tested the nutrient availability of Arctic fox dens and showed dramatic increases of inorganic N and P. These increases, however, are highly variable and fluctuate seasonally, presumably due to the intensity of litter/pup rearing and the intensity of urine, feces, and food waste accumulation. This research has implications for interpreting features based purely on common soil nutrient minerals such as $\mathrm{N}$ and $\mathrm{P}$, where burrowing animals may have affected or contributed to the geochemical signature.

\section{Limitations of Geochemical Analysis and Identifying Features and Function}

Geochemical analysis has two major limitations relevant to this study. First, while elemental enrichment and depletion levels are useful for detecting anthropogenic phenomena, elemental data alone does not provide a complete picture of the past, and 
accompanying analyses (i.e. micromorphology, detailed excavation) are required to fully contextualize geochemical findings for meaningful archaeological interpretation. This limits the level at which interpretation can be made in identifying the specific past event, behavior, or item that created the signature. While research suggests that distinctions between features types (e.g. house versus caches) is possible, geochemical studies alone are not sufficient to determine the specific species people were processing or storing in features. However, in conjunction with other data on cultural behavior (e.g. feature form) and analyses (e.g. aDNA, or soil lipids) it is possible to generate more broad information regarding food contents as marine versus terrestrial mammal use (Knudsen et al. 2004; Knudson and Frink 2010), or internal spatial distinctions (Couture et al. 2016); this is minimally a greater level of detail than what could be said with limited excavation in features where physical materials (i.e. bone or structural materials) have not preserved.

Second, this limitation is further compounded by the need for a deep understanding on the effects that weathering and other post-depositional processes such as diagenesis, cryoturbation, etc. can have on the potential chemical properties of sediments and soils. This understanding is necessary to account for the observations and interpretations of elemental concentrations. This limitation is more easily overcome by understanding the geochemistry of local native sediments and having a robust set of natural non-cultural control samples provides a baseline to asses any potential affect that post depositional and or weathering processes may have. 


\section{Chapter 3 - Materials and Methods}

In Chapter 3 I discuss the materials and methods used in this study. First, I present the hypothesis and expectations of my research project. I then consider the Cape Krusenstern bulk sample collections and the sample selection process. I introduce the methods I use for bulk soil sample preparation and acid digestion methods. I then discuss the Phase I soil spot tests and Phase II ICP-MS elemental composition methods. I conclude with a discussion of the statistical methods I use to compare and interpret the geochemical data.

\section{Hypothesis and Expectations}

My research addresses two question: 1) Are the vegetation anomalies at the site complex natural or anthropogenic features? And: 2) What behaviors created the indeterminate cultural features? Addressing these questions required a two-phase approach (Table 3-1).

The primary goal of Phase I was to determine if the vast number of vegetation anomaly features present at the complex actually represent a large unidentified anthropogenic component of the archaeological record. Unfortunately, as the vegetation anomalies did not contain archaeological materials, only a single feature was sampled in the field. I tested multiple samples from Vegetation Anomaly 3624B (samples; CAKR 14172-14176) to assess if the vegetation anomaly feature class are likely a natural or cultural feature. To do this, I compared vegetation anomaly samples to natural control samples and to samples from known cultural features (specifically houses). Phase I had an additional implication for Phase II of my analysis; that is, identifying which samples had 
the highest concentrations of phosphates, and thus the greatest potential to contain archaeological residues. I use these samples in Phase II.

Table 3-1. Hypotheses, Expectations, and Analytical Methods

\begin{tabular}{|c|c|c|c|}
\hline Hypothesis & Description & Expectation & Analysis Method \\
\hline H-1 & $\begin{array}{l}\text { Vegetation anomaly is a } \\
\text { natural feature }\end{array}$ & $\begin{array}{l}\text { Similar phosphate levels to } \\
\text { control samples }\end{array}$ & $\begin{array}{l}\text { Phosphates Spot } \\
\text { tests }\end{array}$ \\
\hline H-1 1 : & $\begin{array}{l}\text { Vegetation anomaly is } \\
\text { anthropogenic }\end{array}$ & $\begin{array}{l}\text { Elevated phosphate levels } \\
\text { indicate anthropogenic }\end{array}$ & Phosphate spot tests \\
\hline H-20: & $\begin{array}{l}\text { House and food storage } \\
\text { features are indistinguishable. }\end{array}$ & $\begin{array}{l}\text { Indistinct elemental } \\
\text { concentrations }\end{array}$ & ICP-MS \\
\hline H-2,: & $\begin{array}{l}\text { House and food storage } \\
\text { features have distinct } \\
\text { geochemical signatures }\end{array}$ & $\begin{array}{l}\text { Distinct elemental } \\
\text { concentrations }\end{array}$ & ICP-MS \\
\hline 2a: & $\begin{array}{l}\text { Indeterminate features are } \\
\text { houses }\end{array}$ & $\begin{array}{l}\text { Element concentrations } \\
\text { group with houses }\end{array}$ & ICP-MS \\
\hline 2b: & $\begin{array}{l}\text { Indeterminate features are } \\
\text { food storage features }\end{array}$ & $\begin{array}{l}\text { Element concentrations } \\
\text { group with food storage } \\
\text { features }\end{array}$ & ICP-MS \\
\hline H-30: & $\begin{array}{l}\text { Food storage features have } \\
\text { indistinguishable geochemical } \\
\text { signatures }\end{array}$ & $\begin{array}{l}\text { Distinct elemental grouping } \\
\text { within food storage features }\end{array}$ & ICP-MS \\
\hline H-31: & $\begin{array}{l}\text { Food storage features have } \\
\text { multiple distinct geochemical } \\
\text { signatures }\end{array}$ & $\begin{array}{l}\text { Distinct elemental grouping } \\
\text { within food storage features }\end{array}$ & ICP-MS \\
\hline
\end{tabular}

Null Hypothesis $\left(\boldsymbol{H}-\mathbf{1}_{0}\right)$ : If the level of phosphorus in the vegetation anomaly samples are not elevated, or are at similar concentrations in comparison to control samples, then Vegetation Anomaly 3624B is likely a natural feature.

Hypothesis 1 (H-1 $)$ : If levels of phosphorous in the vegetation anomaly samples are a) observed as elevated in comparison to control samples and b) at similar levels to house and food storage features, Vegetation Anomaly 3624B is likely anthropogenic and will be reclassified as an indeterminate feature. Samples from this feature are used regardless of phosphate testing results for further analysis in Phase II testing Hypothesis 2. 
The goal of the second phase of my analysis was to identify the past behaviors that created the indeterminate features, i.e. whether the indeterminate features were occupation features (i.e. houses) or food caching features (i.e. food storage features). In Phase II, I establish that differences between house and food storage features exists $\left(\mathrm{H}-2_{1}\right.$ and $\left.\mathrm{H}-2_{2}\right)$, and I then compare the elemental concentrations of the indeterminate features to the elemental concentrations of control samples and features of known function (house and food storage features).

Null Hypothesis (H-20): The cultural features will not have distinctions in elemental composition based on use and past activities that created them. The cultural features are not geochemically distinguishable between each other and the elemental signatures are reflective of general anthropogenic activities. I compare house and food storage feature samples to evaluate this hypothesis.

Hypothesis $2\left(\boldsymbol{H}-2_{1}\right)$ : The cultural features will have distinctions in elemental composition based on use and past activities that created them. The house and food storage features are geochemically distinguishable between each other and the elemental signatures are reflective of the anthropogenic activities that created them. Indeterminate features are similar to house or food storage feature signatures. I compare cultural feature samples to evaluate this hypothesis and explore the nature of the indeterminate features by the subhypotheses below.

Hypothesis 2a: The indeterminate features are houses. House deposits have a broad range of elevated or depleted elements within the soils, reflecting the wider range of daily activities that took place within the house structure. Specifically, food preparation and 
consumption will elevate levels of $\mathrm{Ca}$ and $\mathrm{Sr}$ if small bones are discarded and the use of seal oil lamps and ash from cooking fires will elevate $\mathrm{Ba}, \mathrm{Fe}, \mathrm{Na}, \mathrm{K}, \mathrm{P}$ and $\mathrm{Mg}$ (Middleton and Price 1996). Decomposition of plant and animal materials such as hides and bone implements will elevate $\mathrm{Ca}, \mathrm{K}, \mathrm{Mg}, \mathrm{Na}$, and $\mathrm{P}$ in soils (Table 2-1; Entwistle et al. 1998; Entwistle et al. 2000; Middleton and Price 1996). There are a variety of potential elemental enrichment patterns that could be expressed in house features and the signatures of houses are not limited to those discussed here. I compare indeterminate feature samples to house feature samples to evaluate this hypothesis.

Hypothesis $2 \boldsymbol{b}$ : The indeterminate features are food storage features. Food storage features will have fewer elements at elevated or depleted levels in comparison to house features. This chemical composition reflects the more limited use or activities related to storage features in comparison to occupation features. In particular, decomposition of plant materials from pit linings, and animal/food material contents will elevate $\mathrm{Ca}, \mathrm{K}, \mathrm{Mg}, \mathrm{Na}$, $\mathrm{Cu}$ and $\mathrm{Pb}$ and $\mathrm{P}$ in as well as deplete Fe and $\mathrm{Mn}$ soils (Table 2-1; Entwistle 2007; Middleton and Price 1996). I compare indeterminate feature samples to food storage feature samples to evaluate this hypothesis.

After I identify probable new food storage features, I then assess the potential of identifying the stored contents of the food storage features.

Null Hypothesis 3 (H-30): If the food storage features (including reclassified indeterminates) do not represent distinct storage features related to the contents of that feature, then the geochemical signatures will be similar to each other, and no distinctions between the features can be made. 
Hypothesis $3\left(\boldsymbol{H}-3_{1}\right)$ : If the food storage features were used to store different materials, the specific elements that are elevated or depleted within food storage feature samples will reflect the contents of that feature. Fish remains have been shown to elevate $\mathrm{Ca}, \mathrm{P}, \mathrm{Na}$, and Sr levels in soil, and to deplete Ba levels (Knudson and Frink 2010; Middleton and Price 1996; Misarti et al. 2011). I compare the specific patterning between food storage feature samples (including reclassified indeterminate feature samples) to evaluate this hypothesis.

\section{Materials}

I analyze a 151 -sample subset of the 230 bulk sediment samples collected from Cape Krusenstern between 2008 and 2010 (Freeburg and Anderson 2012). As a field crew member for the project in 2008 and 2009, I participated in the collection and field processing of these bulk samples. The bulk samples I analyze are from the first three beach ridge segments and represent 39 unique feature locations associated with houses $(n=7$ features; 36 samples), food storage features ( $\mathrm{n}=4$ features; 23 samples), indeterminate features ( $\mathrm{n}=27$ features; 87 samples), and vegetation anomalies ( $\mathrm{n}=1$ features; 5 samples) from the Thule occupation of the site complex (Figure 3-1; Table 3-2; Appendix A Table A-1). Samples from features that were designated in the field as house and food storage features are used as cultural controls in this analysis. Samples came from a variety of contexts and features encountered during the archaeological investigations. Generally, bulk samples were collected from shovel tests and excavation units either in arbitrary $10 \mathrm{~cm}$ levels or natural levels when identified in the field. Not all features were sampled at the same regular intervals or to the same depth and some sampling occurred only in cultural deposits. Some samples represent replicate and or duplicate sample elevations from the 
features; these samples are included in Phase 1 analysis to address any potential postcollection biases introduced by splitting bulk samples (replicate) or sample collection location (duplicate). Control samples ( $\mathrm{n}=1$ locus; 8 samples) were also collected from presumed non-cultural deposits (areas removed from feature locations and where no surface or subsurface archaeological materials had been identified). Bulk samples collected from 2008 and 2009 were not screened in the field, while bulk samples collected in 2010 were screened through 0.25 -inch mesh in the field to reduce packing weight and to identify any small artifacts that were present. Additional sorting of the 2008 and 2009 collected materials occurred in lab to reduce the bulk, and sediment materials were separated into multiple size fractions down to $1 \mathrm{~mm}$ (.039 inches). Additional control samples ( $\mathrm{n}=4)$ were collected from four unique locations in the summer of 2017 by NPS archaeologist Andrew Tremayne.

Table 3-2. Features and Samples used in Analysis

\section{Beach Ridge Segment}

\begin{tabular}{|c|c|c|c|c|c|}
\hline & $\begin{array}{l}\text { Feature Class: } \\
\text { Feature Quantity } \\
\text { (Number of Samples) }\end{array}$ & $\mathbf{I}$ & II & III & Total \\
\hline \multirow{3}{*}{$\frac{\bar{\pi}}{\stackrel{\vec{Z}}{E}}$} & Houses & $3(15)$ & $4(21)$ & - & $7(36)$ \\
\hline & Food Storage Features & $4(23)$ & - & - & $4(23)$ \\
\hline & Indeterminate Features & $3(17)$ & $25(68)$ & $1(2)$ & $28(87)$ \\
\hline \multirow{2}{*}{ 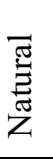 } & Vegetation Anomalies & - & $1(5)$ & - & $1(5)$ \\
\hline & Controls & $1(8)$ & $4(4)$ & - & $5(12)$ \\
\hline & Tota & $11(63)$ & $31(98)$ & $1(2)$ & 44 \\
\hline
\end{tabular}




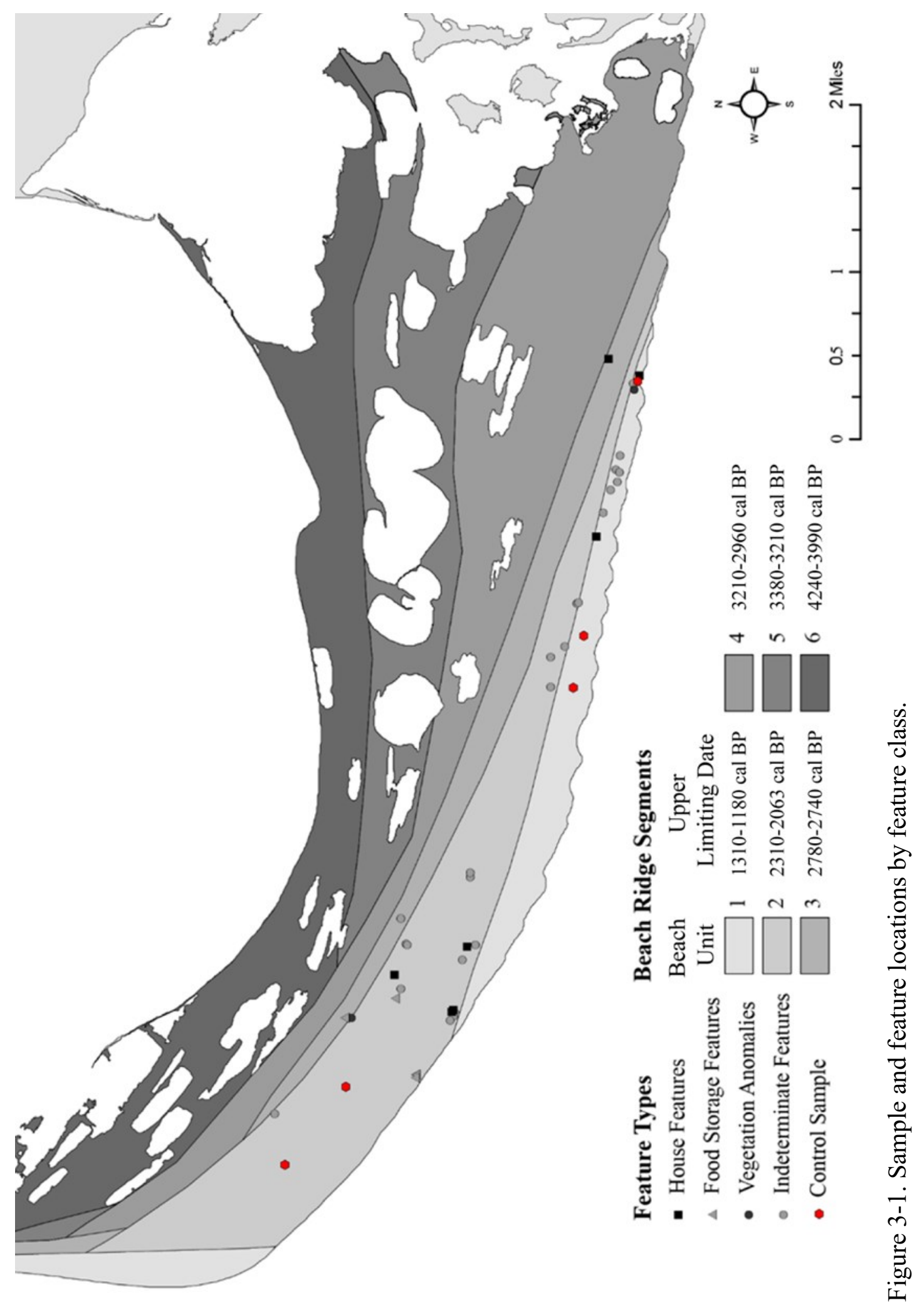




\section{Geochemical Methods}

The use of geochemical analysis to identify anthropogenic indicators in archaeological sediments has stirred much debate regarding appropriate digestion methods. It is possible that acid digestion procedures may be too strong and hide anthropogenic inputs in geologic backgrounds, or conversely too weak and unable to fully digest the anthropogenic inputs. Many studies attempted to address these methodological issues, however, there is little consensus regarding the best method to capture anthropogenic residues (see Knudsen and Frink 2010; Wells 2010; Wilson et al. 2006).

One study, Wilson et al. 2006, looked at the distinction between two methods, a strong acid dissolution versus a five-step sequential digestion. The results of the study suggested that the use of weak acid digestion method could result in the loss of information regarding anthropogenic inputs, but the study concluded that the choice of extraction method is ultimately element and soil specific (Wilson et al. 2006:443). The authors suggest that a pseudo-total extraction method such as HNO3 strong acid digestion is a suitable method to identify such interactions and any issues that would warrant the use of element specific extraction methods.

Despite this, a majority of archaeological chemical studies in the Arctic (see Knudson and Frink. 2010; Wells 2010; Wilson et al. 2006) have placed an emphasis on the use of weak or mild acid extraction methods, commonly an open digestion with a mixture of $\mathrm{HCl}$. The basis of this digestion method is to digest what are believed to be more mobile elemental sediments and soil inputs which are assumed to reflect anthropogenic additions rather than fully digest geologic background signatures. This digestion method has shown 
to give reliable results, and has been used across both ICP-AES/OES and ICP-MS. I elected to use this method in my analysis based on its relative simplicity of execution and for regional comparison.

\section{Phase I Method: Photometric Spot Tests}

In Phase I, I selected 151 sediment samples of the total 230 collected samples from the first three beach ridge segments. I selected samples from known feature classes, indeterminate features, and the vegetation anomaly, as well as control samples from independent locations presumed to be non-cultural (Appendix A; Table A-1). Controls were considered to be from non-cultural contexts and representative of natural sediments as they did not react for phosphates in Phase 1. Initial sample preparation included air drying as necessary for 24-48 hours before being sifted through $0.25 \mathrm{inch}(6.35 \mathrm{~mm}), 0.125$ inch $(3.175 \mathrm{~mm}), 0.078$ inch $(2 \mathrm{~mm})$, and $0.039 \mathrm{inch}(1 \mathrm{~mm})$ graduated sieves to remove large constituents and identify any cultural materials (i.e. debitage, bone, wood). I use the fine $<1 \mathrm{~mm}$ fraction in my analysis as sand size materials are necessary and allow for comparability in results to the geochemical methods I selected to use (Barba et al. 1991; Knudson et al. 2004; Knudson and Frink 2010; Middleton and Price 1996; Wells 2010; Wilson et al. 2006. The samples were then subsampled by weight as required for the soil composition tests (between $0.05 \mathrm{~g}$ and $0.20 \mathrm{~g}$ per sample).

After initial sample preparation, I performed a series of simple chemical procedures (spot tests) to identify the presence of soil phosphates. Spot tests are an inexpensive and simple first step to assess anthropogenic soil inputs. These spot tests utilize methods set forth by Luis Barba et al. (1991). The soil phosphates test required $50 \mathrm{mg}$ of the prepared 
fine fraction $(<1 \mathrm{~mm})$ sample. I placed the sample on Whatman \#42 filter paper and added a few drops of reagent $\mathrm{A}$ (a mixture of 35 milliliters $(\mathrm{ml})$ hydrochloric acid $(\mathrm{HCl})$ mixed with $5 \mathrm{~g}$ of ammonium molybdate, dissolved into $100 \mathrm{ml}$ of solution with distilled water) to the sample. After 30 seconds I added two drops of reagent B ( $0.5 \mathrm{~g}$ of ascorbic acid in $100 \mathrm{ml}$ of distilled water) to the sample. After two minutes, I added reagent $\mathrm{C}$ (one-part sodium citrate and two-parts distilled water) to stop the reaction and set the color. The filter disks were then dried completely. The resulting color shows the presence and relative concentration of phosphorous in the sample. Low phosphorus concentrations are indicated by lighter, diffuse blue coloring, and high phosphorus concentrations are indicated by an intense dark blue color.

I rated the dried filter disks on a five-point scale based on observed reaction intensity: (1) no reaction, (2) very little reaction, (3) little reaction, (4) moderate reaction, and (5) intense reaction (photographs of example reaction levels are presented in Appendix A, Figure A-1). To address potential bias of qualitative interpretation based on the knowledge of the samples, three volunteers visually assessed the reaction intensity on three separate occasions and the results were averaged to account for variation in interpretations of reaction intensity.

\section{Phase II Method: ICP-MS}

I analyzed an additional subsample ( $\mathrm{n}=44$ samples) of sediment from samples with the highest level of phosphate intensity identified in the geochemical analysis of Phase I. I also included samples that showed small, very small, or no reactions in Phase II of my analysis if they were the only samples from a feature. Phase II geochemical analysis was 
performed at Portland State University's Trace Element Analytical Laboratory using an Agilent 7900 quadrupole ICP-MS to determine elemental concentrations of sample digests.

I chose to use weak or mild acid extraction methods for this analysis (See Knudson et al. 2004; Knudson and Frink 2010; Middleton and Price 1996; Wells 2010; Wilson et al. 2006). This allowed for consistency and regional comparability of results. Specifically, using an OHOUS Scout Pro SP202 digital balance with $.01 \mathrm{~g}$ readability, I placed a subsample of $0.2 \mathrm{~g} \pm .01 \mathrm{~g}$ in $100 \mathrm{ml}$ virgin polypropylene digestion vials that had been cleaned in 5\% nitric acid bath and rinsed using deionized water. I added $20 \mathrm{ml}$ of 1 Molarity $\mathrm{HCl}(1 \mathrm{M} \mathrm{HCl})$ acid (made from Fisher Chemical Optima grade high purity acid with purity levels in parts per trillion) to the digestion vessel and loosely placed caps to allow for ventilation during digestion. Samples were allowed to digest for two weeks at room temperature.

I then filtered the digested samples into clean sample vials and diluted the samples to $50 \mathrm{ml}( \pm 0.5 \mathrm{ml})$ with deionized water to be within instrumentation limits $(<3 \% \mathrm{HCl})$. Initially, I diluted $1 \mathrm{ml}$ aliquots of digested samples into $9 \mathrm{ml}$ of dilution fluid for analysis . Some element concentrations were too high for the available standards, so I diluted an additional set of half milliliter $(0.5 \mathrm{ml})$ aliquots of the digested samples into $9.5 \mathrm{ml}$ of dilution fluid and reanalyzed for $\mathrm{Al}, \mathrm{P}, \mathrm{S}, \mathrm{K}$, and $\mathrm{Ca}$.

\section{Calibration and Validation}

The instrument was calibrated with external standards (concentrations ranging from $0.1 \mathrm{ppb}$ to $5,000 \mathrm{ppb}$ ) prepared from NIST-traceable commercial stock standards(Inorganic Ventures IV-ICPMS-71A; Inorganic Ventures IV-ICPMS-27A SPEX CL-ICV-1) in 
matrix matched dilution fluid. Analytical accuracy was verified using verification standards prepared from the available commercial stock solutions. Precision (accounting for digestion and analysis) was assessed by preparing and analyzing duplicate samples on one of every ten samples. A certified reference material (CRM) (Sigma Aldrich Trace Metals Sand 1; CRM 048-50g lot\#LRAB1604) was chosen as a suitable material given the similarity in sediment matrix to the Krusenstern sediment samples and replicate house and food storage features was digested and analyzed as a sample to confirm element recoveries and reproducibility. Instrument drift was accounted for by re-analyzing select standards at the midpoint and end of the run.

The concentration of analyte elements was determined using calibration curves built from a linear regression across the expected concentration range of external standards with the measured intensities; $y=a x+b$, where $y$ is the analyte intensity (CPS), $a$ is the slope of the line, $x$ is the predicted analyte concentration, and $b$ is the y-axis intercept. Calibration curves with correlation coefficient $\left(\mathrm{R}^{2}\right)$ values greater than 0.995 were achieved by either forcing the regression through the intercept or removing select internal standards. All tested sample concentrations were below the highest available standard concentration. Assessing of the validity of the collected data set was performed by examining the parameters of the linear regression including recovery of standards and $\mathrm{R}^{2}$ values. I corrected measured concentration values for dilution levels and sample size to get the ppb concentrations of each analyte element in the digest CRM sample by multiplying the calculated concentration by total dilution level $(50 \mathrm{ml})$ and dividing by the sample weight and analyzed volume $(10 \mathrm{ml})$ for each sample. 


\section{Statistical Methods}

While the machine provides concentrations of an element in a sample as analyzed, absolute concentrations are not of primary interest as individual element concentrations do not tend to distinguish cultural from natural deposits (Knudson and Frink 2010; Wells 2004b; Wells et al. 2007). It is the relative concentrations of the elements and elemental ratios from features in comparison to control samples and samples from known feature classes that are important for drawing conclusions from an analysis (Wells 2004b; Wells et al. 2007). The concentration data dilution level corrections, and statistical analyses were performed using Microsoft Excel and IBM's SPSS (Statistical package for the social sciences). I used statistical analyses to identify significant elements, and to understand how groupings of those elements may represent archaeological features.

Natural abundances of elements tend to not be normally distributed, but rather skewed to the positive (Ahrens 1965; Burton and Simon 1993). To address this issue, I normalized the concentration data using a base 10 logarithmic transformation $(\log 10)$ prior to performing the statistical analyses described below, and all references to concentration in the document are to the converted $\log 10 \mathrm{ppb}$ concentrations. This type of transformation is commonly used for its simplicity in displaying the data and in data analysis (Burton and Simon 1993; Drennan 1996). The following descriptions provide a basic concept of the statistical analysis I use in this thesis.

I first gathered descriptive statistics to summarize and identify patterns in the concentration data. Descriptive statistics include measures of central tendency (e.g. mean and the range of the data set such as minimum, maximum, and standard deviations) of each 
analyte element and feature class (Drennan 1996:17-20;27-29). I then performed several analyses of variance (ANOVA) tests for each analyte element concentration by feature class. ANOVA is used to establish whether significant variation between samples exists (Drennan 1996:171-186) for a given analyte element. The ANOVA test assumes the null hypothesis that the mean concentration of the independent variable (here, feature class) is statistically the same or similar for each analyte element (the dependent variable), and an alternative hypothesis that the mean of at least a single population (feature class) is dissimilar. Comparison of element concentrations found in indeterminate, vegetation anomaly, and house features to the element concentrations of the control samples is important for establishing that distinctions exist between anthropogenic and natural inputs in the data set. Concentrations in elements differing significantly from the control samples are likely generated from human activities.

While ANOVA identifies whether significant variation exists in a data set, it does not identify specifically where the variation occurs. To address this, I used a series of posthoc t-tests assuming equal variance to identify the source of variance between feature categories, and a Bonferroni correction to the significance value (Corrected $p$ values are derived by dividing the original $\alpha$-value by the number of analyses on the dependent variable). The Bonferroni correction is a multiple-comparison correction to the confidence interval of a statistical analysis. It is used when several dependent or independent statistical tests are being performed simultaneously and provides a more accurate assessment of the significance of an individual test (Weisstein 2018).

I performed a variety of multivariate statistical analyses including principal component and Discriminant function analysis. I use the principal component analysis 
(PCA) to discover variation in the data set without prior grouping of feature classes. Principal component analysis is a dimension reduction or data compression analysis, commonly used in archaeological geochemistry. Principal component analysis identifies the components (here, elements) that are responsible for the most variance in the entire data set, and thus most likely suitable for distinguishing the nature of the features. These principal components can then be used to interpret the sources and nature of the variation. This is done through examining the patterning of the elemental loadings and factor scores that distinguish each principal component as well as the relative variance explained by each sample. Components with Eigenvalues greater than one are selected for analysis and displayed using a direct Obelimin rotation which rotates the factor axis at an oblique angle (as opposed to orthogonal angle) to create a more simplistic output for interpretation. Oblique rotations allow for factors to be correlated but does not force the factors to be uncorrelated as an orthogonal rotation does. Additionally, if the data is not correlated the outputs are nearly orthogonal (Brown 2009). This is advantageous for multi-elemental analysis as elemental loadings (what defines a factor) may be related to many archaeological behaviors (the interpretation of a factor) that have a similar source for an element enrichment and would potentially be represented by correlation between factors. It must be noted, however, that once a principal component is identified, there is no assurance that the source of variation can be identified, as this relies primarily on the assumed and interpreted meanings of the variables included in the analysis (Baxter and Hayworth 1989; Carlson 2017).

Lastly, I used discriminant function analysis (DFA) to assess the correctness of the original classification of features and attempt to reclassify the indeterminate features as 
house or food storage features (Davis 1986; Glascock 1992). While PCA can be used to identify patterning and sources of variation in a data set, it does not directly group or provide a statistically significant assessment. Discriminant function analysis provides a statistical significance assessment of categories (here, feature classes). Discriminant function analysis is similar to ANOVA in that it is an analysis of variance that defines a group of known categories from a set of variables (elemental concentrations) and reclassifies the individual entries (samples) to the predefined categories. Discriminant function analysis requires that the categories be known a priori (unlike cluster analyses, which generate groupings without prior knowledge of a classification group) (Glascock 1992). The effectiveness of the discriminant function is determined by how accurately it classifies known samples into the correct classification groups by cross validation. This allows us to compare the indeterminate features to classified feature classes based upon the identified distinguishing elements, and to assess the potential for them to be reclassified as a known feature category. 


\section{Chapter 4 - Results}

In Chapter 4, I present the results of all phases of the geochemical analysis. I first examine the soil phosphates photometric spot tests relating to Hypothesis 1, and the selection of feature samples included in Phase II of my analysis (Phase I). I then present the results of Phase II (ICP-MS geochemical characterization of the sediment samples). The raw data for all phases of the analysis are in appendices B and C respectively.

\section{Phase I: Photometric Spot Test Results}

Similar rates of phosphate reaction intensities are seen across the cultural feature classes (Figure 4-1; Table A-1). All control samples ( $\mathrm{n}=12$ ) tested negative for the presence of soil phosphates. As such the control samples are confirmed as collected from noncultural contexts and represent suitable sources of local background sediment composition for use in Phase II of this analysis. Of the 151 archaeological samples, 47\% (n=70) showed no reaction for soil phosphates. All vegetation anomaly samples $(\mathrm{n}=5)$ tested negative for the presence of soil phosphates. I tested seven distinct house features and five (71\%) showed positive reactions. I tested four food storage features, and all showed positive results for soil phosphates. Of the 28 tested indeterminate features, $26(92 \%)$ had positive reactions for soil phosphates. The results of the photometric spot tests are presented in Appendix B (Table B-1) and are summarized in Figure 4-1 and Figure 4-2. 


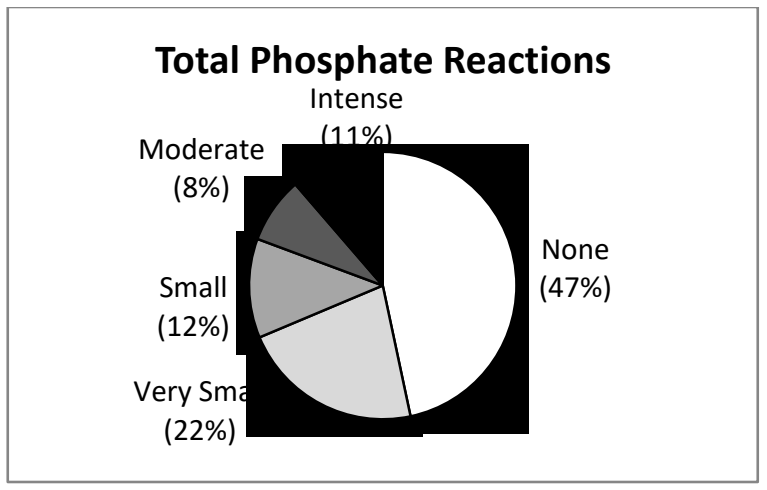

$\mathrm{n}=40$ features, 151 samples; $35(87.5 \%)$ positive features

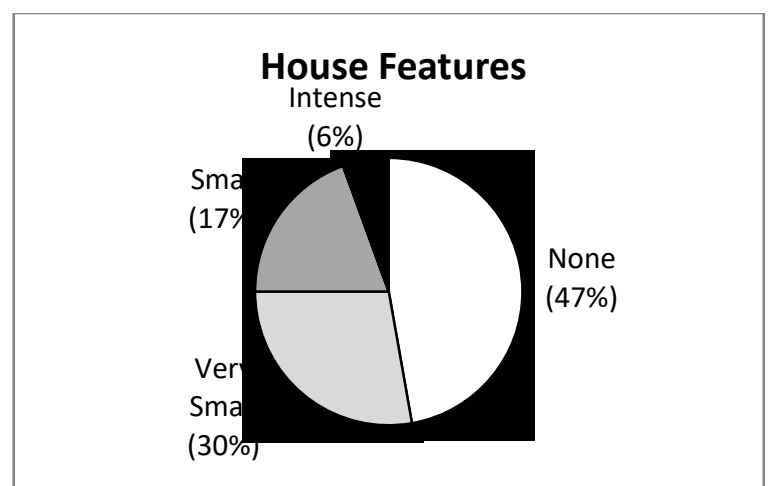

$\mathrm{n}=7$ features, 36 samples; 5 (71\%) positive features

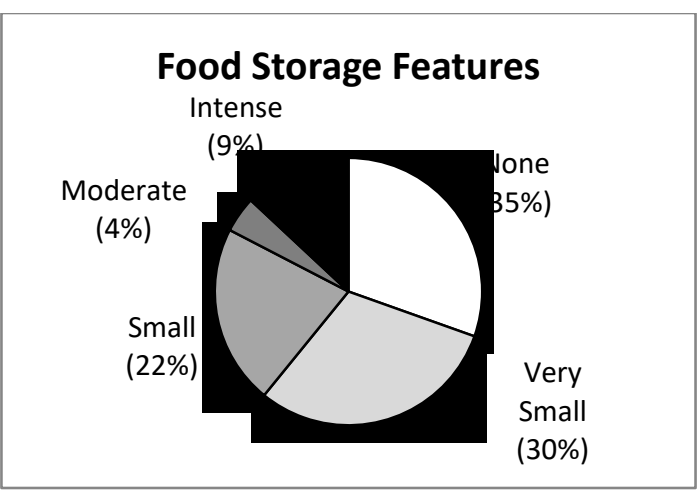

$\mathrm{n}=4$ features, 23 samples; (100\%) positive features

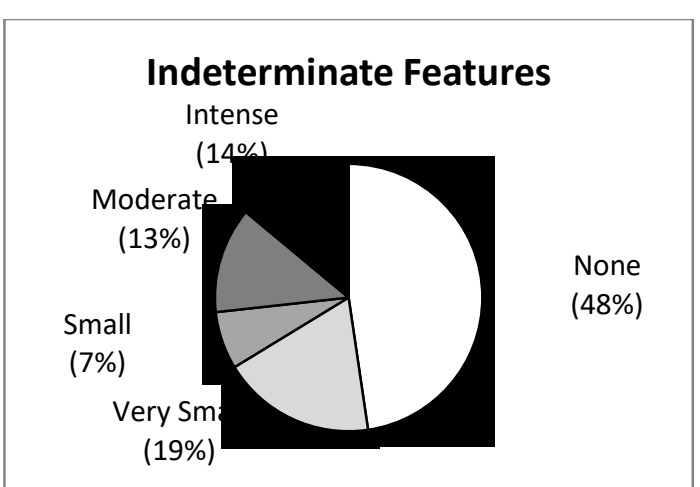

$\mathrm{n}=28$ features, 86 samples; 26 (92\%) positive features

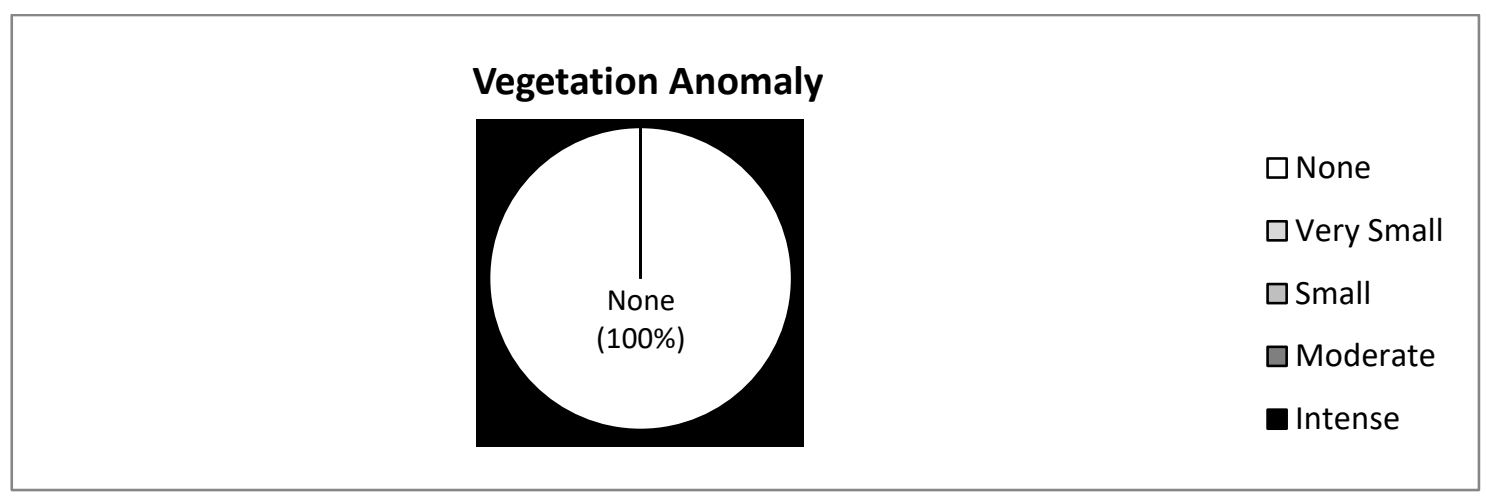

$\mathrm{n}=1$ feature 5 samples; $0(0 \%)$ positive features

Figure 4-1. Bulk sediment phosphate sample reactions. 


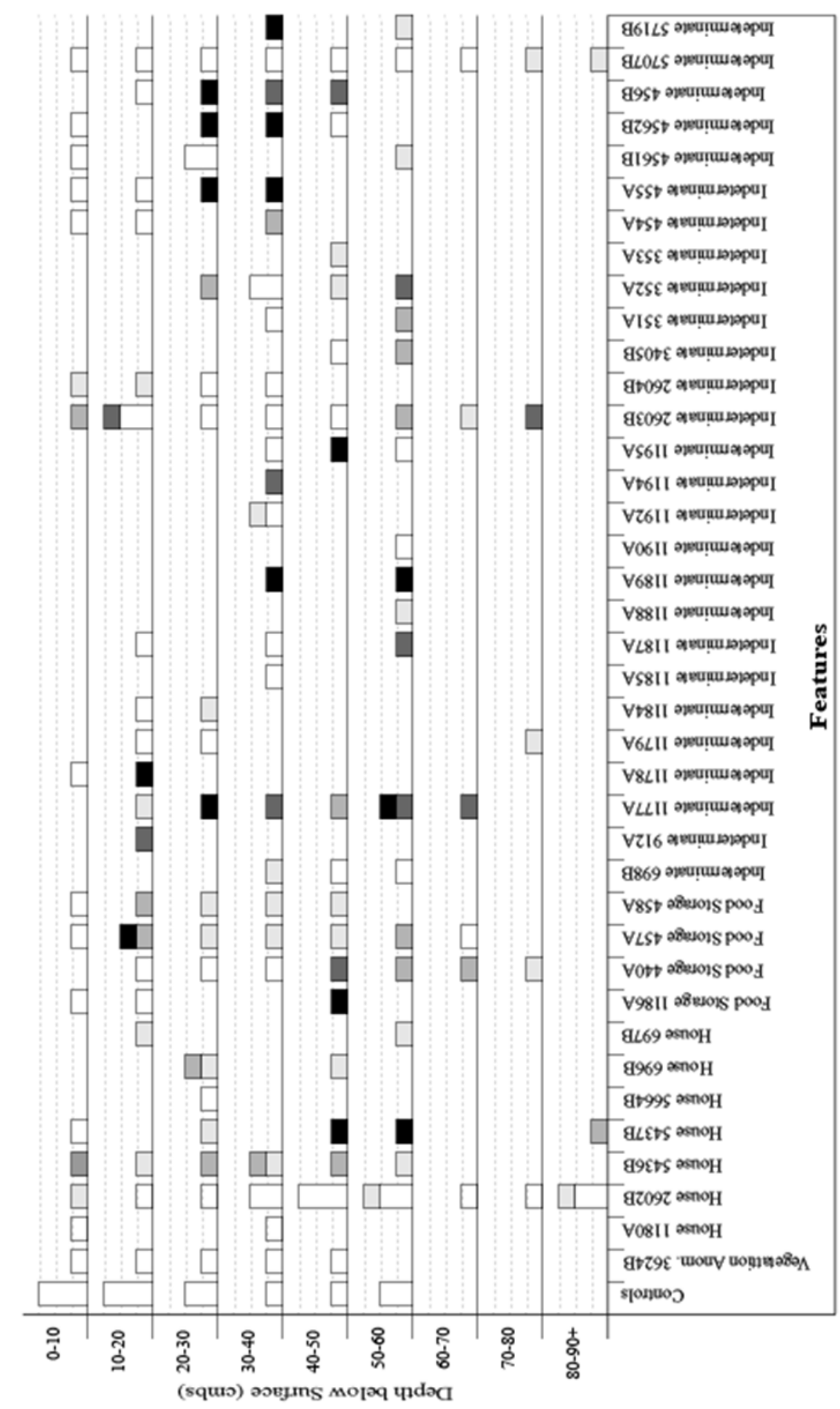

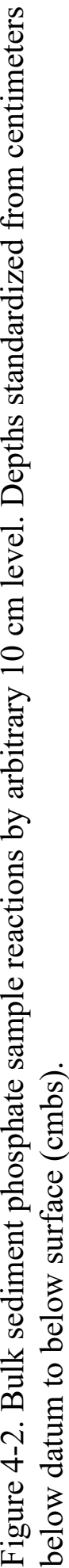


Two samples from a single house feature (House 5437B; Samples CAKR 14916 and CAKR 14976) showed an intense reaction for soil phosphates. No moderate reactions occurred in the house samples. Seven samples from four houses had a small reaction. Nine samples representing five individual houses had a very small reaction. Sixteen samples from the seven tested house features had no reaction at all, and two of these house features, represented by three samples (House 1180A; samples CAKR 15033, CAKR 15034, and House 5664B; sample CAKR 14979), had no reaction at all. The lack of reactions in house feature samples is attributed primarily to sample context being from non-cultural sediments formed post abandonment. However, in Houses 2602B and 5664B no reactions were observed at nearly every sampled depth and only very small reactions were observed at two sample depths in House 2602B (Figure 4-2). This may be a result of the sample matrix which primarily consisted of gravels or coarse sands that allowed for post-depositional processes to affect the preservation of phosphates. I included samples representing the greatest phosphate intensity from all five of the positive house features (Houses: 2602B, 5436B, 5437B, 696B, 697B) and a sample from each negative house feature in Phase II as they are the only samples representing those features, and are an interesting opportunity to assess the variability of house feature geochemical signatures.

Three food storage features had an intense reaction for soil phosphates (Food Storage 440A; sample CAKR 14401, Food Storage 457A; sample CAKR 14410, Food Storage 1186A Sample CAKR 15197). Feature 440A has the most diverse reactions, showing all five reaction levels throughout the vertical column of the feature (Figure 4-2). Feature 457A similarly had a diverse reaction across the vertical column. Small and very small reactions were seen in Feature 458A. Feature 1186A had both negative and intense 
reactions. As all food storage features tested positive for soil phosphates, the samples with the greatest intensities from each feature are included in Phase II of this analysis.

Two indeterminate features (Indeterminate 1185a; sample CAKR 15082, and indeterminate 1190a; sample CAKR 15348) showed no reaction for soil phosphates (Figure 4-2). Each of these features are represented by a single sample. Ten indeterminate features indicate only very small phosphate reactions, while two indeterminate features are represented by small reactions. Five indeterminate features show moderate reactions and eight intense reactions for soil phosphates. Samples with the greatest intensities from each indeterminate feature are included in Phase II of this analysis.

Overall, in Phase I, I eliminated 112 samples from inclusion in Phase II of my analysis. I selected 39 samples from features and five control samples for ICP-MS analysis in Phase II (Figure 4-2; Appendix B, Table B-1). I address any potential bias/obscuring of elemental enrichments by natural processes that may be causing vertical migration or leaching of elements in the sediment column, by selecting the samples from each feature exhibiting the highest phosphates reaction. Intense $(n=12)$ and moderate $(n=5)$ reactions likely indicate the cultural layers with the best preservation of anthropogenic elemental inputs. As such I included the sample with the highest level of phosphate intensity in the geochemical analysis of Phase II. Samples that showed a small $(\mathrm{n}=6)$, very small $(\mathrm{n}=11)$, or no reactions $(\mathrm{n}=5)$ are included in the second phase of analysis if they are the only samples from a feature. 


\section{Phase II: ICP-MS Results}

In Phase II my goal is to elucidate more fully the premise of Hypothesis 1 and evaluate if elemental concentrations differed between feature classes (Hypothesis 2). The purpose of this portion of my analysis is threefold: (1) Confirm the vegetation anomaly is not anthropogenic, (2) investigate the differences between cultural feature types, and (3) identify the past behaviors that created the indeterminate features as outlined in Hypothesis 2. The number features and quantity of samples used in phase two are summarized in Table 4-1. The results of the ICP-MS analysis are presented below; Table B-1 box plots of mean analyte concentration by feature class are displayed in Figure 4-3, and full ICP-MS data outputs are in Appendix B; Table B-1. I was not able to accurately or reliably measure sulfur in the range of available standard concentrations; therefore, it was excluded from further analysis. A detailed discussion addressing the data and method validation results is provided in Appendix B.

Table 4-1. Features and quantity of samples included in Phase 2 ICP-MS analysis

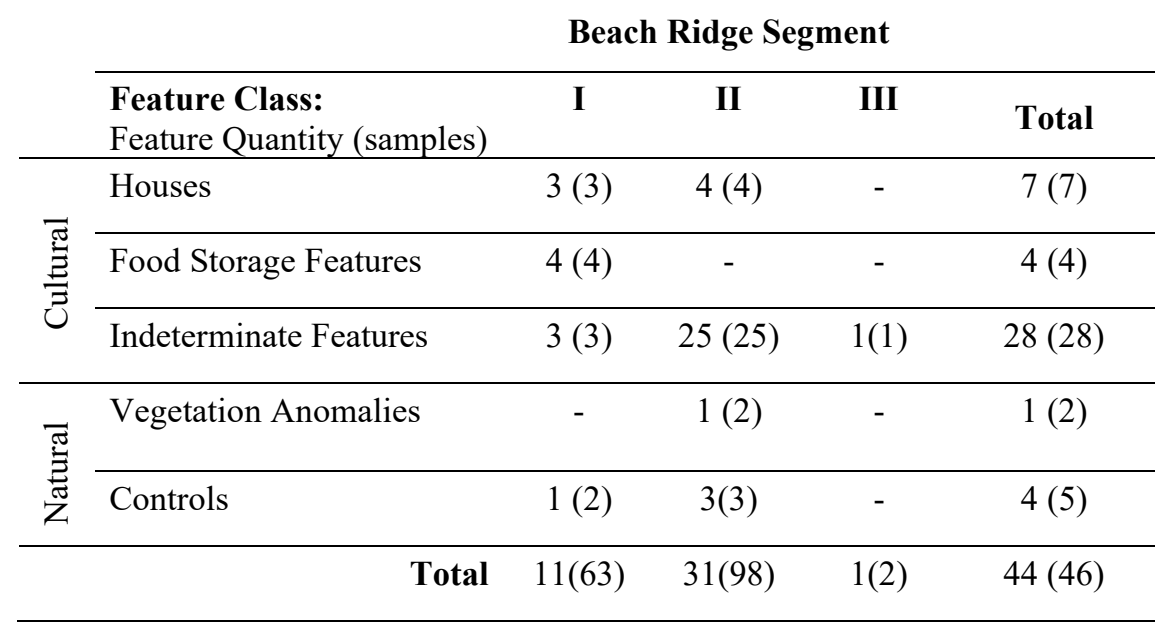




\section{Descriptive Statistics, and ANOVA}

The ICP-MS concentration data collected in Phase II highlights patterns between analyte concentrations and feature classes. Overall, mean concentrations of analyte elements (Figure 4-3;Table 4-2; and Table B-1 located in Appendix B) indicate that while values are generally similar cultural features are enriched in comparison to control and vegetation anomaly samples for $\mathrm{Cr}, \mathrm{Mg}, \mathrm{Ni}, \mathrm{Al}, \mathrm{Ba} \mathrm{Sr}, \mathrm{Cu}, \mathrm{Zn}, \mathrm{P}$ and $\mathrm{Ca}$ analyte elements. Mean concentrations of $\mathrm{Na}, \mathrm{Mn}, \mathrm{Co}, \mathrm{Fe}, \mathrm{K}$ and $\mathrm{Pb}$ are present at similar or slightly depleted concentrations in cultural features compared to control features (Figure 4-3). Vegetation anomaly samples generally follow the patterning of control samples except that vegetation anomaly samples have lower concentrations of $\mathrm{Na}, \mathrm{Sr}$, and $\mathrm{Zn}$, and elevated levels of $\mathrm{K}$ in comparison to control samples. The greatest range of concentrations is present in cultural samples, most notably in indeterminate features.

Some distinctions between cultural feature classes are also observable in the concentration data. In comparison to house features, food storage features have elevated concentrations of $\mathrm{Na}, \mathrm{Mg}, \mathrm{Mn}, \mathrm{Fe}, \mathrm{Cr}, \mathrm{Co}, \mathrm{Cu}, \mathrm{Ba}, \mathrm{Zn}, \mathrm{P}$, and $\mathrm{Ca}$, and lower concentrations of Ni, Sr, and K (Figure 4-3; Table B-1). Despite the patterning seen between cultural feature classes, there is overlap in the ranges of all concentrations between cultural feature classes. Furthermore, the concentration range of the indeterminate features generally covers the ranges observed in both house and food storage feature class for all analyte elements. This overlap is well illustrated by the concentration of $\mathrm{Cr}$ in indeterminate features, which shows a greater range, and values that encompasses house and food storage features and control features. 
To further explore the concentration data set, I analyzed the concentration of each analyte element grouped by feature classes from the ICP-MS analysis for statistical significance using a one-way ANOVA test. The results of the ANOVA analysis indicate that $\mathrm{Na}, \mathrm{Al}, \mathrm{Cr}$, and $\mathrm{Ni}$ are all statistically significant elements at the $95 \%$ confidence interval $(\mathrm{p} \leq .05)$ when comparing across all feature classes (Table 4-2; Table B-2). The post-hoc t-tests indicate that the variation in these elements indicated by the ANOVA is primarily between control and indeterminate feature classes. Statistically significant relationships between feature classes are indicated in bold and/or italic text in Table 4-2 and Table B-2. An exception to this is seen with regards to the variation between control and indeterminate features in $\mathrm{Cr}$ : The vegetation anomaly showed statistically significant variation between both indeterminate and house features, but was not significantly different from the food storage features.

Sodium is a peculiar case; while the ANOVA tests indicate significant variation in the data set, the post-hoc t-tests with Bonferroni corrected significance values indicate that $\mathrm{Na}$ is only statistically significant for distinguishing between the vegetation anomaly and cultural features when they are considered as a single group (Bonferroni corrected $p=\leq$ .1667). When cultural feature classes are considered independently(distinct comparison to house, food storage features, and indeterminates), the post-hoc t-test is not statistically significant (observed $p=.007$; Bonferroni corrected significant $p \leq .005$ ). However, similar to other analyte elements, the variation in $\mathrm{Na}$ is observed between vegetation anomaly and indeterminate feature samples. 
Table 4-2. Elements and Feature Classes with Statistically Significant Variation determined by ANOVA and Post-hoc T-Tests

\begin{tabular}{|c|c|c|c|c|c|c|c|c|c|}
\hline \multirow[t]{2}{*}{$\mathbf{N a}$} & \multicolumn{8}{|c|}{$\mathbf{C r}$} & \multirow{2}{*}{$\begin{array}{l}\text { Std. } \\
\text { Dev. }\end{array}$} \\
\hline & Mean & Max. & Min. & Dev. & & Mean & Max. & Min. & \\
\hline Total: & 5.315 & 5.957 & 4.817 & 0.221 & Total: & 3.854 & 4.078 & 3.476 & 0.142 \\
\hline Control $(n=5)$ & 5.187 & 5.248 & 5.050 & 0.082 & Control $(n=5)$ & 3.667 & 3.863 & 3.476 & 0.153 \\
\hline Veg. Anom. $(n=2)$ & 4.919 & 5.020 & 4.817 & 0.144 & Veg. Anom. $(n=2)$ & 3.601 & 3.712 & 3.490 & 0.157 \\
\hline Cultural $(n=37)$ & 5.356 & 5.957 & 4.962 & 0.893 & Cultural (n=37) & 3.885 & 4.078 & 3.671 & 0.104 \\
\hline House $(\mathrm{n}=8)$ & 5.283 & 5.644 & 5.171 & 0.154 & House $(n=8)$ & 3.862 & 3.920 & 3.807 & 0.045 \\
\hline $\begin{array}{l}\text { Food Storage } \\
(\mathrm{n}=4)\end{array}$ & 5.418 & 5.889 & 5.213 & 0.317 & $\begin{array}{l}\text { Food Storage } \\
(\mathrm{n}=4)\end{array}$ & 3.889 & 3.948 & 3.834 & 0.048 \\
\hline $\begin{array}{l}\text { Indeterminate } \\
(\mathrm{n}=25)\end{array}$ & 5.367 & 5.957 & 4.962 & 0.211 & $\begin{array}{l}\text { Indeterminate } \\
(\mathrm{n}=\mathbf{2 5})\end{array}$ & 3.904 & 4.078 & 3.671 & 0.122 \\
\hline \multirow[t]{2}{*}{$\mathbf{N i}$} & & & & Stc & Al & & & & St \\
\hline & Mean & Max. & Min. & Dev. & & Mean & Max. & Min. & Dev. \\
\hline Total: & 4.300 & 4.754 & 3.644 & 0.216 & Total: & 6.55 & 6.89 & 6.24 & 0.13 \\
\hline Control $(n=5)$ & 4.008 & 4.337 & 3.644 & 0.259 & Control $(n=5)$ & 6.40 & 6.59 & 6.24 & 0.16 \\
\hline Veg. Anom. $(\mathrm{n}=2)$ & 4.124 & 4.186 & 4.062 & 0.088 & Veg. Anom. $(n=2)$ & 6.42 & 6.50 & 6.35 & 0.10 \\
\hline Cultural (n=37) & 4.349 & 4.754 & 3.798 & 0.179 & Cultural (n=37) & 6.58 & 6.89 & 6.34 & 0.11 \\
\hline House $(n=8)$ & 4.344 & 4.471 & 4.196 & 0.099 & House $(n=8)$ & 6.53 & 6.69 & 6.37 & 0.10 \\
\hline $\begin{array}{l}\text { Food Storage } \\
(n=4)\end{array}$ & 4.366 & 4.530 & 4.287 & 0.111 & $\begin{array}{l}\text { Food Storage } \\
(n=4)\end{array}$ & 6.56 & 6.69 & 6.51 & 0.09 \\
\hline $\begin{array}{l}\text { Indeterminate } \\
(\mathrm{n}=\mathbf{2 5})\end{array}$ & 4.347 & 4.754 & 3.798 & 0.209 & $\begin{array}{l}\text { Indeterminate } \\
(\mathrm{n}=\mathbf{2 5})\end{array}$ & 6.60 & 6.89 & 6.34 & 0.12 \\
\hline
\end{tabular}

Bold text indicates ANOVA Significance at $\mathrm{p}=<.05$; Italic text indicates T-test assuming equal variance with Bonferroni correction Significance $p=<.005$. Non-significant results are presented in Appendix B.

The post-hoc t-tests indicate that there is no statistically significant variation between control and vegetation anomaly samples, nor between any cultural feature classes. The vegetation anomaly sample concentrations are dissimilar to the cultural feature classes for most analyte elements, with exception to $\mathrm{Mn}, \mathrm{Fe}$, and $\mathrm{K}$, where mean concentrations of the vegetation anomaly samples are within the concentration range observed in the cultural features. Additionally, as pointed out previously, it is common in elemental analysis of archaeological features that no single analyte element distinguishes between feature classes, but rather the relationship of multiple element concentrations provides the greatest insight into geochemical patterning (Knudson and Frink 2010; Wells 2004b; Wells et al. 2007). 

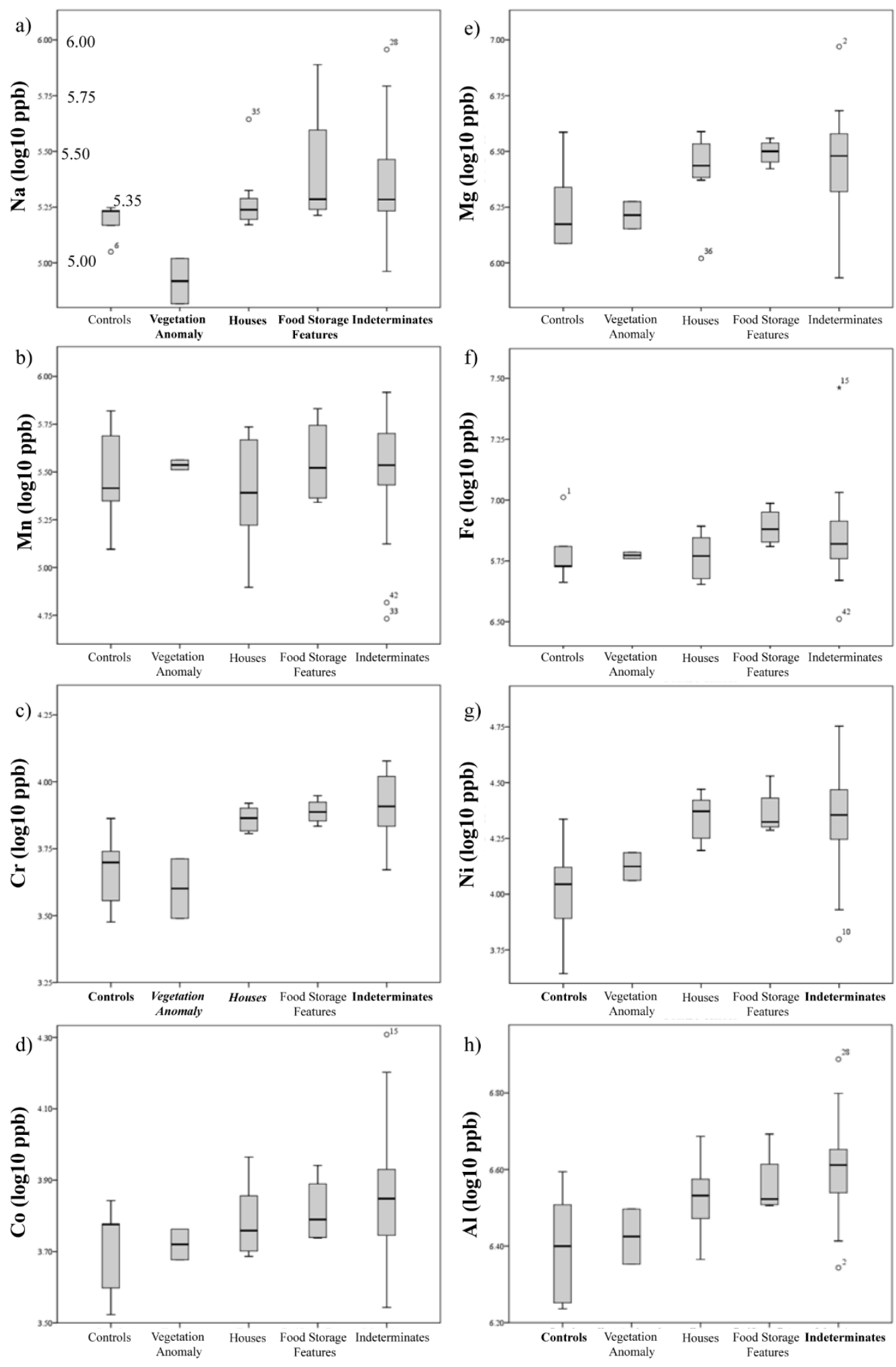

Figure 4-3. Box plots of mean concentration data for all analyte elements. Bold text indicates ANOVA Sig. at $\mathrm{p}=<.05$; Italic text indicates T-test Sig. at $\mathrm{p}=<.005$. 

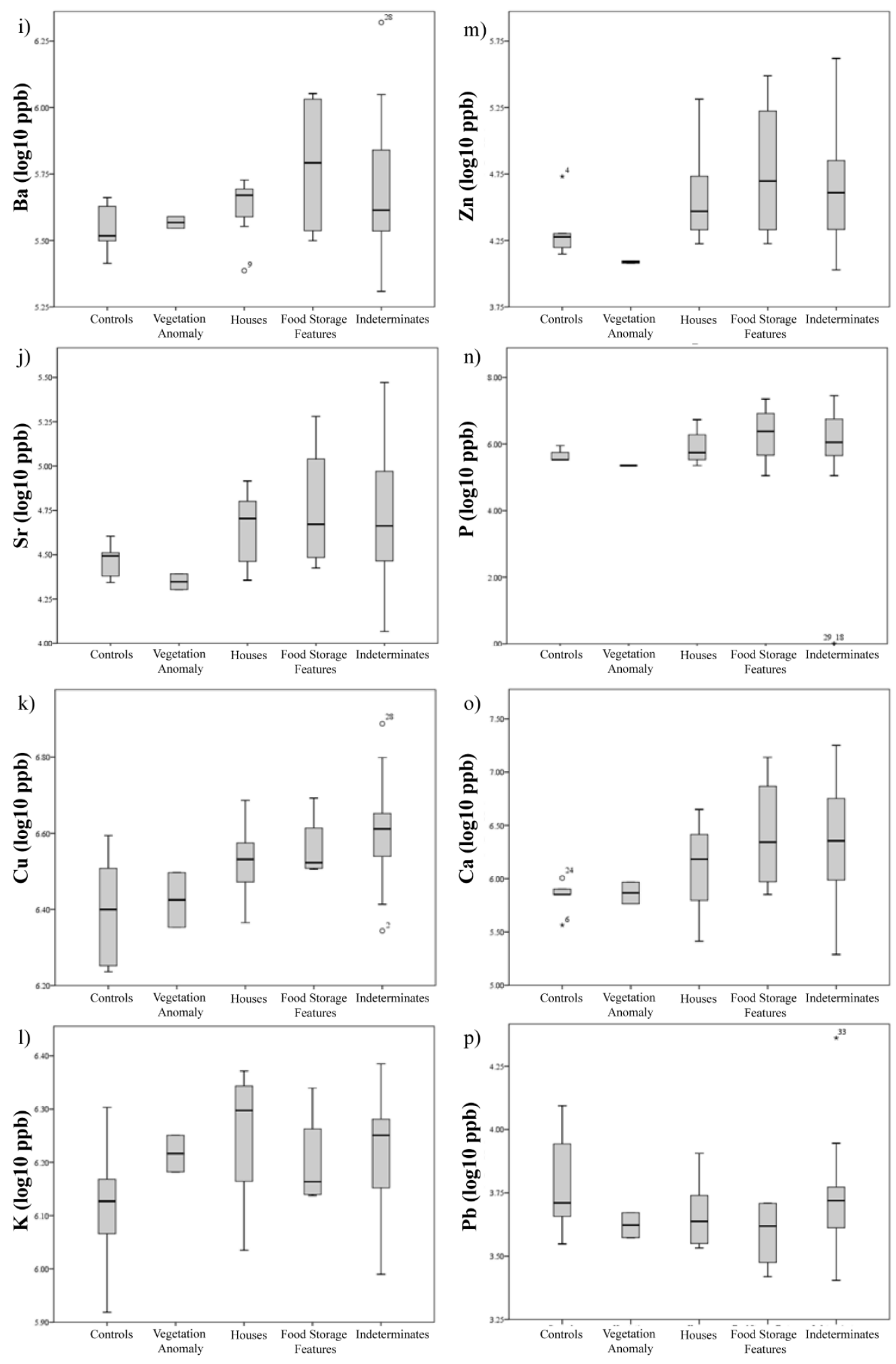

Figure 4-3 cont'd. Box plots of mean concentration data for all analyte elements. Bold text indicates ANOVA Sig.at $\mathrm{p}=<.05$; Italic text indicates T-test Sig. at $\mathrm{p}=<.005$. 


\section{Principal Component Analysis}

To investigate the use of analyte elements as anthropogenic indicators, I ran a PCA including all feature classes and analyte elements to identify the factors and elemental loadings that best explain the data set. After establishing distinctions between control and cultural feature classes, I ran a second PCA using only the cultural feature classes (PCACult). Correlation values of all components in both PCA are $<0.80$ indicating that multicollinearity (when one or more variables are dependent upon each other) is not an issue. The significance values for Bartlett's test of sphericity is $<0.01$, indicating that both PCA are reliable. The elements and relative level of variation of each feature class associated with the principal components are presented in Table 4-3.

Analysis of the entire data set identified five principal components (PC) with eigenvalues greater than 1; eliminating components accounting for less than approximately $5 \%$ of variation. In total, the five principal components account for approximately $79.3 \%$ of the variation in the analyte element concentrations. The first principal component (PC1) showed strong positive loadings of $\mathrm{Sr}, \mathrm{Ca}, \mathrm{Cu}, \mathrm{Ba}, \mathrm{Na}, \mathrm{P}$, and $\mathrm{Zn}$ (in descending order of loading), with loading values ranging from 0.96 to 0.616 . The second principal component (PC-2) contained positive loadings of $\mathrm{Cr}, \mathrm{Al}, \mathrm{Ni}, \mathrm{K}, \mathrm{Co}$, and $\mathrm{Mg}$ with loading values ranging from 0.976 to 0.373 . Generally, cultural features were more varied (wider range of factor scores and overall higher values) than non-cultural features (tighter range and lower factor cores). The biplot of the first two principal components (Figure 4-4a) shows clear distinctions between known feature classes and controls. 
Table 4-3. Principal Components, Loading Elements and Observed Feature Class Variation

\begin{tabular}{|c|c|c|}
\hline $\begin{array}{l}\text { Principal Component } \\
\text { (\% variation) }\end{array}$ & $\begin{array}{l}\text { Associated Elements } \\
\text { (Factor score range) }\end{array}$ & $\begin{array}{l}\text { Feature Class Variation } \\
\text { (by ascending order) }\end{array}$ \\
\hline PC-1 (39.8\%) & $\begin{array}{l}\mathrm{Sr}, \mathrm{Ca}, \mathrm{Cu}, \mathrm{Ba}, \mathrm{Na}, \mathrm{P}, \mathrm{Zn} \\
\text { (-1.56 to } 2.53)\end{array}$ & $\begin{array}{l}\text { Food Storage } \\
\text { Indeterminates } \\
\text { House } \\
\text { Control } \\
\text { Vegetation Anomaly }\end{array}$ \\
\hline PC-2 (13.9\%) & $\begin{array}{l}\mathrm{Cr}, \mathrm{Al}, \mathrm{Ni}, \mathrm{K}, \mathrm{Co}, \mathrm{Mg} \\
(-2.89 \text { to } 1.73)\end{array}$ & $\begin{array}{l}\text { Control } \\
\text { Vegetation Anomaly, } \\
\text { Indeterminates, } \\
\text { House, } \\
\text { Food Storage }\end{array}$ \\
\hline PC-3 (10.1\%) & $\begin{array}{l}\mathrm{K},-\mathrm{Fe},-\mathrm{Mg} \\
(-2.34 \text { to } 1.94)\end{array}$ & $\begin{array}{l}\text { Control } \\
\text { Indeterminate } \\
\text { House } \\
\text { Vegetation Anomaly } \\
\text { Food Storage }\end{array}$ \\
\hline PC-4 (8.9\%) & $\begin{array}{l}-\mathrm{P}, \mathrm{Ni}, \mathrm{Mn}, \mathrm{Co} \\
(-2.48 \text { to } 2.41)\end{array}$ & $\begin{array}{l}\text { Control } \\
\text { House } \\
\text { Indeterminate } \\
\text { Food Storage } \\
\text { Vegetation Anomaly }\end{array}$ \\
\hline PC-5 (7.5\%) & $\begin{array}{l}-\mathrm{Ni}, \mathrm{Pb},-\mathrm{Mg} \\
(-1.72 \text { to } 3.36)\end{array}$ & $\begin{array}{l}\text { Control } \\
\text { House } \\
\text { Indeterminate } \\
\text { Food Storage } \\
\text { Vegetation Anomaly }\end{array}$ \\
\hline
\end{tabular}

While cultural feature classes are highly variable, house and food storage feature samples show moderate to low variation in PC-1 and PC-2 (Figure 4-4a). The first and second principal components show the greatest potential for distinguishing between cultural features, with a slight distinction indicated by the trend of positive factor scores in food storage feature samples and negative factor scores of PC-2 seen in house feature samples. The third principal component (PC-3) shows a distinction similar to that described by PC-2 but with inverted values in house and food storage features (loadings of Mg and Fe are negatively contributing to PC-3) when plotted against PC-1 (Figure 4-4 a \& b; Table 
4-3). The remaining principal components (PC-4 to PC-5) do not show any clear patterning between feature types (Figure 4-4c-d).

To aid in interpreting the nature of the indeterminate feature classes I performed an additional exploratory PCA using only the cultural features as well as a series of K-means and Hierarchical cluster analyses to identify if the loading elements identified in the PCA indicated significant groupings of feature types. The result of the PCA were similar to the initial PCA I performed on the entire data set and indicated minimal additional patterning. A similar suite of elements makes up each component, with the greatest differences coming from the refinement of the second and third principal components. The K-means and hierarchical cluster analysis did indicate distinct groups of cultural features however it did not explicitly distinguish between house and food storage groups beyond what was observable in the PCA analysis, nor did the clustering's reflect a spatial association between features at the complex. As the cultural only PCA results were similar, I focus on the initial PCA in the discussion and remainder of the document. The results of the PCA and K-means cluster analysis using only the cultural feature samples, including tables and biplots, are provided in Appendix B (Table B-2 and Figure B-1). 

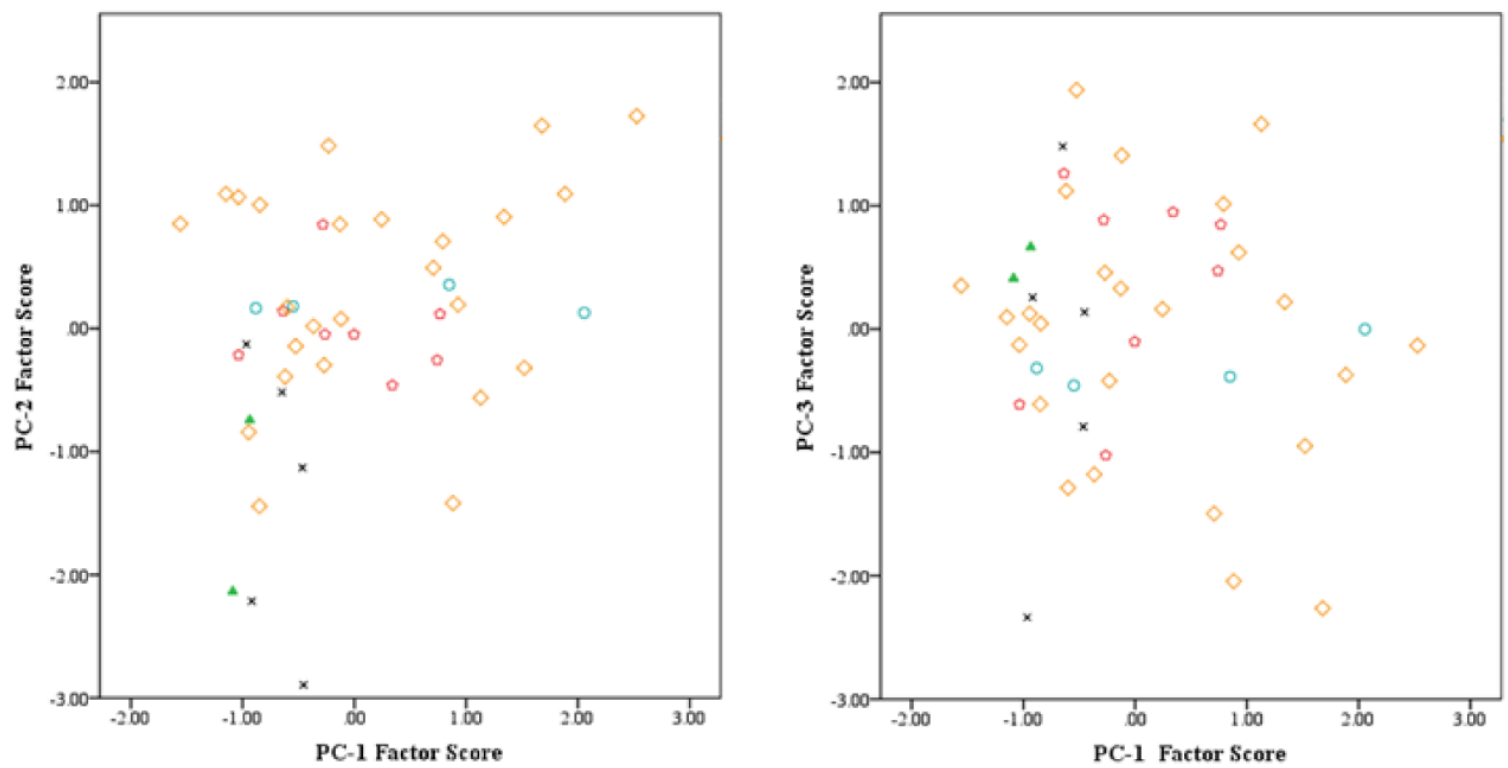

a) PC-1 vs. PC-2

b) PC-1 vs. PC-3
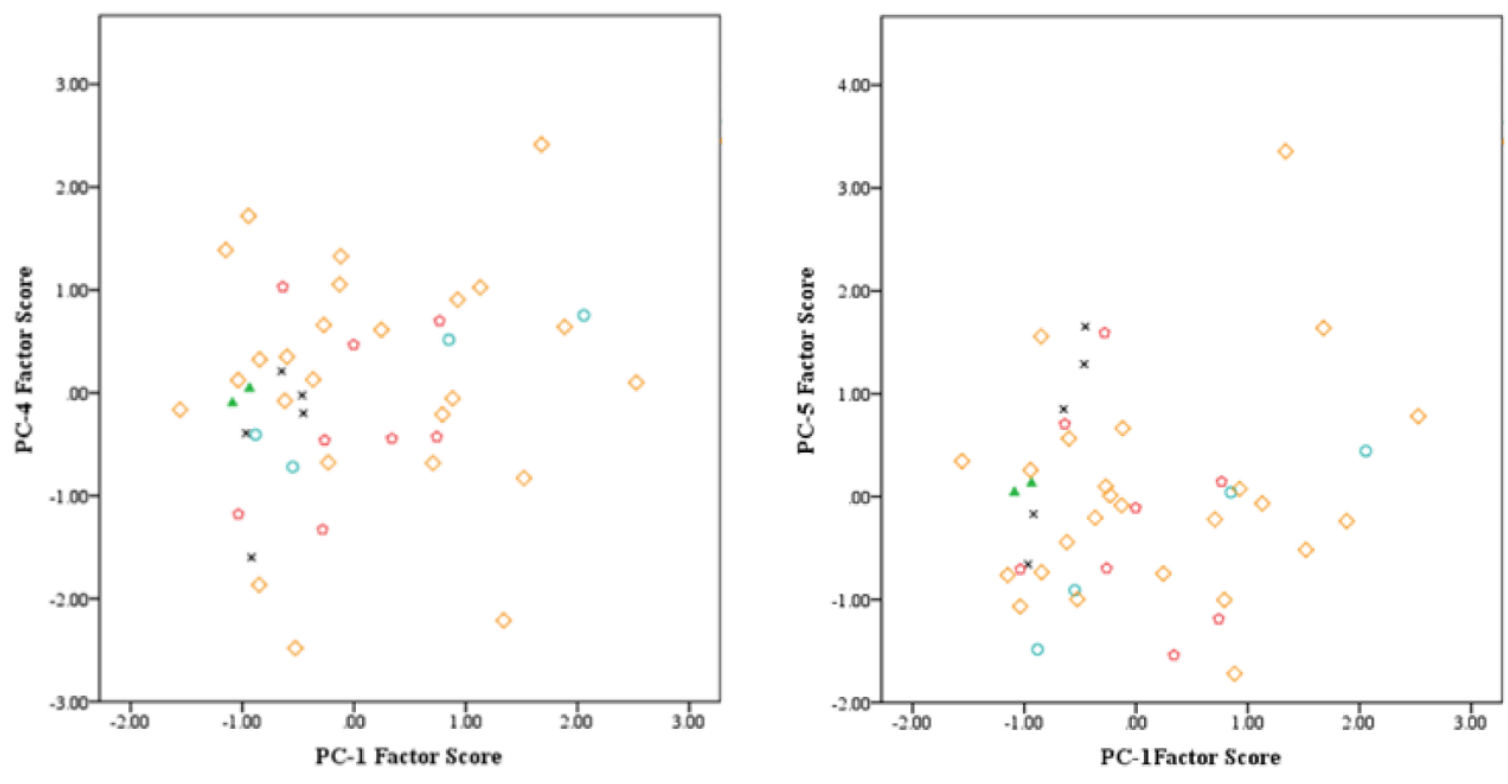

c) PC-1 vs. PC-4

d) PC-1 vs. PC-5

Feature Class
$\times$ Control
$\checkmark$ Houses
$\diamond$ Indeterminates
$\Delta$ Vegetation Anomaly $\bigcirc$ Food Storage Features

Figure 4-4. Biplots of first principal component factor scores vs (a) PC2, (b) PC-3, (c) PC-4, (d) PC-5. 


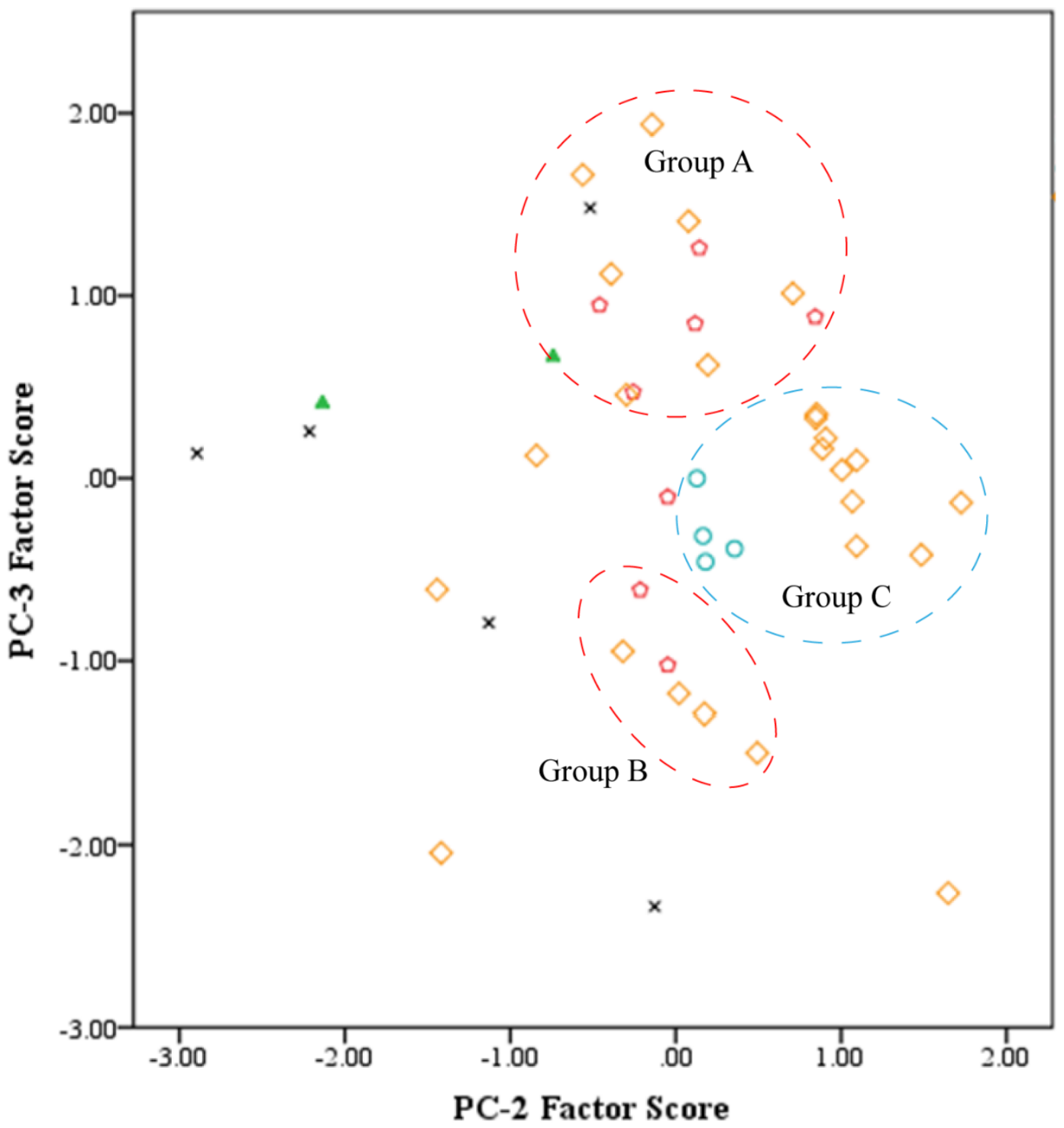

Feature Class
$\times$ Control
$\checkmark$ Houses
$\diamond$ Indeterminates
$\Delta$ Vegetation Anomaly $\bigcirc$ Food Storage Features

Figure 4-5. Biplot of second and third principal component factor scores. 


\section{Discriminant Function Analysis}

I performed multiple DFAs as an exploratory analysis to further investigate the feature classes. First, I used all feature classes as possible group categories (DFAa). Secondly, I removed the vegetation anomaly category and the indeterminate feature class, leaving them as unassigned to be reassigned as known feature classes (DFAb). A third DFA (DFAc) investigates the nature of the cultural features. The results of my DFAs are presented below and summarized in Table 4-4, and biplots of each discriminant function are presented in Figure 4-6 (a-c).

As seen in Table 4-4, When considering all feature class categories (DFAa), prediction of all initial samples for the predetermined categories is moderately accurate (79.5\% correct), with excellent probability of feature class assignment (probability values of 0.1 ). However, cross validation is poor, with only $38.6 \%$ correct classification. All but one control sample is correctly classified; this sample is reclassified as an indeterminate feature. Vegetation anomaly samples, while being correctly classified in totality, have values similar to control features (Figure 4-6a). House and food storage feature samples are only partially correctly classified $(62.5 \%$ and $75 \%$ respectively), with three house samples and food storage feature samples classified as indeterminates. The indeterminates are $84 \%$ correctly classified, with a single sample each reclassified as a control and a food storage feature and three samples reclassified as houses. DFAa indicates that there are distinctions between all feature classes, however, the relationship between them is complex.

To further explore the relationship between feature classes, I performed a second DFA (DFAb) with the indeterminate and vegetation anomaly feature classes removed. 
Prediction of all initial samples in DFAb for the predetermined categories (control, house, and food storage), is again excellent (100\%), with probability values of feature class assignment at 0.1 . Cross validation of the classification is still poor at $35.3 \%$. Classification of the unassigned samples is dispersed across all categories; with seven indeterminate samples classified as control features, 12 of the unassigned samples (ten indeterminate, two vegetation anomaly) are classified as house features and eight are classified as food storage features (Table 4-4Error! Reference source not found.). The biplot of DFAb functions (Figure 4-6b) indicates two unique aspects: (1) Dispersion of the unassigned samples is greater across all predetermined feature classes, and (2) the vegetation anomaly samples are classified as house features (discussed in greater detail in the following chapter). I believe the inclusion of these samples in the house category is due to the natural enrichment of the sediment in the few analyte elements discussed above.

Thirdly, I performed DFAc to explore the reclassification of the indeterminates with greater focus on the cultural features by classifying the vegetation anomaly samples as control samples, leaving only the indeterminate feature samples as unassigned. Prediction of all initial samples in DFAc for the predetermined categories (control, house, and food storage), is again excellent (100\%), and all probability values of feature class assigned at 0.1 . Cross validation of the classification improved but is again only moderately correct (57.9\%). Reclassification of unassigned indeterminate samples is dispersed across all feature categories; with eight indeterminate samples classified as control features, ten samples classified as house features and four samples classified as food storage features). The biplot of DFAc functions (Figure 4-6c) again shows high level of dispersion in 
unclassified features; though food storage features grouped well together, only a few indeterminate features are classified as food storage features.

Table 4-4. Summary of Discriminant Function Analyses

DFAa) All feature classes included

\begin{tabular}{l|cl|l|rl}
\hline $\begin{array}{l}\text { Original } \\
\text { groupings: }\end{array}$ & $\begin{array}{l}\text { Predicted } \\
\text { cases }(\%)\end{array}$ & $\begin{array}{l}\text { Reclassification } \\
\text { Class }(\mathrm{n})\end{array}$ & $\begin{array}{l}\text { Cross validation } \\
\text { results: }\end{array}$ & $\begin{array}{l}\text { Predicted } \\
\text { cases }(\%)\end{array}$ & $\begin{array}{l}\text { Reclassification } \\
\text { Class }(\mathrm{n})\end{array}$ \\
\hline Control $(\mathrm{n}=5)$ & $4(80 \%)$ & Indeterm. $(\mathrm{n}=1)$ & Control $(\mathrm{n}=5)$ & $2(40 \%)$ & $\begin{array}{l}\text { Veg. Anom }(\mathrm{n}=1) \\
\text { Indeterm. }(\mathrm{n}=2)\end{array}$ \\
\hline $\begin{array}{l}\text { Veg. Anom. } \\
(\mathrm{n}=2)\end{array}$ & $2(100 \%)$ & - & $\begin{array}{l}\text { Veg. Anom. } \\
(\mathrm{n}=2)\end{array}$ & $1(50 \%)$ & Control $(\mathrm{n}=1)$ \\
\hline House $(\mathrm{n}=8)$ & $5(62.5 \%)$ & Indeterm. $(\mathrm{n}=3)$ & House $(\mathrm{n}=8)$ & $2(25 \%)$ & $\begin{array}{l}\text { Control }(\mathrm{n}=1) \\
\text { Indeterm. }(\mathrm{n}=5)\end{array}$ \\
\hline Food Stor. $(\mathrm{n}=4)$ & $3(75 \%)$ & & Food Stor. $(\mathrm{n}=4)$ & $1(25 \%)$ & $\begin{array}{l}\text { Control }(\mathrm{n}=1) \\
\text { House }(\mathrm{n}=3)\end{array}$ \\
\hline Indeterm. $(\mathrm{n}=25)$ & $21(85 \%)$ & $\begin{array}{l}\text { Control }(\mathrm{n}=1) \\
\text { House }(\mathrm{n}=3)\end{array}$ & Indeterm. $(\mathrm{n}=25)$ & $11(44 \%)$ & $\begin{array}{l}\text { Control }(\mathrm{n}=1) \\
\text { Veg. Anom. }(\mathrm{n}=1) \\
\text { House }(\mathrm{n}=6)\end{array}$ \\
& & & & & Food Stor. $(\mathrm{n}=4)$ \\
\hline
\end{tabular}

DFAb) Indeterminates and Vegetation Anomaly unassigned

\begin{tabular}{|c|c|c|c|c|c|}
\hline $\begin{array}{l}\text { Original } \\
\text { groupings: }\end{array}$ & $\begin{array}{l}\text { Predicted } \\
\text { cases (\%) }\end{array}$ & $\begin{array}{l}\text { Reclassification } \\
\text { Class (n) }\end{array}$ & $\begin{array}{l}\text { Cross validation } \\
\text { results: }\end{array}$ & $\begin{array}{l}\text { Predicted } \\
\text { cases }(\%)\end{array}$ & $\begin{array}{l}\text { Reclassification } \\
\text { Class (n) }\end{array}$ \\
\hline Control $(n=5)$ & $5(100 \%)$ & & Control $(\mathrm{n}=5)$ & $1(20 \%)$ & $\begin{array}{l}\text { House }(n=3) \\
\text { Food Store. }(n=1)\end{array}$ \\
\hline Veg. Anom $(n=2)$ & - & House $(n=2)$ & Veg. Anom. $(n=2)$ & - & - \\
\hline House $(\mathrm{n}=8)$ & $8(100 \%)$ & 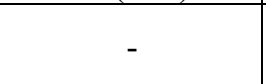 & House $(n=8)$ & $3(37.5 \%)$ & $\begin{array}{l}\text { Control }(\mathrm{n}=2) \\
\text { Food Stor. }(\mathrm{n}=3)\end{array}$ \\
\hline Food Stor. $(n=4)$ & $4(100 \%)$ & - & Food Stor. $(\mathrm{n}=4)$ & $2(50 \%)$ & $\begin{array}{l}\text { Control }(\mathrm{n}=1) \\
\text { House }(\mathrm{n}=1)\end{array}$ \\
\hline Indeterm. $(n=25)$ & - & $\begin{array}{l}\text { Control }(n=7) \\
\text { House }(n=10) \\
\text { Food Stor. }(n=8)\end{array}$ & Indeterm. $(n=25)$ & - & 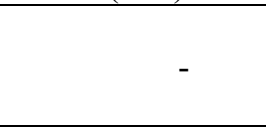 \\
\hline Overall Correct & $100 \%$ & & & $35.3 \%$ & \\
\hline
\end{tabular}

DFAc) Vegetation Anomaly samples assigned as controls

\begin{tabular}{|c|c|c|c|c|c|}
\hline $\begin{array}{l}\text { Original } \\
\text { groupings: }\end{array}$ & $\begin{array}{l}\text { Predicted } \\
\text { cases }(\%)\end{array}$ & $\begin{array}{l}\text { Reclassification } \\
\text { Class (n) }\end{array}$ & $\begin{array}{l}\text { Cross validation } \\
\text { results: }\end{array}$ & $\begin{array}{l}\text { Predicted } \\
\text { cases }(\%)\end{array}$ & $\begin{array}{l}\text { Reclassification } \\
\text { Class (n) }\end{array}$ \\
\hline Control $(n=5)$ & $7(100 \%)$ & - & Control $(\mathrm{n}=5)$ & $4(57.1 \%)$ & - \\
\hline Veg. Anom. $n=2$ ) & - & Control $(n=2)$ & $\begin{array}{l}\text { Veg. Anom. } \\
(n=2)\end{array}$ & - & Control $(n=2)$ \\
\hline House $(n=8)$ & $8(100 \%)$ & - & House $(n=8)$ & $7(87.5 \%)$ & Food Stor. $(\mathrm{n}=1)$ \\
\hline Food Stor. $(n=4)$ & $4(100 \%)$ & - & Food Stor. $(n=4)$ & $0(00.0 \%)$ & $\begin{array}{l}\text { Control }(\mathrm{n}=2) \\
\text { Food Stor. }(\mathrm{n}=2)\end{array}$ \\
\hline Indeterm. $(n=25)$ & - & $\begin{array}{l}\text { Control }(n=8) \\
\text { House }(n=13) \\
\text { Food Stor. }(n=4)\end{array}$ & Indeterm. $(n=25)$ & - & 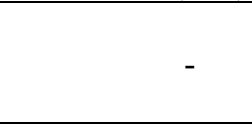 \\
\hline Overall Correct & $100 \%$ & & & $57.9 \%$ & \\
\hline
\end{tabular}



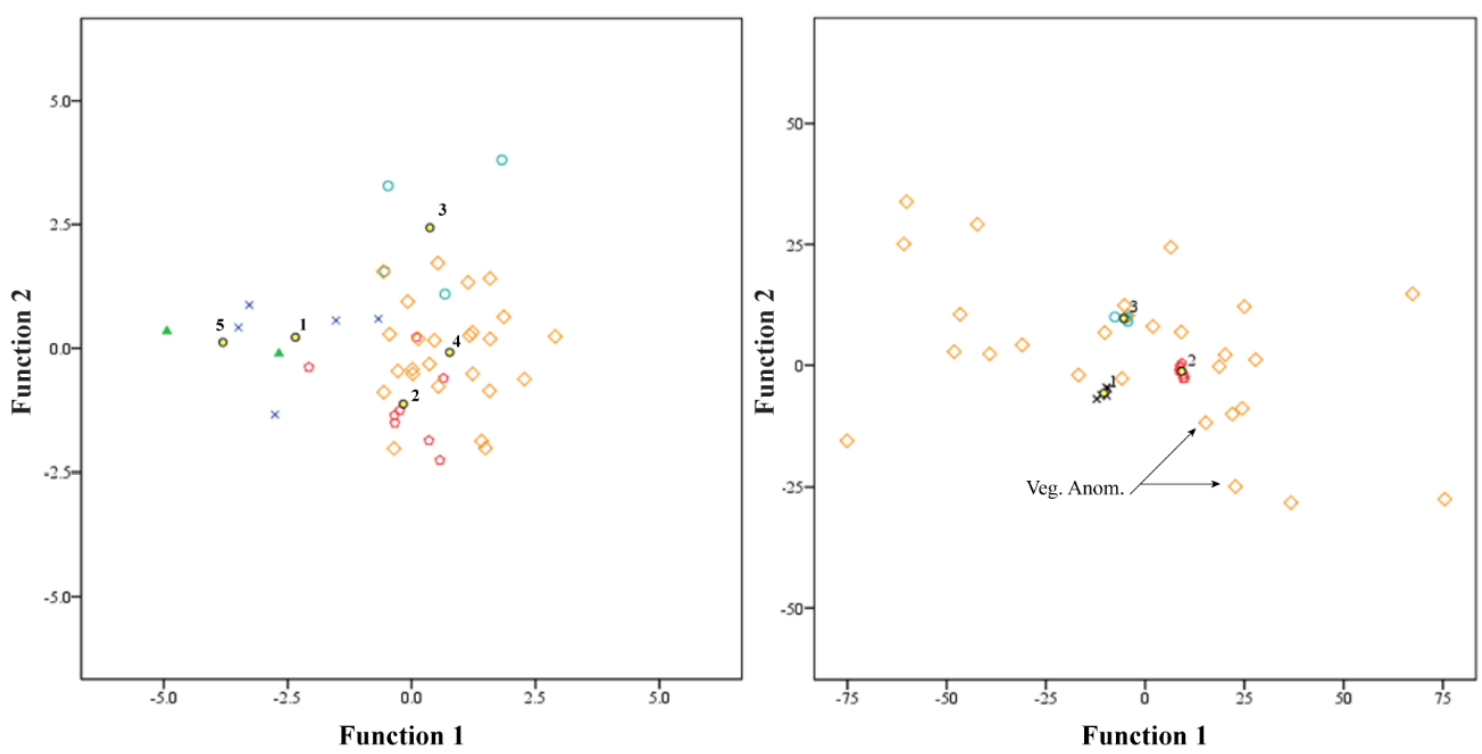

a) DFAa. All feature classes included.

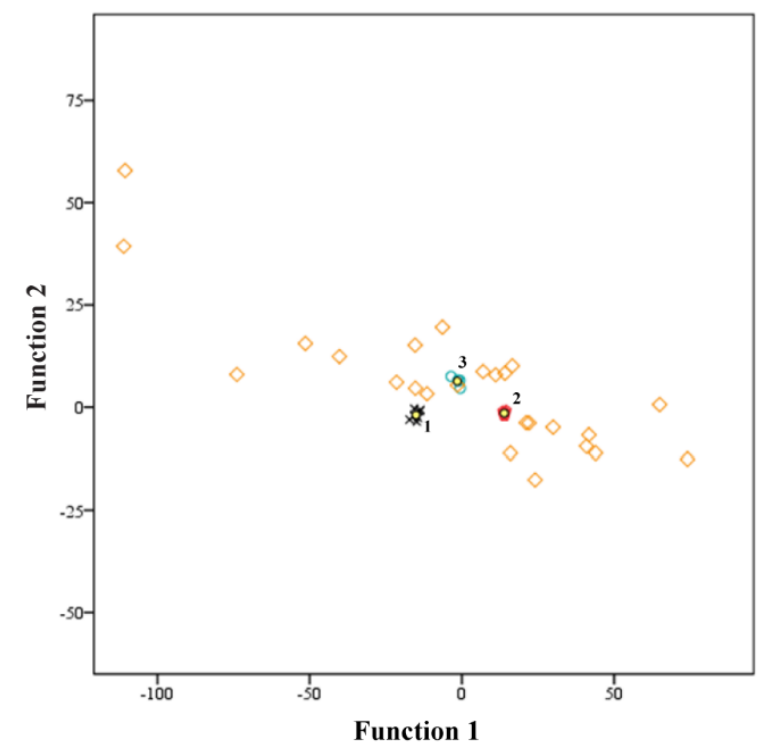

b) DFAb. Indeterminate and vegetation anomaly left unassigned.
Feature Class
$\times$ Control
$\Delta$ Vegetation Anomaly
$\checkmark$ Houses
$\circ$ Food Storage Features
$\diamond$ Indeterminates
○ Group Centroid

c) DFAc. Vegetation anomaly as control samples, indeterminates left unassigned.

Figure 4-6. Canonical discriminant function analyses biplots. 


\section{Results Summary}

Overall in Phase I, I confirmed that the control samples were not from cultural contexts, and that cultural deposits did contain elevated levels of soil phosphate. The samples from Vegetation Anomaly 3624B did not have a reaction for soil phosphates suggesting that it is likely a natural feature. However, given that some samples from cultural features also showed no reaction for soil phosphates I included two samples from the vegetation anomaly in Phase 2 analysis to further explore the nature of the feature. I eliminated 112 samples from inclusion in Phase II of my analysis, selecting a total of 39 samples from cultural features with the greatest potential (highest available phosphate reaction per feature) for exploring anthropogenic elemental inputs and five control samples for ICP-MS analysis in Phase II. The statistical analysis of ICP-MS concentration data I performed in Phase II of my analysis shows that concentrations of elements do vary by feature class, however, only a few elements are statistically significant according to ANOVA and post-hoc t-tests. PCA of the data set confirms that, similar to many previous geochemical analyses (Knudson et al. 2004; Knudson and Frink 2010; Wells 2004b; Wells et al. 2007), no single element distinguishes between feature classes and three main components account for the major sources of variation in the data set. Primarily, the suite of elements that are defined as the first principal component across all principal component analyses is consistent regardless of feature class exclusions. I used multiple DFAs to explore these data and attempt to reclassify and interpret the original function of the vegetation anomaly and indeterminate features as control, house, or food storage features. The results are discussed in further detail and specifically as they apply to my hypotheses in the following chapter. 


\section{Chapter 5 - Discussion}

In Chapter 5 I discuss the results of my analysis. I start by discussing the patterning seen in the elemental compositions data analyses presented in Chapter 4 in relation to the hypotheses of this thesis, including interpreting the nature of Vegetation Anomaly 3624B (Hypothesis 1) and the relationship of the indeterminate features to house and food storage feature classes based on their geochemical signatures (Hypothesis 2) (Table 5-1). Interpretations are given to assign the indeterminate feature samples as house or food storage cultural features (Hypothesis 2a) and to explore the potential of multiple food storage feature types (Hypothesis 2c).

\section{Hypothesis 1: The Vegetation Anomaly is a Natural or Cultural Feature}

The initial goal of my geochemical analysis was to determine whether Vegetation Anomaly 3624B is a natural or cultural feature. Hypothesis 1 is repeated here: $\left(\mathrm{H}-1_{0}\right)$ If levels of phosphates in the vegetation anomaly samples are observed at similar levels in comparison to control samples and at lower intensities to house and food storage features, Vegetation Anomaly 3624B will be identified as a natural feature; (H-1 $\left.1_{1}\right)$ If levels of phosphate are observed as elevated in the vegetation anomaly samples in comparison to control samples and at similar intensities to house and food storage features, Vegetation Anomaly 3624B will be identified as likely anthropogenic and reclassified as an indeterminate feature.

My work indicates that Vegetation Anomaly 3624B is a natural feature (Table 51). The vegetation anomaly samples showed no reaction for soil phosphates, suggesting that the feature may be natural in origin. However, I was not able to reject the null 
hypotheses on soil phosphates data alone based on the presence of negative results in cultural feature samples. To further explore this, I included two samples from Vegetation Anomaly $3624 \mathrm{~B}$, representing two depths in the second phase of analysis to confirm the feature's origin as natural. Samples from multiple depths were included in order to asses if natural or other cultural processes are interfering with or obscuring the interpretation of these features.

Table 5-1. Hypothesis 1 Results and Summary Hypothesis

H-10: Vegetation Anomaly is as natural feature

Results Phase I:

- No soil phosphates reaction in vegetation anomaly samples

Results Phase II:

- Similar compositions to control

- Few elements elevated - attributed to animal and natural processes

- PCA-Grouped near control samples

- DFA- Reclassed as control features

Conclusion: Supported

H-1 1: Vegetation Anomaly is anthropogenic

Results Phase I:

- No soil phosphates reaction in vegetation anomaly samples

Results Phase II:

- Lower concentrations than cultural feature samples.

- Few elements elevated - attributed to animal and natural processes

- PCA- Lower concentration values in PC-1, PC-2, and PC-3 elemental loadings

- DFA-Reclassed as houses based on few elemental enrichments- attributed to animal and natural processes

Conclusion: Not Met 
The results of Phase II also indicate that the Vegetation Anomaly is a natural feature $\left(\mathrm{H}-1_{0}\right)$. The results of the ICP-MS analysis and statistical analysis (ANOVA and PCA) indicate that the vegetation anomaly samples have compositions and concentrations of analyte elements most similar to the control samples (Table B-1, ). Some elements, however, are elevated and depleted in comparison to control samples, including elevated $\mathrm{K}$ and depleted $\mathrm{Na}, \mathrm{Zn}$, and $\mathrm{Pb}$. My DFA does not refute the conclusion that Vegetation Anomaly 3624B is a natural feature. Samples are generally grouped as control samples and none are reclassified as cultural features when used as a known or defined feature class (DFAa). When removed as a feature class, DFAb indicated that vegetation anomaly samples group more closely with house features. This grouping likely results from the variation and relative enrichment of the select elements mentioned above. I believe the enrichment of these elements is the result of animal and plant activity rather than an anthropogenic source or primary geologic or geomorphic process. Specifically, the low $\mathrm{Pb}$ and elevated $\mathrm{K}, \mathrm{Ca}$, and $\mathrm{Ba}$ compared to control samples may be from the input and decomposition of wastes, bone, and feces deposited by animals such as fox or ground squirrel (Knudson et al. 2004; Wilson et al. 2007) (See Table 2-1). However, Misarti et al. (2011) observed low levels of $\mathrm{K}$ in areas in the presence of fox.

Elevated levels of $\mathrm{K}$ in comparison to controls is suggestive that multiple factors may be contributing to the unique signature observed in the vegetation anomaly samples, including plant and/or sedimentologic processes. The low levels of Fe may be attributed to the accumulation and decomposition of organic material from the relatively lush vegetation that defines the feature class (Couture et al. 2016). Additionally, the low P levels observed may be related to seasonal depletion of vegetated arctic soils observed during the growing 
season (Weintraub 2011), which is when the bulk samples were collected. The fine sediments that accumulate as a result of this decomposition of plant and animal wastes may contribute to the high level of $\mathrm{K}$ in the vegetation anomaly samples as a result of K's relatively high susceptibility to cation exchange in fine sediments. Overall this suggests that Vegetation Anomaly 3624B is distinct in regard to its geochemical signature based on non-human inputs but is similar to control samples and likely a natural feature.

\section{Hypothesis 2: The Indeterminate Features are House or Food Storage Features}

The primary goal of my analysis was to identify the past behaviors that created the indeterminate features. Hypothesis 2 explores the potential of identifying the Indeterminates as house or food storage features. To do this, I first establish that house and food storage features have distinct geochemical signatures as hypothesized (Table 52). Under Hypothesis $2\left(\mathrm{H}-2_{0}\right)$, if the house and food storage features show little or no distinction from each other in their elemental composition and concentrations, then no distinction between cultural feature classes can be made. Alternatively, $\left(\mathrm{H}-2_{1}\right)$ if house and food storage features are observed to have dissimilar elemental compositions and concentrations in comparison to each other, then distinctions can be made, and the indeterminate features can be further identified based on their original function and use.

I am not able to make distinctions between the cultural features based on photometric phosphates test I performed in Phase I. Though the results suggest distinctions between the natural and cultural feature classes, the cultural feature classes had similar rates of reaction intensity for soil phosphates. The similarity of phosphate reaction levels between house and food storage features suggests that the source of $\mathrm{P}$ in these 
archaeological sediments is not explicitly traceable to a distinct past behavior, but rather

that the general decomposition of anthropogenic wastes as is common in Arctic systems

(Derry et al. 1999; Proudfoot 1976).

Table 5-2. Hypothesis 2 Results and Summary

Hypothesis

H-20: Cultural features (including indeterminates) are indistinguishable from each other. Conclusion: Not Met

H-2 1: Indeterminate features show compositions similar to house and food storage features Results Phase I:

- Controls and vegetation anomaly samples all tested negative for soil phosphates.

- Cultural feature samples showed similar rates of positive reactions for soil phosphates.

Results Phase II:

- Cultural samples elevated in comparison to control samples in all but $\mathrm{Mn}, \mathrm{Fe}$, and $\mathrm{Pb}$ analyte elements.

- Houses are elevated in comparison to control samples in all but $\mathrm{Mn}, \mathrm{Fe}$ and $\mathrm{Pb}$ analyte elements, but less elevated than food storage features.

- Indeterminates have broad range of high concentrations that include both house and food storage features.

Conclusions: Supported

H-2a: Indeterminate features are houses

Results Phase II

- DFA indicates that some are possibly associated with house activities

- Between 10 and 13 indeterminate features are possible houses

Conclusions: Supported

2b: Indeterminate features are food storage features

Results Phase II:

- DFA indicates that some are possibly associated with food storage features

- $\quad$ Between 4 and 15 possibly storage features

Conclusions: Supported 
In Phase II, I established that house and food storage features are somewhat distinct in elemental composition. However, ANOVA indicates that there is only statistical significance between these features for four $(\mathrm{Na}, \mathrm{Al}, \mathrm{Cr}$, and $\mathrm{Ni}$ ) individual analyte elements. While the lack of significant variation between indeterminate features and house or food storage features independently suggests similarity between feature types, it is not entirely unexpected as it is believed that the indeterminate features could represent both house and food storage features as discussed in Hypotheses $2 \mathrm{a}$ and $2 \mathrm{~b}$. The lack of statistically significant variation in elemental concentrations between house and food storage features, however, is unexpected. I expected the past behaviors that created and occurred in the use of these features to be unique, and that variation would exist between their geochemical signatures. However, while these features are created and used in different ways, the anthropogenic signature is likely similar because of similarity in the past behaviors represented and because of overlap in the source of the residues. That is, the behaviors (e.g. caching of food, discarding of food wastes in houses and midden deposits, and tool manufacturing) could have similar signatures because of a common source for the residues from animal products and food resources. This interpretation is supported by the high variation and overlap in elemental composition and concentration between the feature classes in the first and second principal component of my PCA analysis (Figure 4-4a). The elemental loadings of these principal components are interpreted as common indicators of cultural residues, including the presence of marine resources and the decomposition of waste materials such as bone and fish remains (Table 2-1). It is not entirely unexpected that a majority of the cultural features are enriched in these elements as the source of these 
elements are relatively common in Arctic archeological sites and are often present in most Arctic cultural features, including house, midden, and food storage features.

My PCA results indicate that while there is considerable overlap in the elemental concentrations, there are differences between the feature classes which support my alternative hypothesis. I interpret the separation of two food storage feature groups, and the lower concentrations in house features, by the first principal component to indicate distinctions between the two features based on contents or in-feature spatial patterning. Primarily, the food storage features with higher concentrations may represent features whose contents were not removed, or it is possible that the signatures of specific past behaviors tied to use of these features may be masked by other behaviors, such as cleaning events in house deposits. The third principal component, indicates more clear variation between cultural feature classes. In particular, PC-3 indicates that food storage features are uniquely defined by low variation in $\mathrm{K}, \mathrm{Mg}$ and $\mathrm{Fe}$, and offers a unique perspective for interpreting distinctions between them and House features. Biplots of the second and third components (Figure 4-5) show tight definitions of the food storage features and high variation in the house features, but there is still much overlap in their elemental concentrations, particularly in third principal component loading elements. Specifically, the lower Fe and $\mathrm{Mg}$ and higher $\mathrm{K}$ levels may be tied to a greater accumulation of organic matter in house features. These residues may be sourced from fur items (e.g. floor linings), general waste deposition on house floors, and/or sod roof collapse. The elevated level of K and lower $\mathrm{Mg}$ in house features is likely connected to the processing and cooking of food resources and the accumulation of food waste materials into floor midden deposits. These enrichment patterns would not necessarily occur as a result of simple storage feature 
construction and use. However, interpreting the nature of this spatial patterning is not directly possible without further work in these features.

My discriminant function analysis supports my alternative hypotheses that the house and food storage features are distinct. Only a few house $(n=1)$ and food storage feature $(n=2)$ samples are reclassified to other cultural feature classes, suggesting a good statistical definition of each feature class. Unfortunately, the four known food storage features do not correctly cross validate, but probability of group assignments is low for these reclassifications. The limited precision of the cross validation results and associated low prediction values are the result of the high variation in, and similarity between, elemental compositions in both feature classes. Two food storage features are reclassified as possible controls and the other two as house features. The two features reclassified as control features may be storage features that were emptied prior to abandonment, or storage of non-food related resources. Those reclassified as house features likely indicate storage features whose contents were not removed prior to abandonment or features that saw particularly intensive use. Additionally, it is possible that it may represent a storage feature associated with a house feature. Interestingly, one of the eight original house features were reclassified as a food storage feature; the sample may represent a spatial patterning within a distinct portion of a house structure such as an alcove or storage feature of a house. I interpret the observed low reclassification, and diffuse patterning seen in the canonical function plots, to be indicative of spatial patterning in the features and complexity in the use of space, with potential overlap in the sources of signatures from multiple types of cultural activities and features being represented. 
There were few statistically significant relationships (Table 4-2) and broad overlap in the loadings of my PCA. But, the concentrations of most analyte elements are distinct between house and food storage features. Specifically, food storage features having higher mean concentrations than houses in all elements but $\mathrm{Cu}, \mathrm{K}$, and $\mathrm{Pb}$. The chemical concentrations measured in these features probably overlap because of the complexity of cultural phenomena or behaviors, taking place as part of feature creation or use (e.g. spatial patterning of activities within a house). A diversity of activities could have involved similar organic by-products. Unfortunately, most Arctic archaeological materials are derived from common material resources, and I cannot fully attribute the geochemical signatures to any specific or unique behaviors associated with the respective features. As such I accept the alternative hypothesis $\left(\mathrm{H}-2_{1}\right)$ that distinctions between cultural feature classes exist, however, the nature of such patterning based on the original function and activities or behaviors that created them is not clear given the limited contextual information available and it is likely that many behaviors have similar geochemical expressions. Much more field and lab work would be needed to fully assess the specifics of these interpretations. I discuss identifying the indeterminates as house or food storage features in the following sections.

\section{Hypothesis 2a and 2b: The Indeterminate Features are Houses or Food Storage}

\section{Features}

As I ultimately accepted my alternative hypothesis $\left(\mathrm{H}-2_{0}\right)$, I next attempted to identify whether indeterminate features were house or food storage features. Under hypotheses $2 \mathrm{a}$ and $2 \mathrm{~b}$, if the indeterminates are house or food storage features I expected that they would have elemental compositions and concentrations at similar levels to the 
tested known house or food storage features, respectively. I interpreted the similarity of concentrations for all analyte elements (as indicated by a lack of statistically significant variation by ANOVA) between indeterminate features and house or food storage features independently to support my hypothesis, indicating different origins for the indeterminate features; specifically, here as house and or food storage features.

As discussed previously, I identified patterns in my PCA results that help to distinguish the indeterminates as house or food storage features. The variability of concentration in the first principal component loading elements, attributed to the likely overlap in the source of archaeological residues, makes interpretations between cultural features based on this component difficult. However, the biplot of the second component with the third component indicates that approximately 11 indeterminate features have similar compositions and concentrations to house features that are separated between two groups based on high (Group A) and low (Group B) values. I attribute the separation of two distinct house groups to spatial patterning in house features. The high elemental loading values in some houses may represent floor deposits and the low values in others may represent roof or infill/alcoves etc.

There is little variation in the food storage features based on the loading elements of the second and third components, and food storage features are clustered tightly in the biplot. Interestingly, no indeterminates are plotted directly adjacent to the food storage features, but two known house features plot near the food storage features. It is plausible that these features represent components of house features where caching of resources occurred. While no indeterminate features plot directly adjacent to food storage features, a distinct cluster of 10 indeterminate features (Group C) is observed with elevated PC-2 
elements. I believe these features likely represent a cluster of food storage features, as food storage features showed higher PC-2 factor scores than most houses. In particular, the Al, $\mathrm{Fe}$, and $\mathrm{K}$ may be tied to food processing and possibly the elevated Fe could be sourced from meat resources (Brunborg et al. 2006; Shahidi and Synowiecki 1993; Yamamotto 1987).

I used DFA to statistically identify the nature of indeterminate features as house or food storage features. I believe the reclassification of a few $(n=5)$ house and food storage features $(n=3)$ as indeterminate features in DFAa supports my hypothesis that the indeterminate features represent multiple types of cultural activities and features . Despite this, as many as 13 indeterminate feature samples are reclassified as houses and four as food storage features. I interpret the lack of tight clustering (variation of chemical enrichments) in indeterminates reclassified as house features (Figure 4-6) to most likely represent spatial patterning associated with activity areas around occupation sites and in house features. The lack of clustering in those reclassified as food storage features is likely tied to various use patterns and post depositional and/or taphonomic processes. Due to the likely overlap in anthropogenic sources for the geochemical residues, I suspect that only 10 represent house features (Figure 5-1; Group A), as three plotted close to an indeterminate feature reclassified as a food storage feature. However, it is also possible that these features may represent a distinct portion of a house structure, such as an alcove or storage feature of a house.

In addition to the four indeterminates reclassified as food storage features, eight indeterminate features reclassified as controls plotted more closely (and thus have similar elemental concentration patterning)to food storage features than house features (Figure 5- 
1 Group B). It is possible that these indeterminate features (particularly the outliers; Group $\mathrm{C}$ on Figure 5-1) represent caching of non-food resources or storage features in various states of abandonment which have been emptied prior to their disuse. Unfortunately, interpretation of specific indeterminate features as house or food storage features is complicated by many factors including poor to moderate cross validation. The factors that interfere with interpreting the DFA results are discussed in the 'confounding factors' section that follows the remainder of my hypothesis discussion.

The results of my analysis indicate that elemental compositions and concentrations of house features are distinct from the food storage feature class and that the indeterminates are cultural deposits. The clustering of as many as 13 indeterminates near house features in the PCA is supported in the DFA reclassification of the indeterminate feature samples. Hypothesis $2 \mathrm{a}(\mathrm{H}-2 \mathrm{a})$ is partially supported and as many as 13 indeterminate features may be houses. However, based on the dispersion observed in the PCA and DFA, paired with the nature of the three indeterminates that plot near food storage features, I suspect only 10 may represent houses or minimally intensive occupation surfaces. Hypothesis $2 b(\mathrm{H}-2 \mathrm{~b})$ is also shown to be partially true; at least four are likely food storage features, but as many as 15 may be some form of storage feature, including the eight indeterminates reclassified as control, as well as the three classified as houses that are similar in composition to food storage features. 


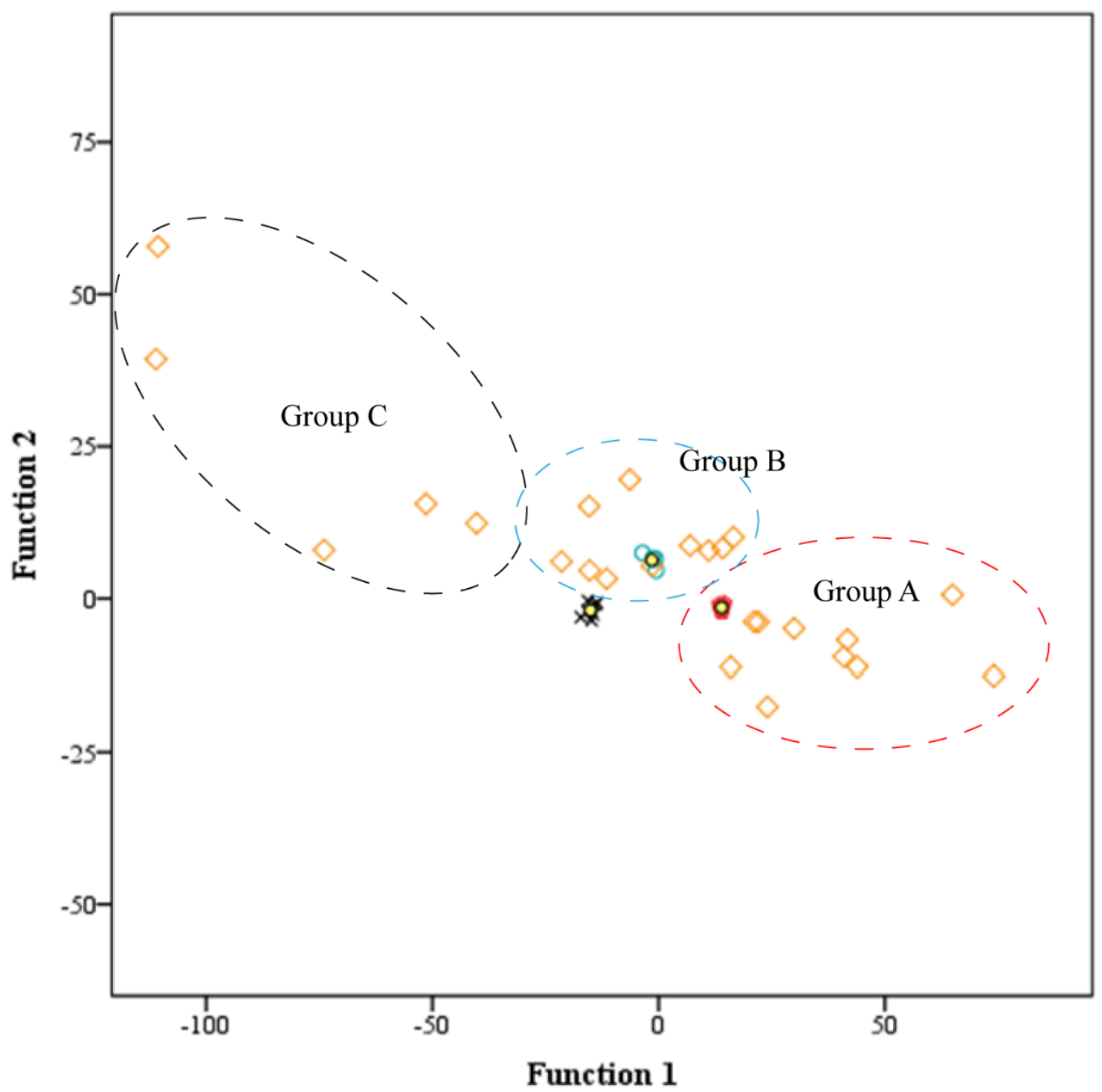

Feature Class
$\times$ Control
$\checkmark$ Houses
$\circ$ Food Storage Features $\diamond$ Indeterminates

Figure 5-1. Proposed groupings of cultural features from DFAc. 


\section{Hypothesis 3: Food Storage Features Represent Different Contents}

In Chapter 3 I hypothesized that multiple food storage feature types may exist at the Complex and that elemental composition of the bulk sediment samples may allow for the identification of the specific use of each food storage feature (Hypothesis 3; Table 53). Under Hypothesis 3, if the food storage features held similar contents, they will have similar elemental compositions $\left(\mathrm{H}-3_{0}\right)$. If different food storage contents are represented in the data set, then individual food storage features will have distinct elemental compositions $\left(H-3_{1}\right)$. The dispersion of samples seen in the PCA and DFA analyses suggest that some distinctions are present in the data set. The first principal component showed a distinct split in the food storage features based on high and low concentrations of elemental loadings tied primarily to anthropogenic residues associated with marine resources ( $\mathrm{Sr}, \mathrm{Ba}$, $\mathrm{Ca}, \mathrm{Zn}$, and P). It is possible that this distinction reflects the type of resource stored in a feature. To explore this, I looked at the potential of identifying the type of resources based on a trophic level distinction using $\mathrm{Sr} / \mathrm{Ca}$ and $\mathrm{Ba} / \mathrm{Ca}$ ratios (Burton and Price 1990, 1999; Knudson et al. 2004; Knudson and Frink 2010). As many of the indeterminate features could not clearly be reclassified as food storage features, I include all previously identified food storage features and all indeterminate features, including those grouped as controls or houses, to distinguish between the possible types of storage features present at the Complex. 
Table 5-3. Hypothesis 3 Results and Summary

Hypothesis

\begin{tabular}{|c|c|}
\hline H-3: & Food storage features are similar in geochemical composition \\
\hline & $\begin{array}{l}\text { Results Phase II: } \\
\text { - Distinct groups of } \mathrm{Ba} / \mathrm{Sr} \text { Ratios suggest distinct contents. } \\
\text { - But resource distinctions not clear. }\end{array}$ \\
\hline & Conclusion: not met \\
\hline H-31: & Food storage features have distinct geochemical compositions \\
\hline & $\begin{array}{l}\text { Results Phase II: } \\
\text { - } \quad \text { Multiple storage features likely represented. } \\
\text { - } \quad \text { Low Ba/Sr Ratios suggest in some features marine inputs. }\end{array}$ \\
\hline
\end{tabular}

The mean $\mathrm{Ba}$ and $\mathrm{Sr}$ concentrations, and mean $\mathrm{Ba} / \mathrm{Ca}$ and $\mathrm{Sr} / \mathrm{Ca}$ ratios, are both lower in food storage feature samples than the control samples as expected (Table 5-4). A biplot of $\mathrm{Ba} / \mathrm{Ca}$ and $\mathrm{Sr} / \mathrm{Ca}$ ratios suggest two possible groups. One group (A) contains higher values which are slightly lower than but similar to the control samples (Figure 5-1). A second group (B) is described by both lower $\mathrm{Sr}$ and $\mathrm{Ba}$ concentrations than $\mathrm{Ca}$. Both groups' ratios are in the range that Price and Middleton (1999) plotted as indicative of plant materials, however, the study used direct samples of plant and animal tissues, so the values are not directly comparable; presumably, those resulting from the decomposition in sediments would be lower. The mean $\mathrm{Ba} / \mathrm{Sr}$ ratios are also lower in food storage feature samples than the control samples at similar rates, but slightly lower than Knudson and Frink’s (2010) study of archaeological sediments from food processing features.

While the lower $\mathrm{Ba} / \mathrm{Sr}$ ratios may indicate the presence of marine resources, the elemental compositions of the Group B also indicate potential marine/anadromous fish and terrestrial inputs. The composition Group B features have the lowest $\mathrm{Ba} / \mathrm{Sr}$ levels and are also more elevated than the group describing fish $(\mathrm{Na}, \mathrm{Mg}, \mathrm{Mn}, \mathrm{P}$, and $\mathrm{K}$ ) and terrestrial 
resources such as plant or caribou processing areas $(\mathrm{K}, \mathrm{Mg}, \mathrm{Sr}, \mathrm{Cr}, \mathrm{Fe}, \mathrm{Ni}$, and $\mathrm{Pb})(\mathrm{Table}$ 5-4) (Butler et al. 2013; Knudson and Frink 2010). However, these elements are observed at similar concentrations in Group A features. Additionally, Group B have higher concentrations of $\mathrm{Fe}$ and $\mathrm{Zn}$ which may be indicative of marine mammal soft tissue and blood (Couture et al 2016; Brunborg et al. 2006; Yamamotto, 1987; Shahidi and Synowiecki 1993). Overall, I interpret this to indicate that different contents are represented in the food storage features. Group A likely represents storage features used primarily for terrestrial resources and Group B represents food storage features that stored marine resources.

Interestingly, Indeterminate 1188A (CAKR 15345), where a whale vertebra was recovered from the lower deposits, is reclassified as a house feature that plotted near the food storage features. The $\mathrm{Ba} / \mathrm{Sr} / \mathrm{Ca}$ ratios of this feature place it as a transitional feature between the two groups and supports the interpretation of marine inputs for Group B. It is possible that the observed differences do not explicitly reflect the specific use of a feature for distinct food resource type but rather, more generally, a pattern of caching. Particularly in Group A, this interpretation may be explained by the removal of food resources from storage features. Removal of contents from a food storage feature may not leave behind adequate archaeological/anthropogenic residues to identify the contents of a feature, However, repeated use of a storage feature as it remains in the systemic context (repetitive filling and removal of contents), or if the contents are left in place, entering the archaeological context, and thus allowed to decompose in situ it is likely that adequate residues will be present. 
While I accept the alternative hypothesis $\left(\mathrm{H}-3_{1}\right)$ that different contents of the food storage features are represented, my analysis also shows that interpretation of food storage features contents is more complicated than initially thought. My results suggest that the use of storage features is more nuanced, and perhaps the food storage features present at the Cape Krusentern site complex were, unsurprisingly, used to hold more than a single food resource type or perhaps both food and non-food resources all together. 
Table 5-4. $\mathrm{Ba} / \mathrm{Ca}$ and $\mathrm{Sr} / \mathrm{Ca}$ Ratios for Feature Classes

\begin{tabular}{|c|c|c|c|c|c|}
\hline Sample & Feature Class & $\mathrm{Ba} / \mathrm{Ca}$ & $\mathrm{Sr} / \mathrm{Ca}$ & $\begin{array}{l}\mathrm{Log} \\
\mathrm{Ba} / \mathrm{Ca} \\
\end{array}$ & $\begin{array}{l}\text { Log } \\
\text { SR/Ca }\end{array}$ \\
\hline CAKR 14015 & Control & 0.261 & 0.022 & -0.583 & -1.653 \\
\hline CAKR 14018 & Control & 0.307 & 0.016 & -0.514 & -1.795 \\
\hline BCS-02 & Control & 0.307 & 0.03 & -0.513 & -1.52 \\
\hline BCS-03 & Control & 0.337 & 0.032 & -0.473 & -1.497 \\
\hline BCS-04 & Control & 0.442 & 0.044 & -0.355 & -1.36 \\
\hline CAKR 14173 & Control/ Vegetation Anomaly & 0.367 & 0.026 & -0.436 & -1.59 \\
\hline \multirow[t]{2}{*}{ CAKR 14175} & Control/ Vegetation Anomaly & 0.291 & 0.015 & -0.536 & -1.822 \\
\hline & Mean control & 0.342 & 0.027 & -0.471 & -1.597 \\
\hline CAKR 14401 & Food Storage Feature & 0.229 & 0.021 & -0.64 & -1.67 \\
\hline CAKR 14410 & Food Storage Feature & 0.068 & 0.013 & -1.166 & -1.896 \\
\hline CAKR 14430 & Food Storage Feature & 0.3 & 0.025 & -0.523 & -1.598 \\
\hline \multirow[t]{2}{*}{ CAKR 15197} & Food Storage Feature & 0.22 & 0.012 & -0.658 & -1.912 \\
\hline & Mean Food Storage Features & 0.204 & 0.018 & -0.747 & -1.769 \\
\hline CAKR 13640 & Indeterminate & 0.148 & 0.021 & -0.83 & -1.683 \\
\hline CAKR 13968 & Indeterminate & 0.281 & 0.019 & -0.551 & -1.724 \\
\hline CAKR 14179 & Indeterminate & 0.265 & 0.017 & -0.577 & -1.772 \\
\hline CAKR 14359 & Indeterminate & 0.28 & 0.042 & -0.552 & -1.379 \\
\hline CAKR 14396 & Indeterminate & 0.093 & 0.014 & -1.033 & -1.851 \\
\hline CAKR 14531 & Indeterminate & 0.147 & 0.018 & -0.832 & -1.743 \\
\hline CAKR 14978 & Indeterminate & 0.15 & 0.027 & -0.825 & -1.567 \\
\hline CAKR 15036 & Indeterminate & 0.392 & 0.018 & -0.407 & -1.75 \\
\hline CAKR 15081 & Indeterminate & 0.275 & 0.021 & -0.561 & -1.686 \\
\hline CAKR 15085 & Indeterminate & 0.243 & 0.019 & -0.615 & -1.713 \\
\hline CAKR 15159 & Indeterminate & 0.094 & 0.006 & -1.025 & -2.229 \\
\hline CAKR 15341 & Indeterminate & 0.05 & 0.004 & -1.303 & -2.389 \\
\hline CAKR 15345 & Indeterminate & 0.195 & 0.019 & -0.711 & -1.719 \\
\hline CAKR 15348 & Indeterminate & 0.351 & 0.03 & -0.455 & -1.529 \\
\hline CAKR 15003 & Indeterminate & 0.041 & 0.009 & -1.383 & -2.042 \\
\hline \multirow[t]{2}{*}{ CAKR 15350} & Indeterminate & 0.088 & 0.013 & -1.054 & -1.878 \\
\hline & Mean Indeterminate & 0.193 & 0.019 & -0.795 & -1.791 \\
\hline
\end{tabular}




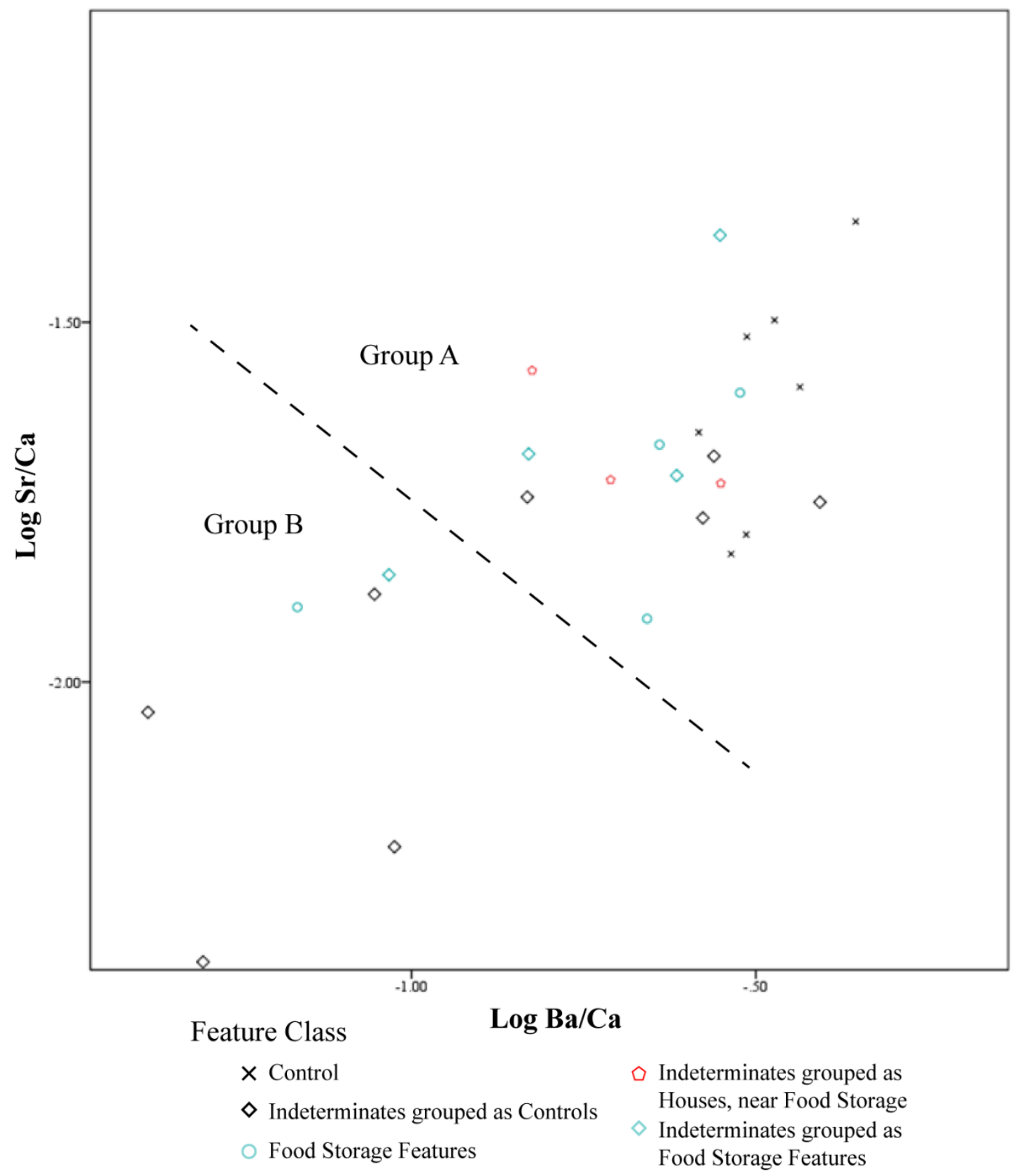

Figure 5-2. Biplot of $\mathrm{Ba} / \mathrm{Sr}$ and $\mathrm{Ba} / \mathrm{Ca}$ Ratios. 


\section{Confounding Factors}

Several confounding factors exist that complicate my data analysis. First, sampling bias represents perhaps the greatest potential in confounding the results of Phase I, as well as challenges in post-hoc geochemical analyses. Though some patterning by sample depths is apparent in the data (Figure 4-2), not all features were sampled at the same regular intervals or to the same depth (Table B-1). Bulk sediment sampling only from cultural deposits is not out of the norm for archaeological studies, but this is problematic as it does not create a complete or even picture of the archaeological features, and skews data toward positive cultural results. Sampling bias does exist in the bulk sample collection from the Complex. Not all features are represented by a complete vertical column of bulk sediment samples, and this sampling bias may account for the lack of moderate range of phosphate reactions in house feature samples, as well as the complete lack of reactions in the two house and indeterminate features (House 1180A-CAKR 15034); House 5664B-CAKR 14979; Indeterminate 1185A-CAKR 15081; Indeterminate 1190A-CAKR 15348). All available samples from these features are from the upper $30 \mathrm{cmbd}$, and examination of the test unit profiles indicates that they are from just above the primary cultural deposits (Profile drawings are provided in appendix C; profile drawings of all features are included in Freeburg and Anderson 2012: 192, 197, 222). While it is possible that leaching and other processes such as permafrost have acted on the sediments in these features, I do not believe that leaching is a major contributing factor to the observed differences in elemental composition or phosphate reactions in these or the other features at the complex. As shown in Figure 4-2 phosphate reaction intensity vary across the range of sample depths. Additionally, permafrost is not interpreted as a confounding factor for interpreting the 
results as while it was encountered during the shovel testing survey, it was primarily limited to the older ridges, and explicitly was not encountered in the exaction units of features used in my analysis.

The lack of reactions in Vegetation Anomaly 3624B and select known cultural deposits is interesting but not entirely unexpected given the multitude of possibilities that may affect where archaeological residues may be present. Such factors as archaeological context (roof sods, posit abandonment infill, etc.) or post-depositional processes may affect the expression or preservation of archaeological residues. However, given that the house and indeterminate features with only negative results are sampled from relatively close to the surface, this cannot be confirmed, and sampling bias is likely a contributing factor for these specific features. As the sample depths are within the depth range of a majority of the positive phosphate reactions (Figure 4-2), it is also possible that they may represent cultural phenomena. Specifically, if the indeterminates represent storage features that had been emptied prior to abandonment or only saw short term use, their geochemical expression may be limited. Therefore, I recognize that the lack of deeper deposits in the two house features are likely resultant from sampling bias. However, I do not fully attribute the negative reactions in the indeterminate features to sampling bias. Additionally, I do not attribute sampling bias as a contributing factor in the vegetation anomaly samples as it is vertically well represented. In the vegetation anomaly, five samples cover a depth range of $50 \mathrm{~cm}$, common depths for positive phosphate reactions.

In Phase II three main confounding factors are at play regarding interpreting geochemical analysis data. The first of these factors is founded in my hypothesized geochemical expression of house versus food storage features. In Chapter 3 I postulated 
that house deposits would have a broader range of elevated or depleted elements within the soils, and that these elements would be found at higher concentrations in comparison to food storage features. The wider composition and higher concentrations are thought to reflect the wider range of daily activities that took place within house structures in comparison to the relatively limited types of past activities that are associated with caching of food resources. That is, I expected food storage features to have contained a limited range of items that would have a more simplistic geochemical signature, and be relatively "clean" of waste sediments, such as midden deposits that would be more likely found in house features or other areas. Contrary to this, in my analysis, food storage features showed a broader suite of elemental enrichments at higher elevations than house features. The overall high values observed in the house features, although lower than food storage features, likely indicate that the activities and sources of elemental loadings are being observed as hypothesized but are not interpretable to unique behaviors. In addition to the previously discussed overlap in residue sources, interpreting the results is confounded by the possible masking of enrichment levels from cleaning events, taphonomic processes, or post-depositional processes.

The lower concentrations observed in house deposits may reflect a taphonomic process or an explicit past human activity. It is probable and expected that not all sediments in house deposits would show the same intensities of element enrichments. Deposits found in house features are typically from three contexts: 1) roof, 2) infill, and 3) occupation layers (e.g. living surfaces, floors, subfloors). Sod roof deposits are expected to have some anthropogenic enrichments (likely similar to external midden deposits and general waste decomposition) but are not likely to be as elevated as floor or other occupational cultural 
deposits. Infill usually comes from collapse of roof structures, local sediments, or completely natural sediment influx such as beach overwash from intensive storm activities. Infill deposits representing post-depositional (i.e. abandonment) processes sourced from cultural deposits should still show enrichment levels, but potentially at lower concentrations than living surfaces. This enrichment level however would still likely be dependent on the specific context of the source material; as food, hides and furs as well as other materials that may leave geochemical traces, could have been stored in rafter type storage.

Secondly, the broad composition and lower concentrations in houses may represent well-documented past human activities. Cleaning events, such as regular sweeping and maintenance of house floor deposits, is well known from Arctic research (Couture et al. 2016, 2017; Norman et al. 2017). Additionally, structural elements such as wood from floors and walls were often harvested post-abandonment for use in new structures (Alix 2005, 2016; Larsen and Rainey 1948; Norman et al. 2017). It is expected that as a result of these activities, much of the sediments containing archaeological residues would be masked, removed, or disturbed as it moves from its primary context (systemic context) into secondary refuse deposit as it may be found in the archaeological context (Schiffer 1972, 1987). Cleaning events, if not fully erasing, are likely to muddle and dilute specific anthropogenic signatures from floors or in tunnel deposits in house features. Removal of floorboards and disturbance of sediments would also increase the susceptibility of these deposits to post-depositional processes that may affect the expression of the anthropogenic residues. 
Thirdly, it is possible that the location, construction, and structure of the food storage features are determining factors for their broader and higher geochemical expression in comparison to houses. Specifically, food storage features are often associated with habitation sites, and may be connected internally to, or located externally near, houses. It is also possible that their construction represents simpler structures than expected. Many of the food storage features are likely simple pits with little or no structural elements, or, as discussed above, had their structural elements removed. This would allow for postabandonment infill of these features from sediments, such as external midden, that are heavily influenced by many anthropogenic activities and would likely have geochemical signatures similar to house deposits or at higher enrichments.

Similarly, complexity in human use of space represented by the likely performance of multiple activities at a single location and overlap in the elemental signature sources in house features and occupation sites, confounds the interpretation of the indeterminate features. Specifically, in houses, side rooms and alcoves where storage of materials occurred would likely have similar signatures. This potential is highlighted by the broad overlap in geochemical signatures and limited cross validation in the DFA results. In particular this can be seen in the three indeterminate features reclassified as houses. At Indeterminate 1178A (CAKR 14978) the excavation profiles suggest a small pit feature (Freeburg and Anderson 2012, 187). This feature is adjacent to Indeterminate 1195A which was reclassified as a house and indicates a burn or cooking deposit in the profile (Freeburg and Anderson 2012, 200). At Indeterminate 1188A (CAKR 15345) a whale vertebra was recovered from the lower deposits, but no specific structural components were noted in the profile (Freeburg and Anderson 2012, 195). This feature is associated with a cluster of 
indeterminate features, including Indeterminate 1190A (15348), which was also reclassified as a house feature by my analysis (Freeburg and Anderson 2012, 198). At Indeterminate 2603B (CAKR 13968), the excavation profiles suggest a small pit feature (Freeburg and Anderson 2012, 213) located near Indeterminate 2604B (CAKR 13989), which was reclassified as a house feature in my analysis. It is plausible that some of the indeterminates identified as house or food storage features, and samples from house or food storage features represent components of house features, where caching of resources occurred, or cultural deposits from occupation surfaces.

It is also possible that other types of feature classes (e.g. community structures, processing areas for specific food (i.e. fish) or non-food materials, kitchen alcoves, or open air activity areas), not included in my analysis, are represented in the indeterminate feature class. The dispersion of indeterminate features in the PCA and DFA suggests that the relationship between feature categories, while distinct, is more nuanced than the few specific groups used in my analysis. The dispersion may suggest multiple feature categories not identified by the typical archaeological survey feature classes. In my PCA, four cultural feature samples group close to the control and vegetation anomaly samples. These features include a single house feature sample and three indeterminate samples. The inclusion of indeterminate feature samples in DFAc as controls may represent archaeological activities with limited geochemical expression in sediment residues, such as caching of non-food resources, expedient lithic tool production, or casual discard. 


\section{Discussion Summary}

My analysis indicates that Vegetation Anomaly 3624B (CAKR 14173 and CAKR 14175) lacked consistent cultural indicators and I cannot reject the null Hypothesis 1. I conclude that it is a natural feature and that similar features at the site complex are likely natural features as well. As postulated in Hypothesis 2, both house and food storage features are represented in the indeterminate feature class. From the results of my analysis I conclude both Hypothesis $2 \mathrm{a}$ and $2 \mathrm{~b}$ are supported, though the signatures that define the feature classes are more complex and nuanced than I expected at the outset of this project. Many confounding factors limit the ability to directly estimate the number of house or food storage features represented by the indeterminate features. My analysis indicates that 10 indeterminate features are possibly house features or closely associated with house features, though as many as 13 may represent significant cultural deposits. Minimally four indeterminate features are likely food storage features. The dispersion and classification throughout the PCA and DFA indicate as many as 15 may be some form of storage feature. It is also possible that many of these indeterminate features represent other archaeological activities not clearly defined by the archaeological constituents. 


\section{Chapter 6 - Conclusions}

The goal of this thesis was to identify anthropogenic features and the original human behaviors that contributed to feature formation at Cape Krusenstern through soil geochemical analysis. In Phase I of my analysis, I performed photometric soil phosphates spot tests on bulk soil samples recovered from the Cape Krusenstern National Monument. The purpose of this Phase was twofold; (1) Attempt to reclassify an archaeologically ambiguous vegetation anomaly as an anthropogenic archaeological feature, and (2) identify soil samples with the greatest potential to contain archaeological signatures for elemental composition analysis by ICP-MS in Phase II. In Phase II of my analysis I performed an ICP-MS analysis to characterize the bulk samples and carried out subsequent statistical analysis on the elemental concentration data set. The purpose of the second Phase was threefold: (1) Collect and identify elemental concentrations and significant patterning present in the Cape Krusenstern samples, (2) establish distinctions between cultural feature classes, and (3) identify the range of human activities that created the indeterminate features by reclassifying them as house or food storage features.

The results of the soil phosphates photometric test I performed in Phase I identified the samples with the greatest potential from each feature to contain archaeological residues or signatures, reducing the number of archaeological samples included in Phase II from 150 to 39 samples. Additionally, the analysis did not indicate that Vegetation Anomaly 3624B (CAKR 14173 and CAKR 14175) contained soil phosphates (an indicator of past human presence). Under the criteria of hypothesis 1, Vegetation Anomaly 3624B (CAKR 14173 and CAKR 14175) was not reclassified as an indeterminate feature but was included in Phase II of the analysis to further investigate its origin. The results of Phase II supported 
the interpretation of Vegetation Anomaly 3624B (CAKR 14173 and CAKR 14175) as a natural feature and ultimately PCA and DFA led to the rejection the alternative hypothesis $\left(\mathrm{H}-1_{1}\right)$ and the acceptance of the null hypothesis $\left(\mathrm{H}-1_{0}\right)$ (Table $\left.5-1\right)$.

Many such vegetation anomaly features exist at the Cape Krusenstern National Monument, and identifying their nature is worth pursuing. Although this single feature is not identified as an anthropogenic feature, the other vegetation anomalies may be anthropogenic. This analysis does, however, suggest that limited testing in these features provides adequate information to assess the features' likely origin, and that in-field observations are reliable. ICP-MS represents a valid and low impact method to identify the nature of these features. As a natural feature, the vegetation anomaly may have formed from a multitude of geomorphological processes or natural phenomena such as ice pushups, freeze-thaw, and animal denning. Further research into the nature of these features will help to reconstruct the human occupation history of the Beach Ridge Complex. Further research may identify these processes and explain why archaeological features are not present at certain locations on the beach ridges.

Phase II of my analysis included the elemental characterization of the archaeological samples and offsite control samples using ICP-MS. The results of my geochemical and statistical analysis supported my second hypothesis; ANOVA, PCA, and DFA showed that the distinctions are traceable to distinct feature categories, indicating that the cultural features differed from non-cultural samples, and that archaeological feature classes can be statistically characterized by a suite of elemental concentrations. Using these distinctions, PCA corroborated other geochemical studies and identified element groups that distinguished between control or natural features and cultural features. Secondly, it 92 
indicated that distinguishing between cultural feature classes is possible, substantiating Hypothesis 2. Specifically, it shows that the indeterminate features could be reclassified based on their element concentrations, though interpretation is confounded by many factors including overlap in the source of archaeological residues. There is also the possibility that multiple feature classes not specifically identified by my analysis are represented by the indeterminate samples. My analysis of food storage features did not specifically indicate the anthropogenic source of differences in use, however, a potential distinction based on marine soil inputs is present. A marine resource food storage feature group is described by relative enrichments of $\mathrm{Sr}$ and depletions of $\mathrm{Ba} / \mathrm{Sr}$ and $\mathrm{Ba} / \mathrm{Ca}$, and a second storage feature type may be indicative of another resource type represented by overall higher $\mathrm{Ba} / \mathrm{Sr}$ and $\mathrm{Ba} / \mathrm{Ca}$ ratios. Thus, while I interpret that multiple storage features are represented, their nature as specific food storage feature categories is not explicitly clear. Instead, a more general pattern of caching is expressed in the archaeological record. Hypothesis $2 \mathrm{c}$ is likely but I am not able to explicitly confirm it.

\section{Implications for Regional Research and Study of Thule Subsistence Practices}

Further classifying the indeterminate features has implications for interpretations of the local and regional occupational history of the last 2500 years. Clarifying the archaeological nature of these features advances our understanding of the occupation intensity at the site complex as it relates to the increases in sedentism, population growth, and resource competition that may have led to inland migrations of peoples during the Thule period. At the Cape Krusenstern beach ridge complex, 60\% of features (971 of 1617) are indeterminate features, which hinders our ability to reconstruct past life ways and 
population levels at the site complex. Accurate interpretation of the Complex's occupation history requires accurate identification of archaeological features, their original function, and accurate interpretation of the original behaviors that created them. My analysis shows that 10 to 13 indeterminate features may potentially be house features, and four to 15 features may represent food storage features. Additionally, eight indeterminate features suggest that an additional feature class may be represented in the data set.

In Northwest Alaska and elsewhere, the presence and quantities of semisubterranean houses and food storage features are used as indicators of increased sedentism and intensification of resource use (Ames 1994; Anderson and Freeburg 2014; Dumond 1975; Giddings and Anderson 1986; Mason 1998). Estimates of population derived from the number of house features may be affected dramatically as an increase of 10 to 13 house features at the site complex is a 7.9 to $10.2 \%$ increase, respectively, and an increase of four to 15 food storage features is a 1.5 to $5.2 \%$ increase, respectively. These increases, though small, may help elucidate the nature of decreases in settlement sizes and occupation intensity by providing more known features on which to base our interpretations. Indicating that more houses and food storage features are present at the site complex may help answer questions about increasing population pressures and resource competition that led to the dispersion of Thule people around the coast and migrations into the interior (Gerlach and Mason 1992; Mason 1998; Mason and Barber 2003).

My research accompanies a growing body of work that increases the regional importance of the Cape Krusenstern occupations for interpreting cultural transitions and social interactions in the Arctic (Anderson and Freeburg 2014; Anderson et al. 2018; Freeburg and Anderson 2012). While the total number of features I analyzed is relatively 
small in comparison to the number of features present at the complex, the elucidation of the archaeological nature of these features advances our understanding of the occupation intensity at the site complex as it relates to the increases in sedentism, population growth, and resource competition that may have led to inland migrations of peoples during the Thule period. The increase of possible house features as indicated by my analysis suggests that the population at Cape Krusenstern during the Thule period may be greater than previously thought. Additionally, my results have potential in studying past food processing and storage behavior during the Thule Period.

\section{Implications for Method Application}

The application of multi-elemental geochemical analysis is seeing increasing but still limited application in coastal Arctic settings and represents an opportunity to explore and assess this method for feature identification and interpretation of past human behavior in the Arctic. My research shows that ICP-MS is a useful method in Arctic research. Again, though the number of features I analyze in this study represents only a small portion of the total number of indeterminate features and vegetation anomalies, the results of my project indicate the potential of geochemical analysis for other features from the site complex and can be used to guide further archaeological investigations. Although the results of these tests are highly specific to the locality of the samples, general trends in elemental concentrations associated with known archaeological features are important for testing and corroborating interpretations of elemental signatures as archaeological activities. These results contribute more generally to the understanding of site formation processes and identification of archaeological features. My results align with the growing body of 
geochemical research in Arctic archaeological settings, and I identified a similar suite of elements $(\mathrm{Sr}, \mathrm{Ca}, \mathrm{Cu}, \mathrm{Ba}, \mathrm{Na}, \mathrm{P}$, and $\mathrm{Zn}$ ) that define cultural versus natural deposits. Additionally, I am contributing to the geochemical literature by identifying elemental signatures that possibly show distinctions between cultural feature types, specifically house and resource storage features.

More broadly, my analysis represented an opportunity at exploring and assessing geochemical analysis for feature identification. Traditionally, archaeological geochemical analyses have focused on individual features or sites to guide archaeological excavations or identify aspects of spatial variation within a feature or connect elemental signatures to explicit past behaviors (see Couture et al. 2016 and Knudsen et al. 2010 respectively). In contrast, the analysis I performed uses geochemical signatures to asses archaeological feature identification at the landscape scale, while providing greater details about the archaeological record. My analysis shows that while there is still more work to be done in using geochemical analysis at this scale, there is great potential with these types of analysis.

The results of my project also show the value of analyzing previously obtained collections and bulk samples that have already been removed from the field. I use this conservative ethic to provoke worthwhile research without further destruction to archaeological sites from new excavation. Bulk sediment samples are routinely collected during field projects but are all too often under-investigated or completely ignored after initial collection and curation. And though this process is destructive, it is considered minimally so, requiring that only a few grams of fine sediment be destroyed, and can be conducted using minimally invasive sampling techniques. My research suggests that sediments removed from the field offer a viable route of inquiry to explore and collect 
detailed archaeological data that may not be readily observable through other traditional means. Additional experimental geochemical studies specifically targeted at connecting and identifying past household activities associated with occupation and food storage features may provide greater insight into interpreting the geochemical signatures, and account for the observed variations identified in my analysis. There is great potential for soil geochemical studies to provide the data to illuminate subsistence and settlement patterns, as well as social and population dynamics, and to identify past human behaviors. 


\section{References Cited}

Ahrens, Louis, H.

1965 Distribution of the Elements in Our Planet. McGraw-Hill Paperbacks, New York, New York.

Alix, Claire

2005 Deciphering the Impact of Change on the Driftwood Cycle: Contribution to the Study of Human Use of Wood in the Arctic. Global and Planetary Change 47 (2-4): 83-98

2016 A Critical Resource: Wood Use and Technology in the North American Arctic. In The Oxford Handbook of the Prehistoric Arctic. Ed. Max Friesen and Owen Mason. Oxford University Press, New York, New York.

Ames, Kenneth M.

1994 The Northwest Coast: Complex Hunter-gatherers, Ecology, and Social Evolution. Annual Review of Anthropology, Vol. 23: 209- 229.

Anderson, Douglas D

1984 Prehistory of North Alaska. In Handbook of North American Indians, Arctic 5:pp. 80-93. Smithsonian Institution Press, Wahington D.C.

Anderson, Shelby L., and Adam K. Freeburg

2013 A High Resolution Chronology for the Cape Krusenstern Site Complex, Northwest Alaska. Arctic Anthropology, Vol. 50:49-71

2014 High Latitude Coastal Settlement Patterns: Cape Krusenstern, Alaska. The Journal of Island and Coastal Archaeology 9(3): 295-318

Anderson Shelby.L., Thomas Brown, Justin Junge, Jonathon Duelks

2019 Demographic Fluctuations and the Emergence of Arctic Maritime Adaptations. Journal of Anthropological Archaeology, Vol. 56.

Anderson, S.L., James Jordan, and Adam Freeburg

2018 Human Settlement and Mid-Late Holocene Coastal Environmental Change at Cape Krusenstern, Northwest Alaska. Quaternary International.

Arrhenius, O.

1929 Die Phosphoatfräge. Zeitschrift für Pflanzenenernährung 10: 185-194.

1962 Investigation of Soil from Old Indian Sites. Ethnos 2-4: 122-136. 
Barba, Luis A.

2007 Chemical Residues in Lime-Plastered Archaeological Floors. Geoarchaeology 22(4): 439-452.

Barba, Luis, Roberto Rodríguez, and José Córdoba

1991 Manual de Tecnicas Microquimicas de Campo Para Arqueologia. Ed. Maia F. Miret. Universidad Nacional Autonoma de Mexico Instituto de Investigaciones Antropologicas, Mexico.

Baxter, M.J. and M.P. Heyworth

1989 Principal Components Analysis of Compositional Data in Archaeology, in: Rahtz, S. (ed.), Computer Applications and Quantitative Methods in Archaeology CAA89 (BAR International Series 548). B.A.R., Oxford, pp. 226-240

Braymer-Hayes, K.E.

2018 A Spatial Analysis of Ceramics in Northwestern Alaska: Studying PreContact Gendered Use of Space. Masters Thesis. Portland State University, Anthropology Department.

Brown, J. D.

2009 Choosing the Right Type of Rotation in PCA and EFA. JALT Testing \& Evaluation SIG Newsletter. 13 (3): 20-25.

Brunborg, Linn A., Nortvedt, Ragnar, Julshamn, Kaare, and Froyland, Livar

2006 Nutritional Composition of Blubber and Meat of Hooded Seal (Cystophora cristata) and Harp Seal (Pagophilus groenlandicus) from Greenland. Food Chemistry 96(4): 524-53.

Buonasera, Tammy Y., Andrew H. Tremayne, Christyann M. Darwent, Jelmer W. Eerkens, and Owen K. Mason

2015 Lipid Biomarkers and Compound Specific $813 \mathrm{C}$ Analysis Indicate Early Development of a Dual-economic System for the Arctic Small Tool Tradition in Northern Alaska. Journal of Archaeological Science 61: 129-138.

Burch, Ernest S

1984 Kotzebue Sound Eskimo. In Handbook of North American Indians. Vol. 5. Arctic. D. Damas, ed. Washington, DC: Smithsonian Institution. Pp. 303-319.

1998 The Iñupiaq Eskimo Nations of Northwest Alaska. University of Alaska Press, Fairbanks,Alaska. 
Burton, J.H., and T.D. Price

1990 The Ratio of Barium to Strontium as a Paleodietary Indicator of Consumption of Marine Resources. J. Archaeological Science 17: 547-557.

Butler, Don H.

2008 Geochemical Exploration of Inuit Soilscapes in Northern Labrador. Memorial University of Newfoundland.

Carlson, David L.

2017 Principal Components Analysis. Chapter. In Quantitative Methods in Archaeology Using R Pp. 265-278. Cambridge Manuals in Archaeology. Cambridge: Cambridge University Press.

Chamberlain, Andrew T.

2006 Demography in Archaeology. Cambridge Manuals in Archaeology. Cambridge University Press, New York, New York.

Couture, Andréanne, Najat Bhiry, Yves Monette, and James Woollett

2016 A Geochemical Analysis of 18th-century Inuit Communal House Floors in Northern Labrador. Journal of Archaeological Science: Reports 6: 71-81.

Croll, D. A. , Maron, J. L., Estes J. A., Danner, E.M., Byrd ,G.V.

2005 Introduced Predators Transform Subarctic Islands from Grassland to Tundra. Science Vol. 307(5717): 1959-1961.

Davis, J.C.

2002 Statistics and Data Analysis in Geology (3rd ed.) John Wiley \& Sons, New York.

Derry, Allison, Kevan, Peter G. And Rowley, Susan D.M.

1999 Soil Nutrients and Vegetation Characteristics of a Dorset/Thule Site in the Canadian Arctic. Arctic 52(2): 204-213.

Drennan, Robert D.

1996 Statistics for Archaeologists: a Commonsense Approach. Springer Science and buisness Media, New York, New York.

Dumond, Don E.

1975 Coastal Adaptation and Cultural Change in Alaskan Eskimo Prehistory. In Prehistoric Maritime Adaptations of the Circumpolar Zone, edited by W. W. Fitzhugh, pp. Pp. 167-180. The Hague, Mouton. 
Dussault, Frederik

2014 Early Thule Winter Houses: An Archaeoentomological Analysis. Arctic Anthropology 51(1):101-117

Eidt, R.C.

1977 Detection and Examination of Anthrosols by Phosphate Analysis. Science 1977: $1327-1333$.

Entwistle, J.A.

2007 A Comparison of XRF and Nitric-Extraction/ICP-AES for Differentiating Perthshire, and Interpreting Soils from an Abandoned Rural Township in Scotland. Society of Archaeological Science Bulletin 30: 10-12.

Entwistle, Jane A., Peter W. Abrahams, and Robert A. Dodgshon

1998 Multi-Element Analysis of Soils from Scottish Historical Sites. Interpreting Land-Use History Through the Physical and Geochemical Analysis of Soil. Journal of Archaeological Science 25(1): 53-68.

2000 The Geoarchaeological Significance and Spatial Variability of a Range of Physical and Chemical Soil Properties from a Former Habitation Site, Isle of Skye. Journal of Archaeological Science 27(4): 287-303.

Freeburg, Adam K., and Anderson, Shelby L.

2012 Human-Envirionmental Dynamics at Cape Krusenstern 200 Generations On the Beach of Their Time. Ancorage, AK.

Friesen, Max, \& Mason, Owen (Eds.)

2016 The Oxford Handbook of the Prehistoric Arctic. Oxford University Press, New York, New York.

Gerlach, Craig, and Mason, Owen K.

1992 Calibrated Radiocarbon Dates and Cultural Interaction in the Western Arctic. Arctic Anthropology 29(1): 54-81.

Gharajehdaghipour, Tazarve, Roth, James D., Fafard, Paul M., and Markham, John H.

2016 Arctic Foxes as Ecosystem Engineers: Increased Soil Nutrients Lead to Increased Plant Productivity on Fox Dens. Scientific Reports, 6(1).

Giddings, J. Loius, and Douglas D. Anderson

1986 Beach Ridge Archaeology of Cape Krusenstern: Eskimo and Pre-Eskimo Settlements Around Kotzebue Sound, Alaska. Publications in Archaeology. Vol. 20. National Park service, Washington, D.C. 
Glascock, Michael D.

1992 Characterization of Archaeological Ceramics at Murr by Neutron Activation Analysis and Multivariate Statistics, in Neff 1992, 11-26. In Chemical Characterization of Ceramic Pastes in Archaeology, edited by H. Neff, pp. 11-26. vol. Monographs in New World Archaeology 7. Prehistory Press, Madison.

Goffer, Zvi

2007 Archaeological Chemistry. 2nd ed. John Wiley \&; Sons Inc., Hoboken, New Jersey.

Hall, Edwin S. and Lynne Fullerton (Editors)

1990 The Utqiagvik Excavations. Vol. I: The 1981 Excavations at The Utqiagvik Archaeological Site, Barrow, Alaska. Edited by Edwin S. Hall and Lynne Fullerton. The North Slope Borough Commission on Inupiat History, Language and culture, Barrow, Alaska:

Harrit, Roger K.

2004 Eskimo Prehistory on the Seward Peninsula. U.S. Dept. of the Interior, National Park Service, Alaska Regional Office Alaska. Ancorage, AK.

Hassan, Fekri, A.

1978 Demographic Archaeology. In Schiffer, M. B. (ed.) Advances in Archaeological Method and Theory Vol. I. New York: Academic, pp. 49-103.

Heizer, R. F., \& Cook, S. F.

1965 Studies on the Chemical Analysis of Archaeological Sites. University of California Press, Berkeley, California.

Hoffman, Brian W.

2002 The Organization Of Complexity: A Study of Late Prehistoric Village Organization In The Eastern Aleutian Region. University of wisconsion- madison.

Holliday, Vance T., and William G. Gartner

2007 Methods of soil P Analysis in Archaeology. Journal of Archaeological Science 34(2): 301-333.

Hopkins, J.B.

1977 Coastal Processes and Coastal Erosin Hazards to the Cape Krusenstern Archaeological Site. Open File Report 77-32. Prepared for United States Department of the Interior Geological Survey. Menlo Park Claifornia. 
Junge, J.A.

2017 GIS Spatial Analysis of Arctic Settlement Patterns: a Case Study in Northwest Alaska. Masters thesis Portland State University, Anthropology Department.

Kuhnlein, H.V., Chan, H.M., Leggee, D., and Barthet, V.

2002 Macronutrient, Mineral and Fatty Acid Composition of Canadian Arctic Traditional Food. Journal of Food Composition and Analysis 15, 545-566

Knudson, Kelly J., and Liam Frink

2010 Ethnoarchaeological Analysis of Arctic Fish Processing: Chemical Characterization of Soils on Nelson Island, Alaska. Journal of Archaeological Science 37(4): 769-783.

Knudson, Kelly J., Lisa Frink, Brian W. Hoffman, and T. Douglas Price

2004 Chemical Characterization of Arctic soils: Activity Area Analysis in Contemporary Yup'ik Fish Camps Using ICP-AES. Journal of Archaeological Science 31(4): 443-456.

Lorch, W.

1939 "Neue Methoden Der Siedlungsgeschichte." Geographische Zeitschrift 45(8): 294-305.

Lutz, H.J.

1951 The Concentration of Certain Chemical Elements in the Soils of Alaskan Archaeological Sites. American Journal of Science 249:925-928.

Maron, J.L., Estes, J.A., Croll, D.A., Danner, E.M., Elmendorf, S.C., Buckelew, S.L.,

2006 An Introduced Predator Alters Aleutian Island Plant Communities by

Thwarting Nutrient Subsidies. Ecological Monographs. 76, 3-24.

Maschner, Herbert, Buck Benson, Knudson Garrett, and Nicole Misarti

2010 The Archaeology of the Spsuk River, Alaska. Ocassional Papers in Alaskan Archaeology 3: 71-77.

Mason, Owen, and Valerie Barber

2003 A Paleo-Geographic Preface to the Origins Of Whaling: Cold is Better. In Indigenous Ways to the Present: Native Whaling in the Western Arctic, edited by A.P. McCartney, pp. 69-108. Canadian Circumpolar Institute (CCI) Press and the University of Utah Press, Edmonton and Salt Lake City. 
Mason, Owen K.

1998 The Contest Between the Ipiutak, Old Bering Sea, and Birnirk Polities and the Origin of Whaling during the First Millennium A.D. along Bering Strait. Journal of Anthropological Archaeology 17(3): 240-325.

2012 Memories of Warfare: Archaeology and Oral History in Assessing the Conflict and Alliance model of Ernest S. Burch. Arctic Anthropology 49(2): 7293.

McGhee, Robbert

1984 Thule Prehistory of Canada. In Handbook of North American Indians. Vol. 5. Arctic. D. Damas, ed. Washington, DC: Smithsonian Institution. Pp. 269-376

Middleton, William D., and Douglas T. Price

1996 Identification of Activity Areas by Multi-element Characterization of Sediments from Modern and Archaeological House Floors Using Inductively Coupled Plasma-atomic Emission Spectroscopy. Journal of Archaeological Science 23(5): 673-687.

Misarti, Nicole

2007 Six Thousand Years Of Change In the Northeast Pacific: An Interdiscipilary View of Maritime Ecosystems. PhD Thesis, Institute of Marine Science, University of Alaska Fairbanks, Fairbanks, Alaska.

Misarti, Nicole, Bruce P. Finney, and Herbert Maschner

2011 Reconstructing Site Organization in the Eastern Aleutian Islands, Alaska Using Multi-Element Chemical Analysis of Soils. Journal of Archaeological Science 38(7): 1441-1455.

Nakano, Kazumi

2018 Ultra-Low Level Determination Of Phosphorus, Sulfur, Silicon and Chlorine Using the Agilent 8900 ICP-QQQ. Application Notes. Agilent Technologies. Publicaton 5991-6852EN.

Norman, Lauran E. Y

2018 Ethnohistoric Documents as Analogical Tools: A Case Study from Northwest Alaska. Journal of Anthropological Archaeology 51: 1-15.

Norman, Lauren E. Y, T. Max Friesen, Claire Alix, Michael J. E. O’Rourke, and Owen K. Mason

2017 An Early Inupiaq Occupation: Observations on a Thule House From Cape Espenberg, Alaska. Open Archaeology 3: 17-48. 
Oonk, S., C.P. Slomp, D.J. Huisman, and S.P. Vriend

2009 Effects of Site Lithology on Geochemical Signatures of Human Occupation in Archaeological House Plans in the Netherlands. Journal of Archaeological Science 36(6): 1215-1228.

Oonk, Stijn, C. P. Slomp, and D. J. Huisman

2009 Geochemistry as an Aid in Archaeological Prospection and Site Interpretation: Current Issues And Research Directions. Archaeological Prospection 16(1): 3551.

Park, Robert

1988 "Winter Houses" and Qarmat in Thule and Historic Inuit Settlement Patterns: Some Implications for Thule Studies.Canadian Journal of Archaeology 12:163175.

1999 Seal Use and Storage in the Thule Culture of Arctic North America. Revista de Arqueología Americana 16:77-97

Pastor, Agustin, Gianni Gallello, M. Luisa Cervera, and Miguel de la Guardia

2016 Mineral Soil Composition Interfacing Archaeology and Chemistry. TrAC Trends in Analytical Chemistry 78: 48-59.

Price, T.Douglas, and James H. Burton

2011 An Introduction to Archaeological Chemestry. First edition. Springer, New York and London.

Proudfoot, Bruce.

1976 The Analysis and Interpretation of Soil Phosphorus in Archaeological Contexts. In: Davidson, D.A., and Shackley, M.E., eds. Geoarchaeology: Earth science and the past. Boulder, Colorado: Westview Press. 93-113

Rapp, George (Rip) and Christopher L Hill

2006 Geoarcheology: the Earth-Science Approach to Archaeological Interpretation. Second edition. Yale University Press, New Haven Connecticut.

Roper, Donna C.

1979 The Method and Theory of Site Catchment Analysis: a Review. In Schiffer, M. B. (ed.) Advances in Archaeological Method and Theory Vol. II. New York: Academic, pp. 119-140. 
Rypkema, Heather a., Wayne E. Lee, Michael L. Galaty, and Jonathan Haws

2007 Rapid, In-Stride Soil Phosphate Measurement in Archaeological Survey: a New Method Tested in Loudoun County, Virginia. Journal of Archaeological Science 34(11): 1859-1867.

Schiffer, Michael B.

1972 Archaeological Context and Systemic Context. American Antiquity 37:156165.

1975 Archaeology as Behavioral Science. American Anthropologist 77:836-848.

1976 Behavioral Archaeology. Acedemic Press Inc., New York.

1987 Formation Processes of the Archaeological Record. First edition. University of New Mexico Press, Albuquerque.

Sheehan, G. W.

1995 Whaling Surplus, Trade, War, and the Integration of Prehistoric Northern dand Northwestern Alaskan economies, A.D. 1200-1826. In Hunting the Largest Animals: Native Whaling in the Western Arctic and Subarctic, edited by A. P. McCartney, pp. 185-206. Canadian Circumpolar Institute Press, Edmonton.

Stein, J. k., and W. R. Farrand

2001 Sediments in Archaeological Context. University of Utah Press, Salt Lake City.

Shahidi, Fereidoon and Synowiecki, Jozef

1993 Nutrient Composition of Mechanically Separated and Surimi-Like Seal Meat. Food Chemistry 47(1):41-46.

Waters, Michael R.

1992 Principles of Geoarchaeology : a North American Perspective.University of Arizona Press, Tucson, Arizona.

Wells, E. Christian

2004a A Brief History of Archaeological Soil Chemistry. Newsletter Int. Union of Soil Science Society of America 11(February): 2-4.

2004b Investigating Activity Patterns in Prehispanic Plazas: Weak-Acid Extraction ICP-AES Analysis of Anthrosols of Classic Period El Coyote, Northwestern Honduras. Archaeometry 46: 67-84. 
Wells, E.C., C. Novotny, and J.R. Hawken

2007 Quantitative Modeling of Soil Chemical Reveals, Evidence for Cooking and Eating in Ancient Mesoamerican Plazas Data from Inductively Coupled PlasmaOptical Emission Spectroscopy. In Archaeological American, Chemistry: Analytical Techniques and Archaeological Interpretation, edited by M.D. Glascock, R.J. Speakman, and R.S. Popelka-Filcoff, pp. 210-230. Chemical Society, Washington D.C.

Weisstein, Eric W.

2018 "Bonferroni Correction." From MathWorld--A Wolfram Web Resource. http://mathworld.wolfram.com/BonferroniCorrection.html.

Weintraub, Michael N

2011 Biological Phosphorus Cycling in Arctic and Alpine Soils. In Phosphorus in action -Biological processes in soil phosphorus cycling.E.K. Bünemann, Astrid Oberson, Emmanuel Frossard (eds.) Soil Biology Vol. 26 (pp.295-316). Springer publishing, NewYork.

Wood, W. Raymond, and Donald Lee Johnson

1978 A Survey of Disturbance in Archaeological Processes Formation Site. Advances in Archaeological Method and Theory Vol. 1:315-381.

Yamamoto, Yoshiyuki ; Honda, Katsuhisa ; Hidaka, Hideo ; Tatsukawa, Ryo

1987 Tissue distribution of Meavy metals in Weddell Seals (Leptonychotes weddellii). Marine Pollution Bulletin, 18(4), 164-169. 
Appendix A Phase One: Photometric Phosphates Reactions 

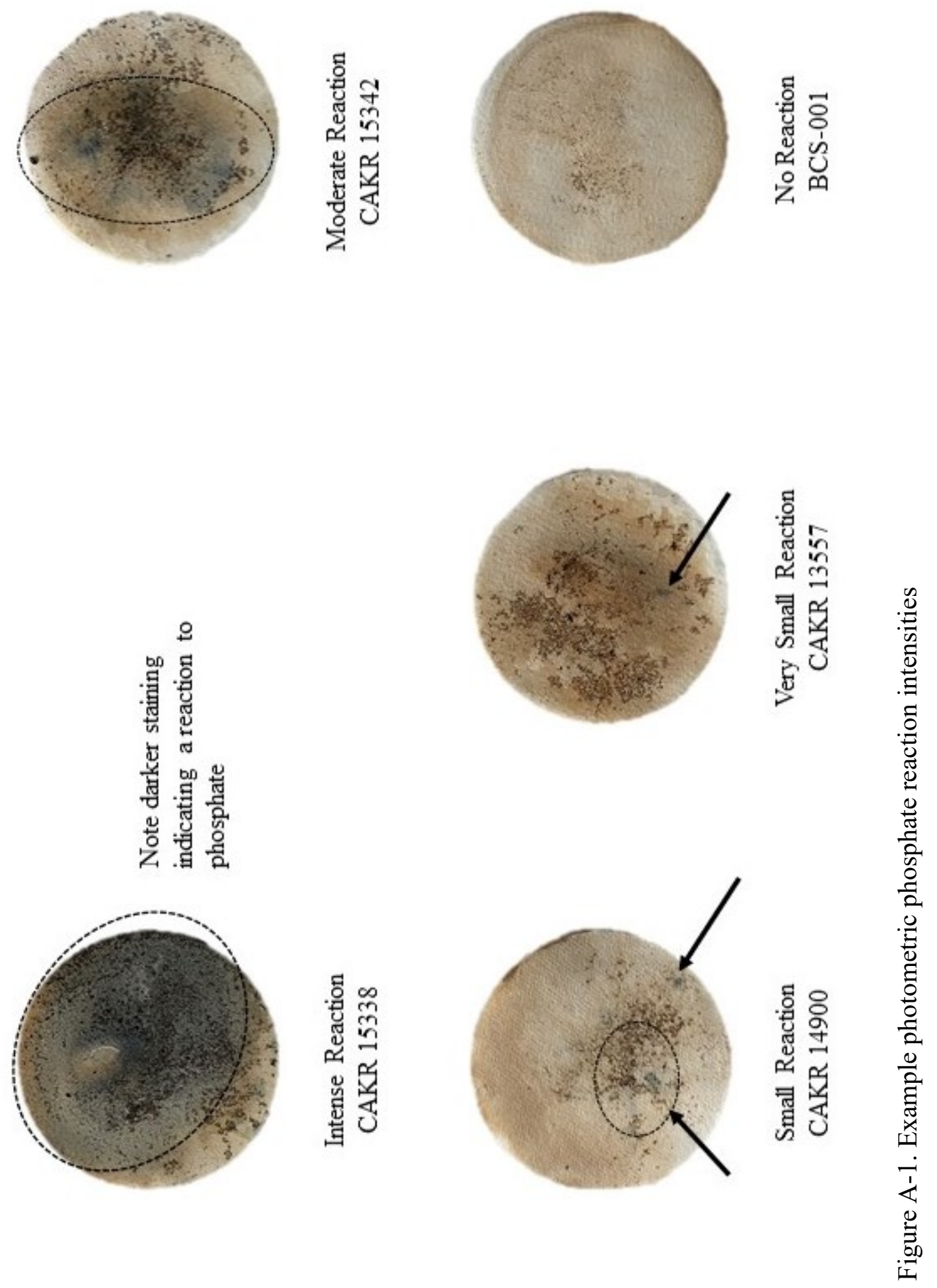


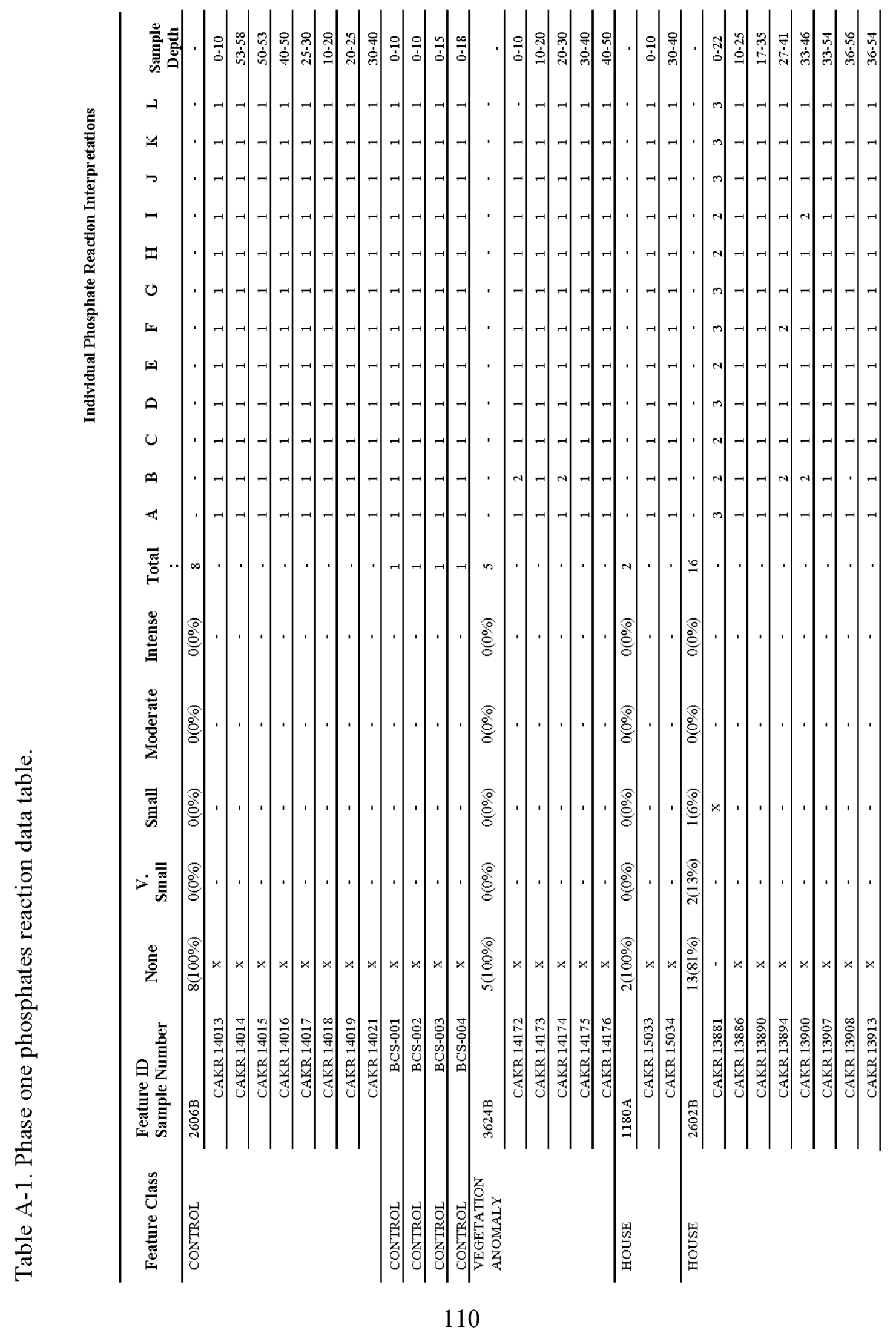




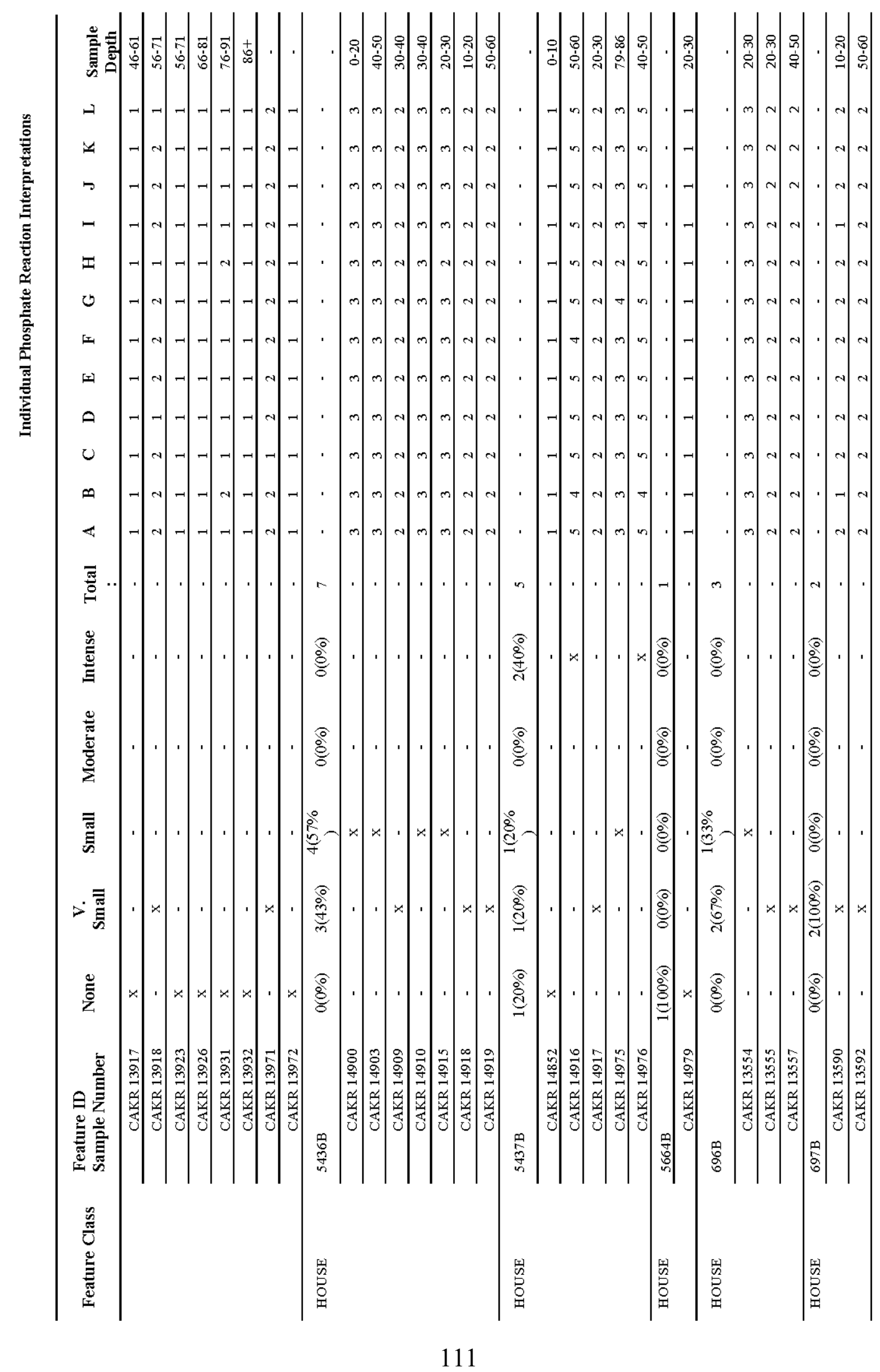




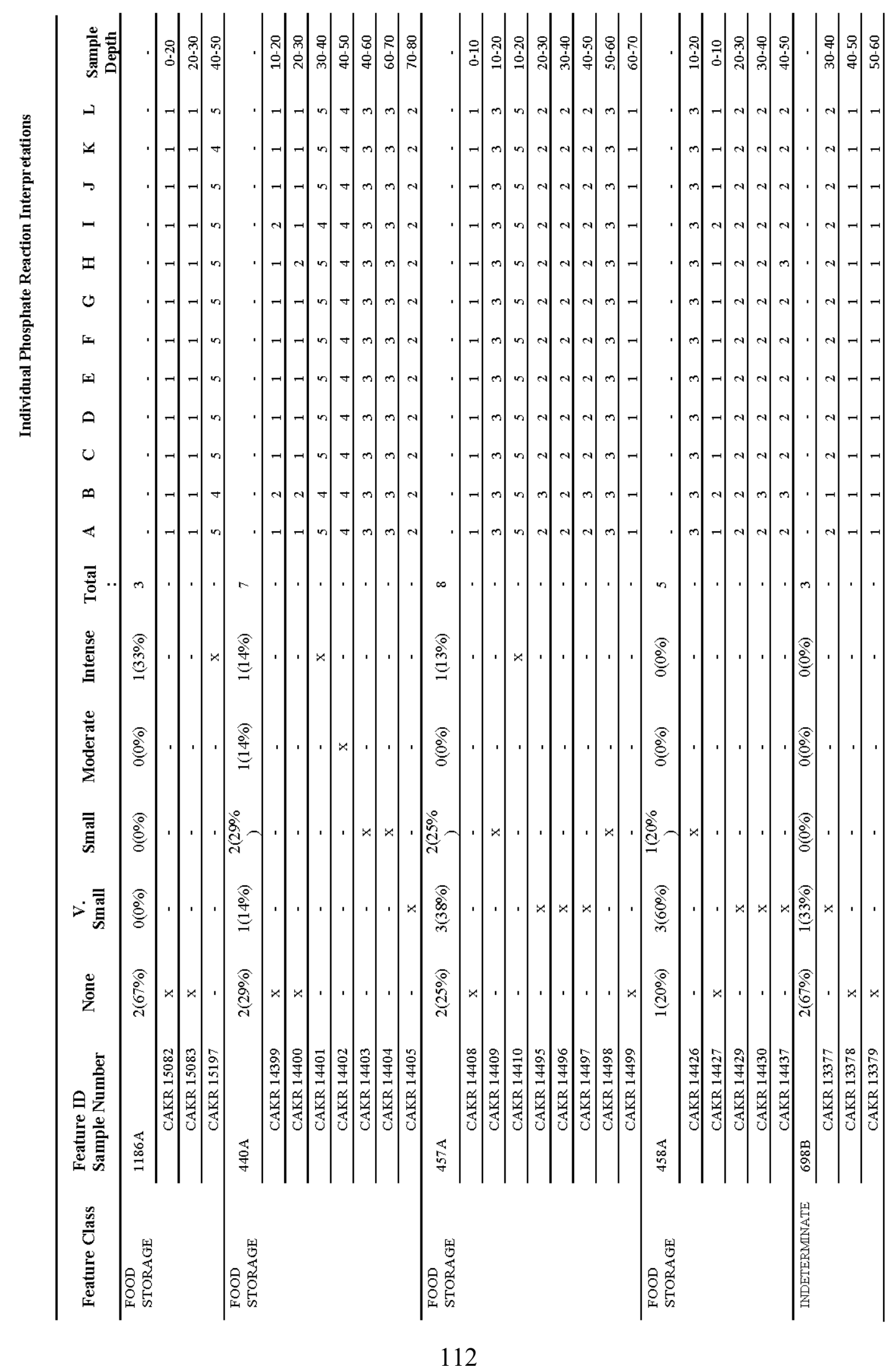




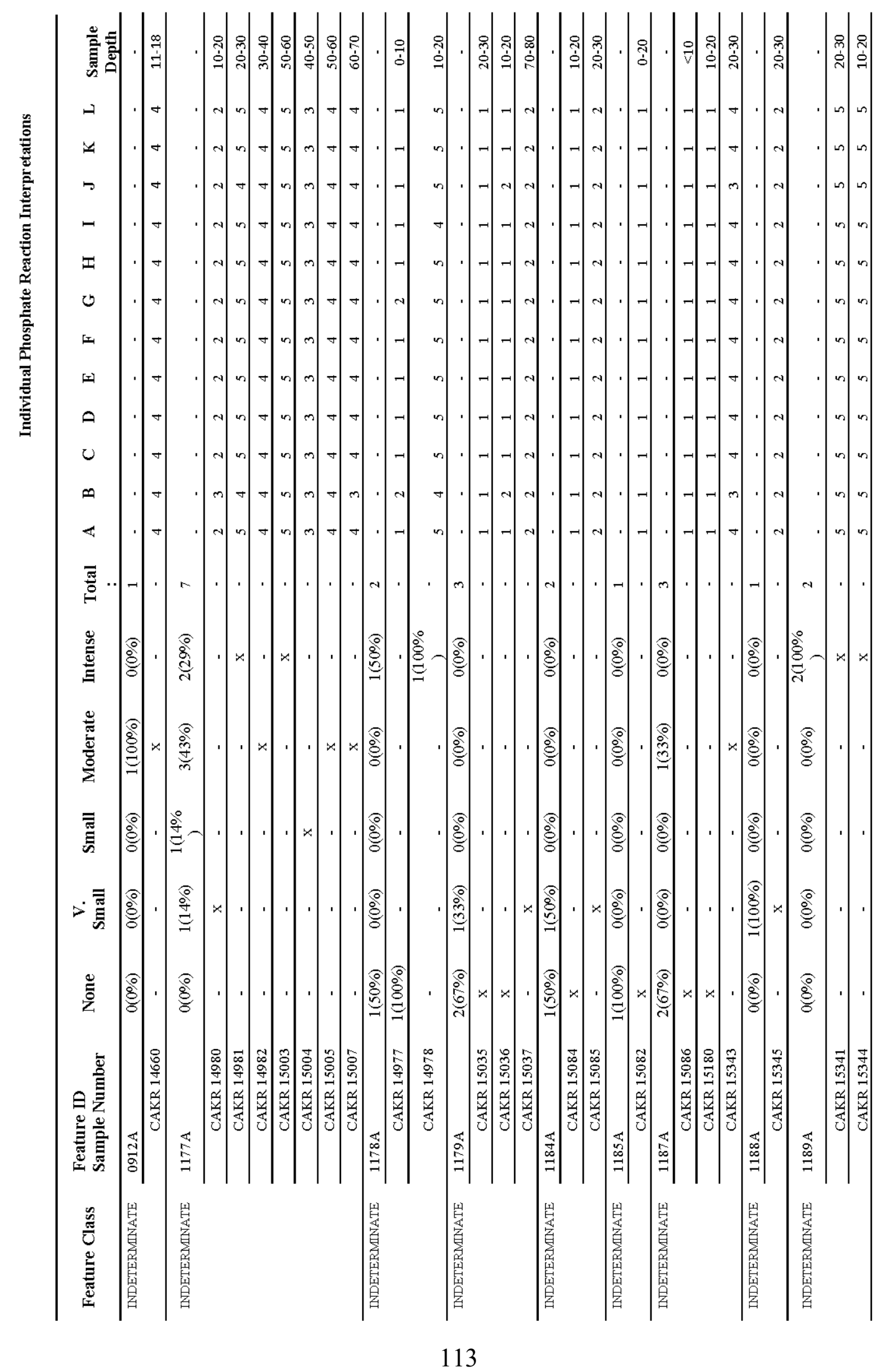




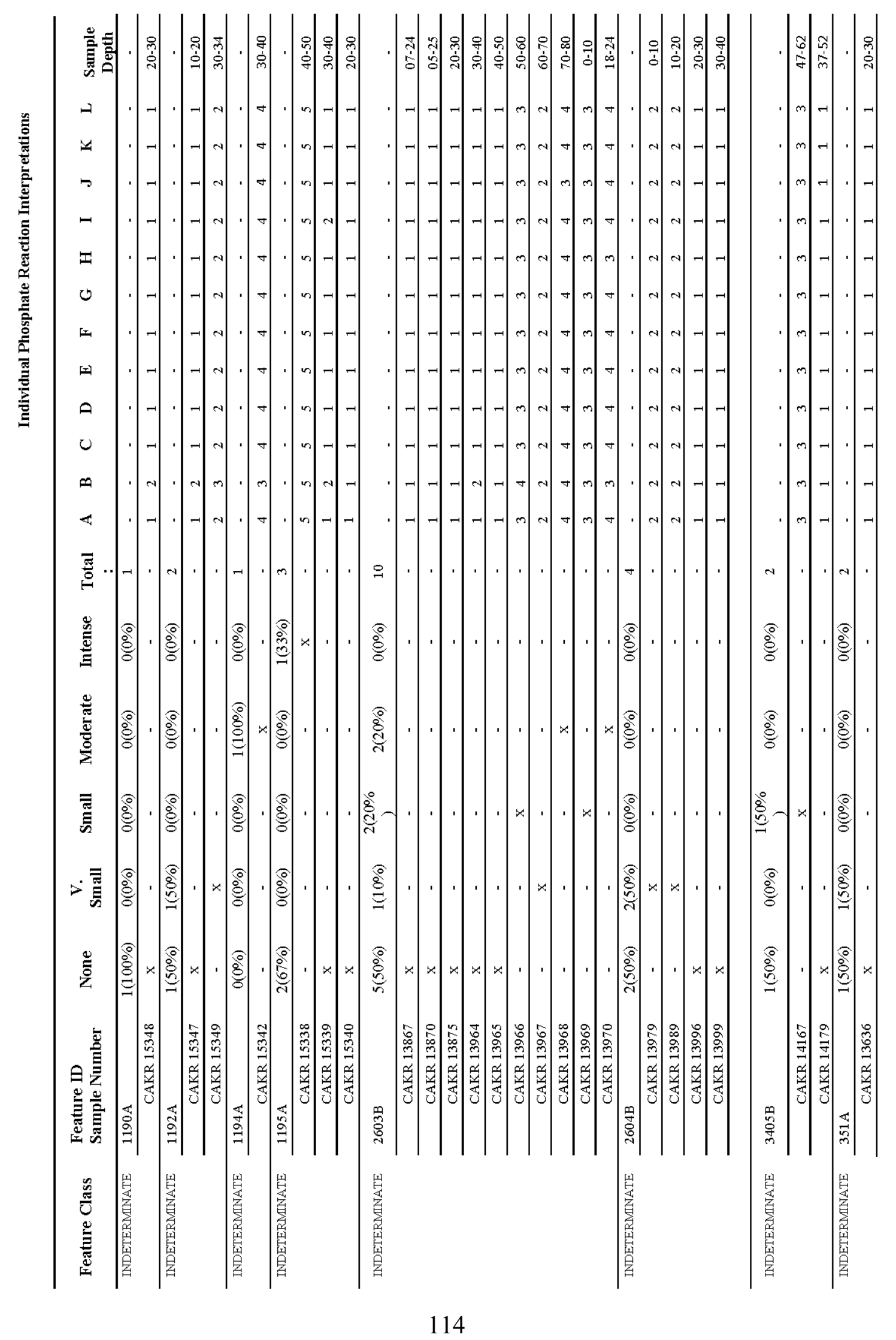




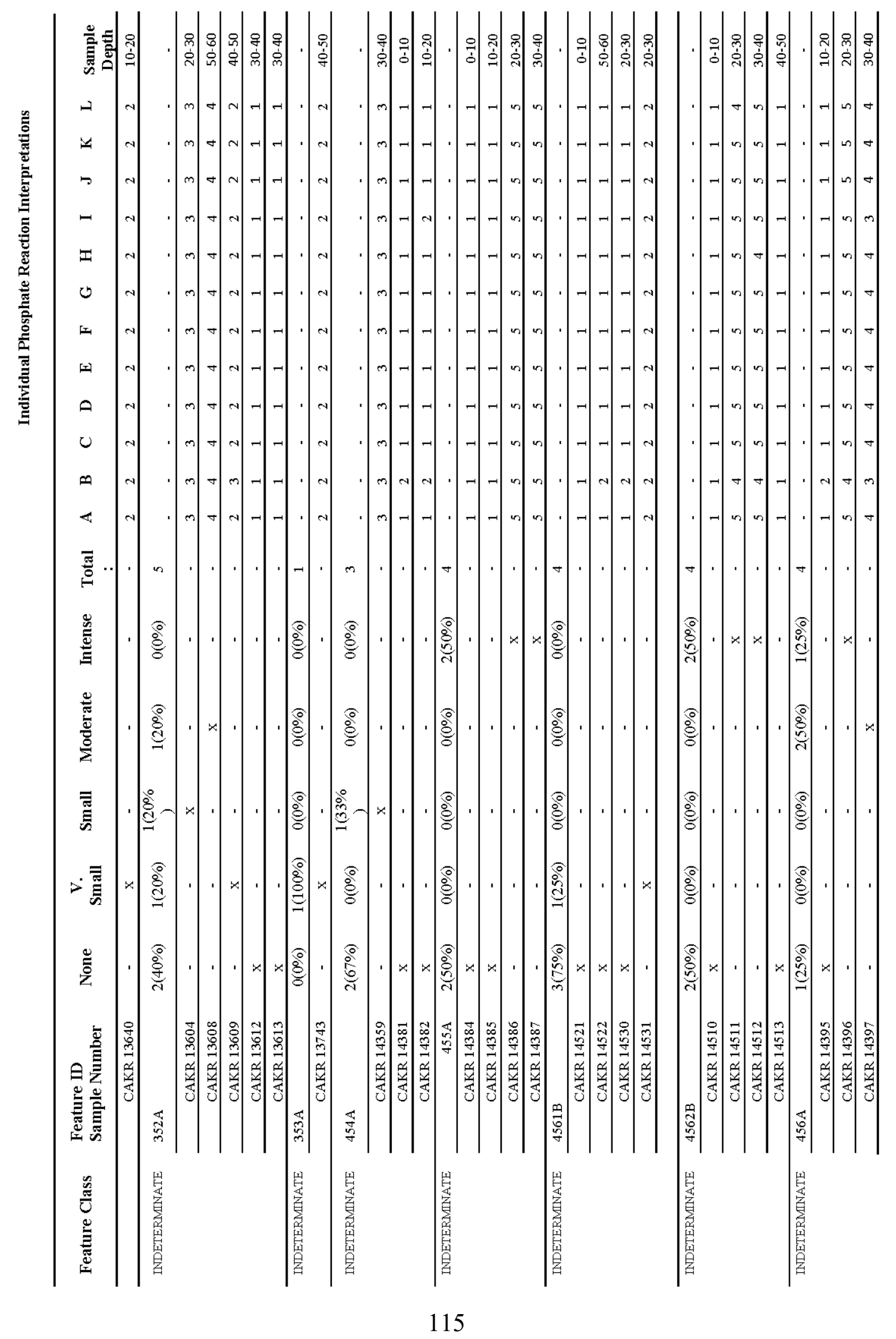




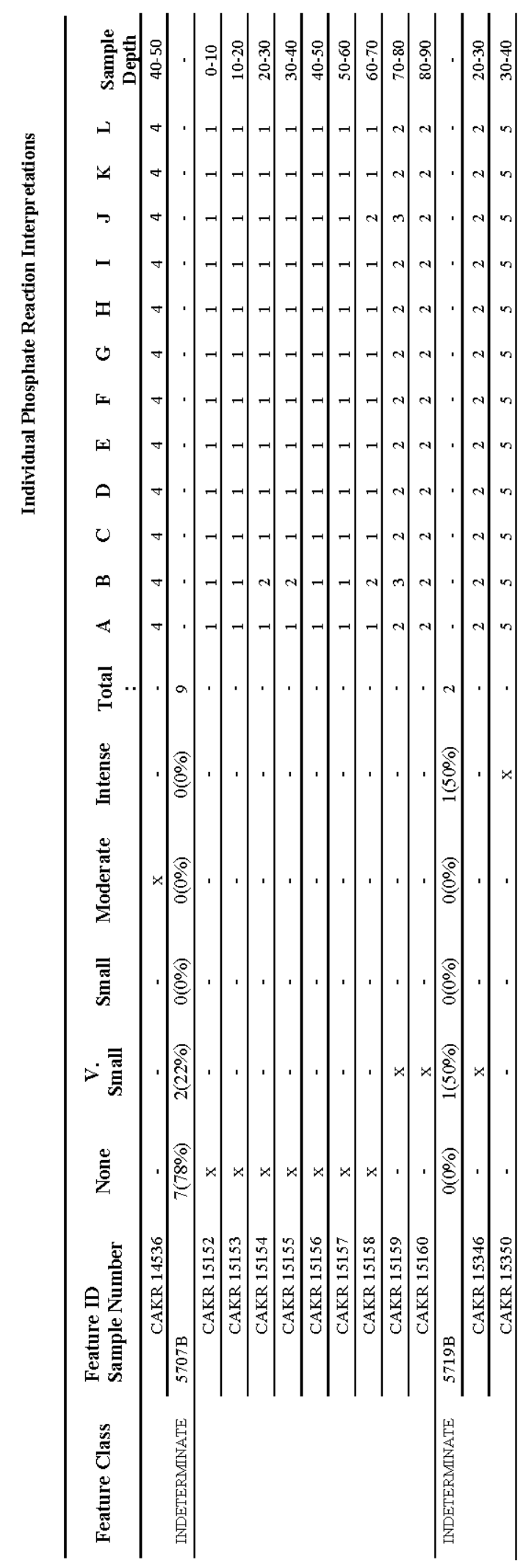


Appendix B Phase Two: ICP-MS Element Concentration Data. 


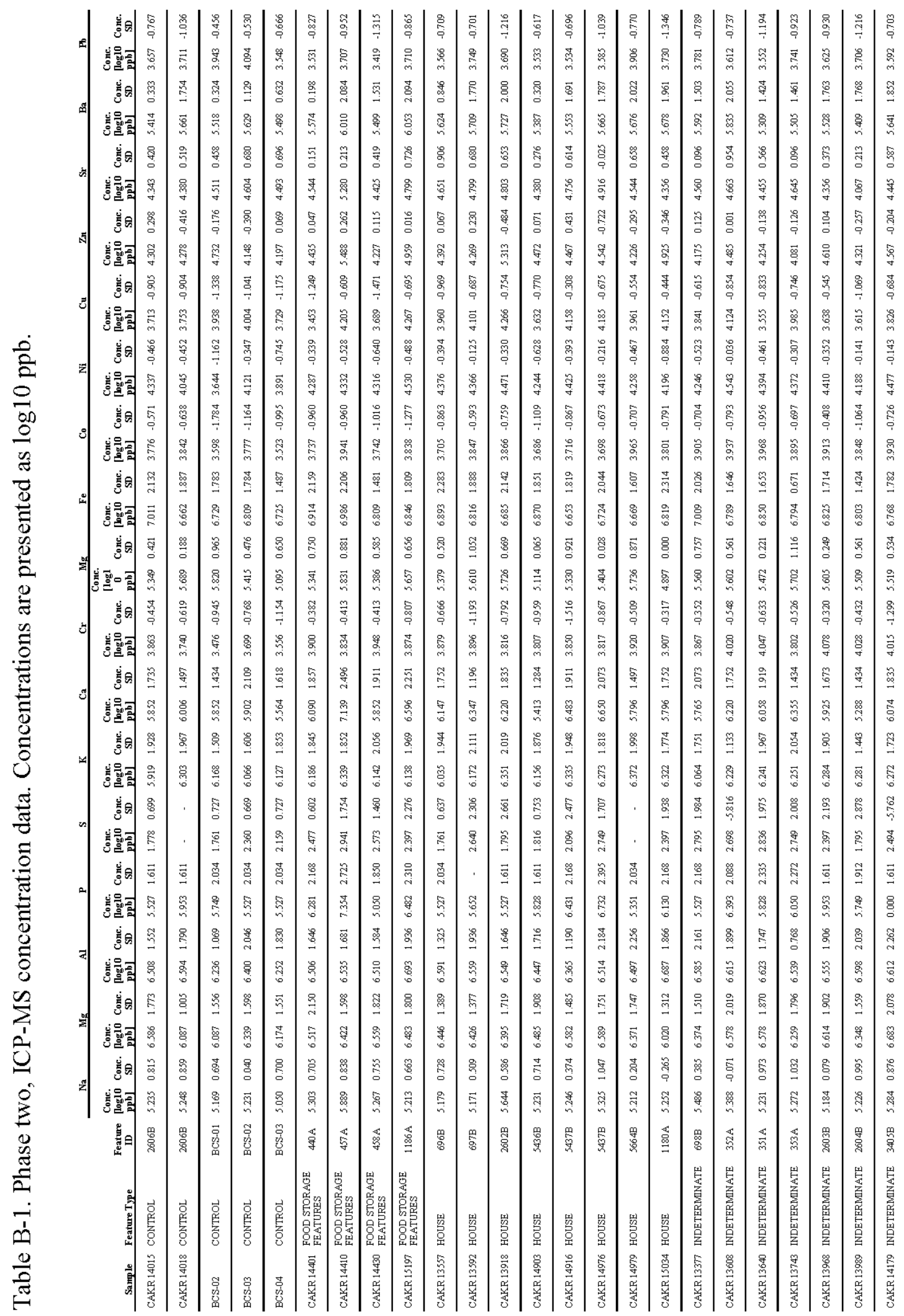




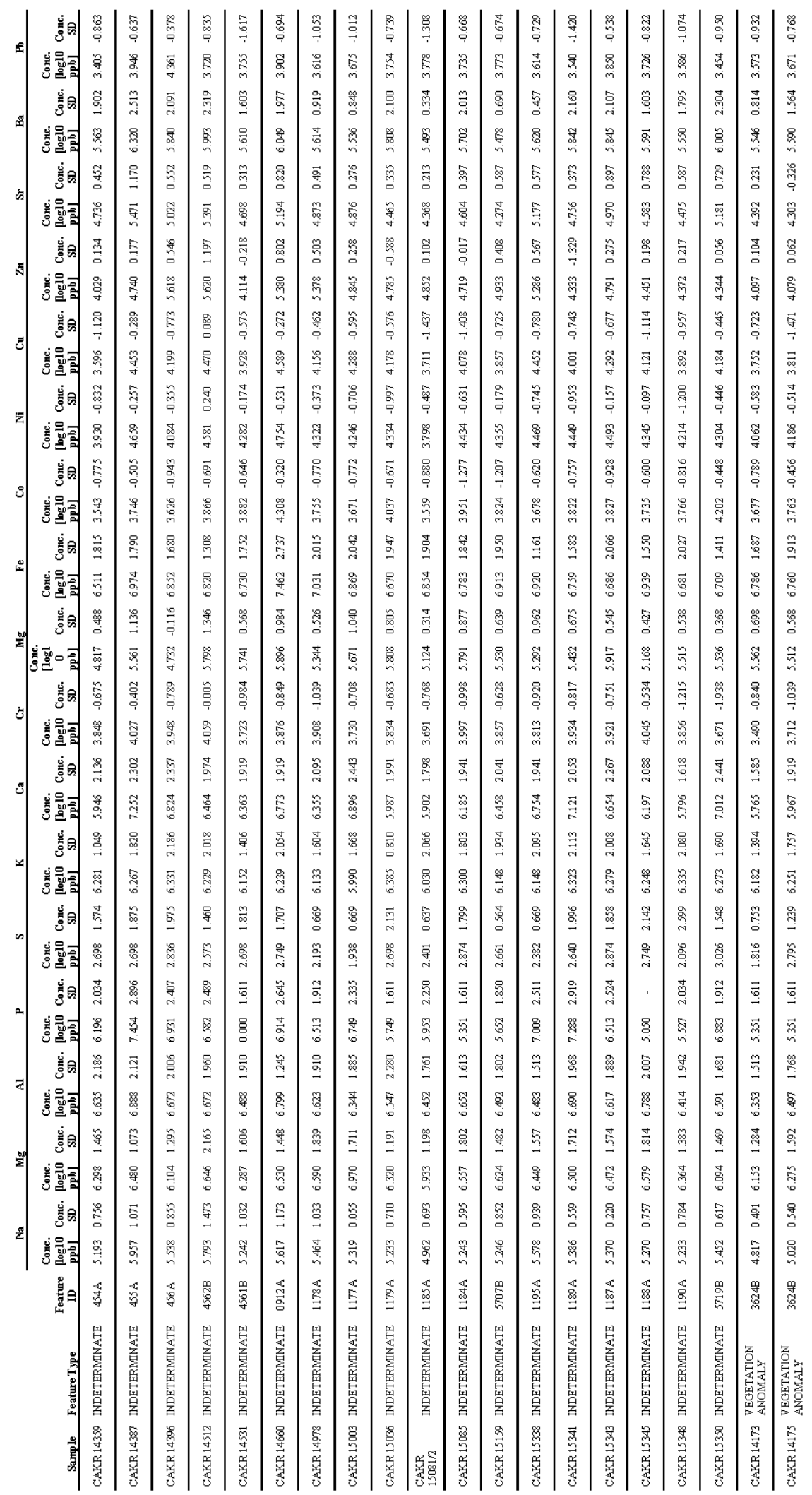




\section{ICP-MS Analysis Data Validation}

Accuracy of the analysis is considered good for all elements with exception of S. Accuracy is measured here as percent difference between expected and predicted values of the external standards. Generally, all standards measured within $10 \%$ of the expected concentration values. Measurements with high $(\geq 20 \%)$ percent differences were not included in calibration curves. Sulfur and phosphorus are hard elements to ionize and measure in ICP-MS analysis (Nakano 2018). Intensities (CPS) of sulfur are low in the available standards and only recorded in higher concentrations of (between 1000 and 5000 ppb). Phosphorus intensities were similarly low in the standards, but were recorded across the range of standard dilutions, and a reliable concentration curve was produced.

Precision of the analysis is considered excellent for select elements and good to poor for the remainder discussed below. The analysis indicated excellent precision $(\% \mathrm{RSD}$ values $\leq 5 \%$ ) for the $\mathrm{Na}, \mathrm{Cr}, \mathrm{Fe}, \mathrm{Co}, \mathrm{Ni}, \mathrm{Cu}, \mathrm{Zn}, \mathrm{Pb}$ standards while precision of $\mathrm{Mg}, \mathrm{K}$, $\mathrm{Mn}, \mathrm{Sr}$, and $\mathrm{Ba}$ is considered good $(\% \mathrm{RSD}$ values $\leq 10 \%)$. Precision is considered fair to poor for analyte elements $\mathrm{Al}$ (Fair; $5 \%$ to $25 \%$ ), P (Poor; $3.3 \%$ to $100 \%$ ), S (Not reliably detectable), and $\mathrm{Ca}$ (Poor; $5.6 \%$ to $173.2 \%$ ). Most often the high \%RSD values are obtained in the low end of standard concentrations $(\leq 50 \mathrm{ppb})$. High $\%$ RSD values are excluded from calibration curves when possible. Unfortunately, $\mathrm{S}$ was not able to be measured accurately or reliably in the range of available standard concentrations, as such it was excluded from further analysis. Despite the fair to poor precision in $\mathrm{Al}, \mathrm{P}$, and $\mathrm{Ca}$, these elements are included in the statistical analysis given their importance in anthropogenic signatures. 


\section{ICP-MS Analysis Method Validation}

Each analyte element was recovered within $\pm 25 \%$ of the expected reference values with exception to $\mathrm{Al}, \mathrm{Mn}, \mathrm{Fe}$, and $\mathrm{Ca}$ which recovered in significantly lower quantities ( $\leq$ $59 \%$ ), while $\mathrm{S}$ and $\mathrm{P}$ are recovered in significantly higher quantities than expected. Precision for the method is considered excellent with \%RSD observed at or below $10 \%$ for all analyte elements with exception to $\mathrm{P}, \mathrm{S}$, and $\mathrm{Ca}$. The low recovery of $\mathrm{Al}, \mathrm{Mn}$, and Fe suggest that the high recovery of $\mathrm{S}$ and $\mathrm{P}$ is likely related to the high imprecision associated in the measurement of these elements in the analysis. As noted previously, these elements are particularly difficulty of measuring in ICP-MS analysis. Due to the importance of $\mathrm{P}$ and $\mathrm{Ca}$ as anthropogenic indicators, I include these elements along with $\mathrm{Al}, \mathrm{Mn}$ and $\mathrm{Fe}$ in the statistical analysis with the caveat that their concentration values are likely reporting as lower than the actual concentration in the samples. 
Table B-1. Descriptive Statistics of Analyte Elements by Feature Class

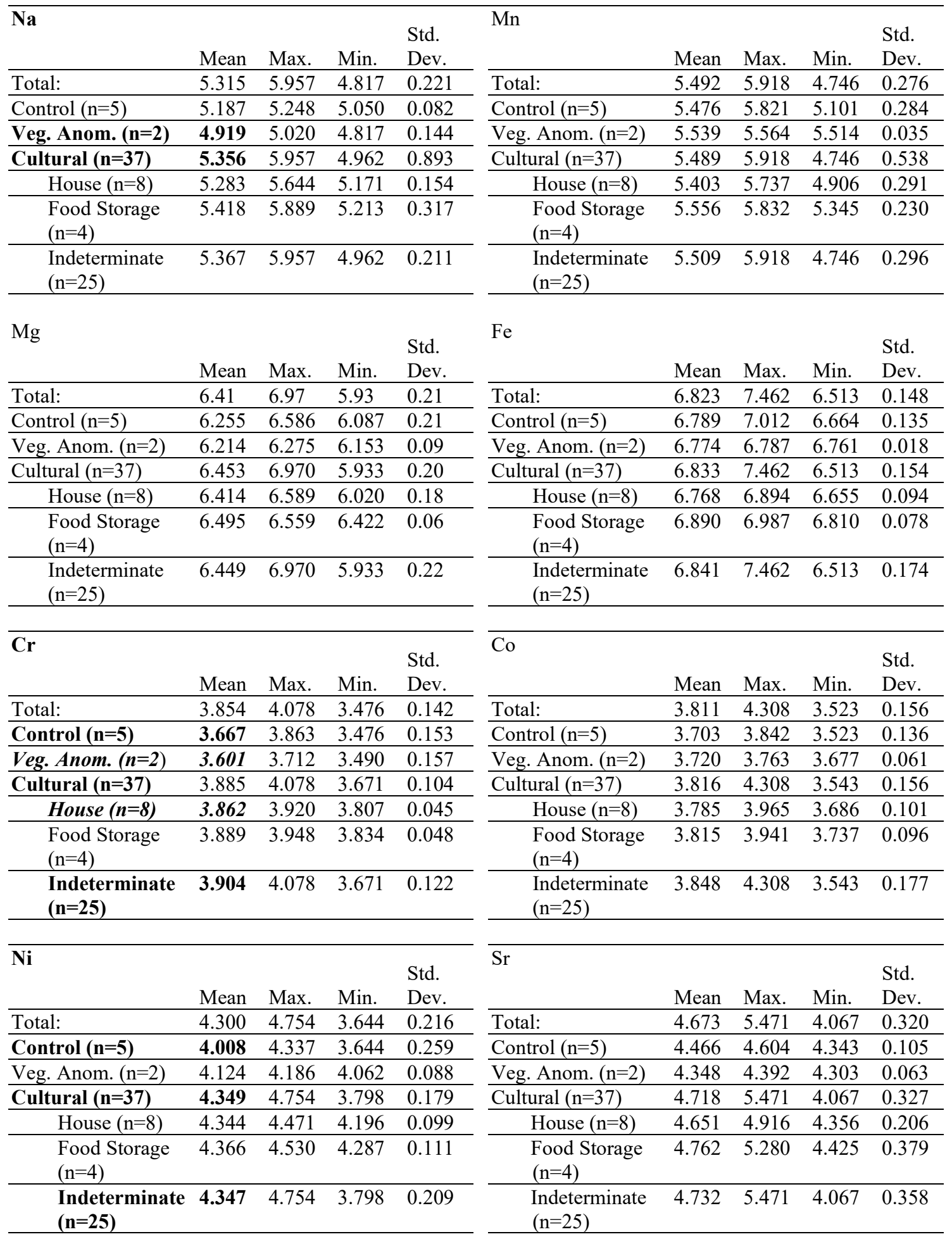


Table C-2 cont'd. Descriptive Statistics of Analyte Elements by Feature Class

\begin{tabular}{|c|c|c|c|c|c|c|c|c|c|}
\hline \multirow[t]{2}{*}{$\mathrm{Cu}$} & \multicolumn{8}{|c|}{$\mathrm{Ba}$} & \multirow{2}{*}{$\begin{array}{l}\text { Std. } \\
\text { Dev. }\end{array}$} \\
\hline & Mean & Max. & Min. & Dev. & & Mean & Max. & Min. & \\
\hline Total: & 3.994 & 4.589 & 3.453 & 0.275 & Total: & 5.666 & 6.320 & 5.309 & 0.207 \\
\hline Control $(n=5)$ & 3.703 & 3.842 & 3.523 & 0.134 & Control $(n=5)$ & 5.544 & 5.661 & 5.414 & 0.101 \\
\hline Veg. Anom. $(n=2)$ & 3.782 & 3.811 & 3.752 & 0.042 & Veg. Anom. $(n=2)$ & 5.568 & 5.590 & 5.546 & 0.031 \\
\hline Cultural $(n=37)$ & 3.999 & 4.589 & 3.453 & 0.284 & Cultural $(n=37)$ & 5.687 & 6.320 & 5.309 & 0.217 \\
\hline House $(n=8)$ & 4.052 & 4.266 & 3.632 & 0.200 & House $(n=8)$ & 5.627 & 5.727 & 5.387 & 0.111 \\
\hline $\begin{array}{l}\text { Food Storage } \\
(\mathrm{n}=4)\end{array}$ & 3.903 & 4.267 & 3.453 & 0.397 & $\begin{array}{l}\text { Food Storage } \\
(\mathrm{n}=4)\end{array}$ & 5.784 & 6.053 & 5.499 & 0.288 \\
\hline $\begin{array}{l}\text { Indeterminate } \\
(\mathrm{n}=25)\end{array}$ & 4.041 & 4.589 & 3.555 & 0.295 & $\begin{array}{l}\text { Indeterminate } \\
(\mathrm{n}=25)\end{array}$ & 5.691 & 6.320 & 5.309 & 0.232 \\
\hline \multirow[t]{2}{*}{$\mathrm{Zn}$} & & & & & \multicolumn{4}{|l|}{$\mathrm{Pb}$} & \\
\hline & Mean & Max. & Min. & Dev. & & Mean & Max. & Min. & Dev. \\
\hline Total: & 4.605 & 5.620 & 4.029 & 0.449 & Total: & 3.697 & 4.361 & 3.405 & 0.176 \\
\hline Control $(n=5)$ & 4.331 & 4.732 & 4.148 & 0.232 & Control $(n=5)$ & 3.791 & 4.094 & 3.548 & 0.223 \\
\hline Veg. Anom. $(n=2)$ & 4.088 & 4.097 & 4.079 & 0.013 & Veg. Anom. $(n=2)$ & 3.622 & 3.671 & 3.573 & 0.069 \\
\hline Cultural $(n=37)$ & 4.670 & 5.620 & 4.029 & 0.453 & Cultural $(n=37)$ & 3.688 & 4.361 & 3.405 & 0.173 \\
\hline $\begin{array}{c}\text { House }(n=8) \\
\end{array}$ & 4.576 & 5.313 & 4.226 & 0.366 & $\begin{array}{c}\text { House }(n=8) \\
\end{array}$ & 3.662 & 3.906 & 3.533 & 0.131 \\
\hline $\begin{array}{l}\text { Food Storage } \\
(n=4)\end{array}$ & 4.777 & 5.488 & 4.227 & 0.565 & $\begin{array}{l}\text { Food Storage } \\
(n=4)\end{array}$ & 3.592 & 3.710 & 3.419 & 0.142 \\
\hline $\begin{array}{l}\text { Indeterminate } \\
(\mathrm{n}=25)\end{array}$ & 4.683 & 5.620 & 4.029 & 0.473 & $\begin{array}{l}\text { Indeterminate } \\
(\mathrm{n}=25)\end{array}$ & 3.712 & 4.361 & 3.405 & 0.186 \\
\hline \multirow[t]{2}{*}{$\mathrm{Ca}$} & & & & & \multicolumn{4}{|l|}{$\overline{\text { Al }}$} & \\
\hline & Mean & Max. & Min. & Dev. & & Mean & Max. & Min. & Dev. \\
\hline Total: & 6.229 & 7.252 & 5.288 & 0.469 & Total: & 6.55 & 6.89 & 6.24 & 0.13 \\
\hline Control $(\mathrm{n}=5)$ & 5.835 & 6.006 & 5.564 & 0.164 & Control $(n=5)$ & 6.40 & 6.59 & 6.24 & 0.16 \\
\hline Veg. Anom. $(n=2)$ & 5.866 & 5.967 & 5.765 & 0.143 & Veg. Anom. $(n=2)$ & 6.42 & 6.50 & 6.35 & 0.10 \\
\hline Cultural $(n=37)$ & 6.301 & 7.252 & 5.288 & 0.474 & Cultural $(n=37)$ & 6.58 & 6.89 & 6.34 & 0.11 \\
\hline House $(\mathrm{n}=8)$ & 6.106 & 6.650 & 5.413 & 0.411 & House $(\mathrm{n}=8)$ & 6.53 & 6.69 & 6.37 & 0.10 \\
\hline $\begin{array}{l}\text { Food Storage } \\
(n=4)\end{array}$ & 6.419 & 7.139 & 5.852 & 0.572 & $\begin{array}{l}\text { Food Storage } \\
(n=4)\end{array}$ & 6.56 & 6.69 & 6.51 & 0.09 \\
\hline $\begin{array}{l}\text { Indeterminate } \\
(\mathrm{n}=25)\end{array}$ & 6.345 & 7.252 & 5.288 & 0.479 & $\begin{array}{l}\text { Indeterminate } \\
(\mathrm{n}=\mathbf{2 5})\end{array}$ & 6.60 & 6.89 & 6.34 & 0.12 \\
\hline \multirow[t]{2}{*}{$\overline{\mathrm{K}}$} & & & & & \multirow{2}{*}{\multicolumn{4}{|c|}{$\mathrm{P}$}} & \\
\hline & Mean & Max. & Min. & $\begin{array}{l}\text { Std. } \\
\text { Dev. }\end{array}$ & & & & Min. & $\begin{array}{l}\text { Std. } \\
\text { Dev. }\end{array}$ \\
\hline Total: & 6.217 & 6.385 & 5.919 & 0.108 & Total: & 5.799 & 7.454 & 0.000 & 1.427 \\
\hline Control $(n=5)$ & 6.117 & 6.303 & 5.919 & 0.141 & Control $(n=5)$ & 5.657 & 5.953 & 5.527 & 0.192 \\
\hline Veg. Anom. $(n=2)$ & 6.216 & 6.251 & 6.182 & 0.049 & Veg. Anom. $(n=2)$ & 5.351 & 5.351 & 5.351 & 0.000 \\
\hline Cultural $(n=37)$ & 6.231 & 6.385 & 5.990 & 0.100 & Cultural $(n=37)$ & 5.842 & 7.454 & 0.000 & 1.553 \\
\hline House $(n=8)$ & 6.252 & 6.372 & 6.035 & 0.119 & House $(n=8)$ & 5.897 & 6.732 & 5.351 & 0.489 \\
\hline $\begin{array}{l}\text { Food Storage } \\
(\mathrm{n}=4)\end{array}$ & 6.201 & 6.339 & 6.138 & 0.095 & $\begin{array}{l}\text { Food Storage } \\
(\mathrm{n}=4)\end{array}$ & 6.292 & 7.354 & 5.050 & 0.950 \\
\hline $\begin{array}{l}\text { Indeterminate } \\
(\mathrm{n}=25)\end{array}$ & 6.229 & 6.385 & 5.990 & 0.098 & $\begin{array}{l}\text { Indeterminate } \\
(\mathrm{n}=25)\end{array}$ & 5.753 & 7.454 & 0.000 & 1.842 \\
\hline
\end{tabular}

Bold text indicates ANOVA Significance at $\mathrm{p}=<.05$; Italic text indicates T-test assuming equal variance with Bonferroni correction Significance $\mathrm{p}=<.005$ 


\section{Principal Component Analysis- Cultural features only}

Table B-2. PCA-Cult. Principal Component Data of Cultural Samples Only

\begin{tabular}{|c|c|c|c|c|c|}
\hline & PC-1c & $\mathrm{PC}-2 \mathrm{c}$ & $\mathrm{PC}-3 \mathrm{c}$ & $\mathrm{PC}-4 \mathrm{c}$ & PC-5c \\
\hline Variance & $35.963 \%$ & $14.021 \%$ & $10.993 \%$ & $9.484 \%$ & $7.695 \%$ \\
\hline $\begin{array}{l}\text { Cumulative } \\
\text { Variance }\end{array}$ & $35.963 \%$ & $49.984 \%$ & $60.977 \%$ & $70.461 \%$ & $78.156 \%$ \\
\hline Eigen Value & 5.754 & 2.243 & 1.759 & 1.517 & 1.231 \\
\hline $\mathrm{Sr}$ & .960 & .026 & -.097 & -.023 & .043 \\
\hline $\mathrm{Ca}$ & .902 & .056 & -.172 & -.015 & .100 \\
\hline $\mathrm{Cu}$ & .816 & .215 & -.070 & .056 & -.087 \\
\hline $\mathrm{Na}$ & .765 & .068 & .193 & .044 & .003 \\
\hline $\mathrm{Ba}$ & .750 & .251 & .131 & -.138 & -.206 \\
\hline $\mathrm{P}$ & .617 & -.408 & .061 & -.029 & .047 \\
\hline $\mathrm{Zn}$ & .577 & -.101 & .080 & .323 & -.213 \\
\hline $\mathrm{Co}$ & -.046 & .894 & .070 & -.037 & -.159 \\
\hline $\mathrm{Mn}$ & .130 & .865 & -.134 & .027 & .216 \\
\hline $\mathrm{Ni}$ & .386 & .523 & .354 & .064 & .394 \\
\hline $\mathrm{Cr}$ & -.221 & -.070 & .988 & -.051 & .207 \\
\hline $\mathrm{Al}$ & .181 & .030 & .732 & .031 & -.263 \\
\hline $\mathrm{Fe}$ & .081 & .156 & .207 & .826 & -.134 \\
\hline $\mathrm{K}$ & .156 & .167 & .362 & -.776 & -.204 \\
\hline $\mathrm{Mg}$ & .101 & .114 & .251 & .249 & .850 \\
\hline $\mathrm{Pb}$ & .152 & .064 & .186 & .243 & -.677 \\
\hline
\end{tabular}


a) $\mathrm{PC}-1$ vs. PC-2

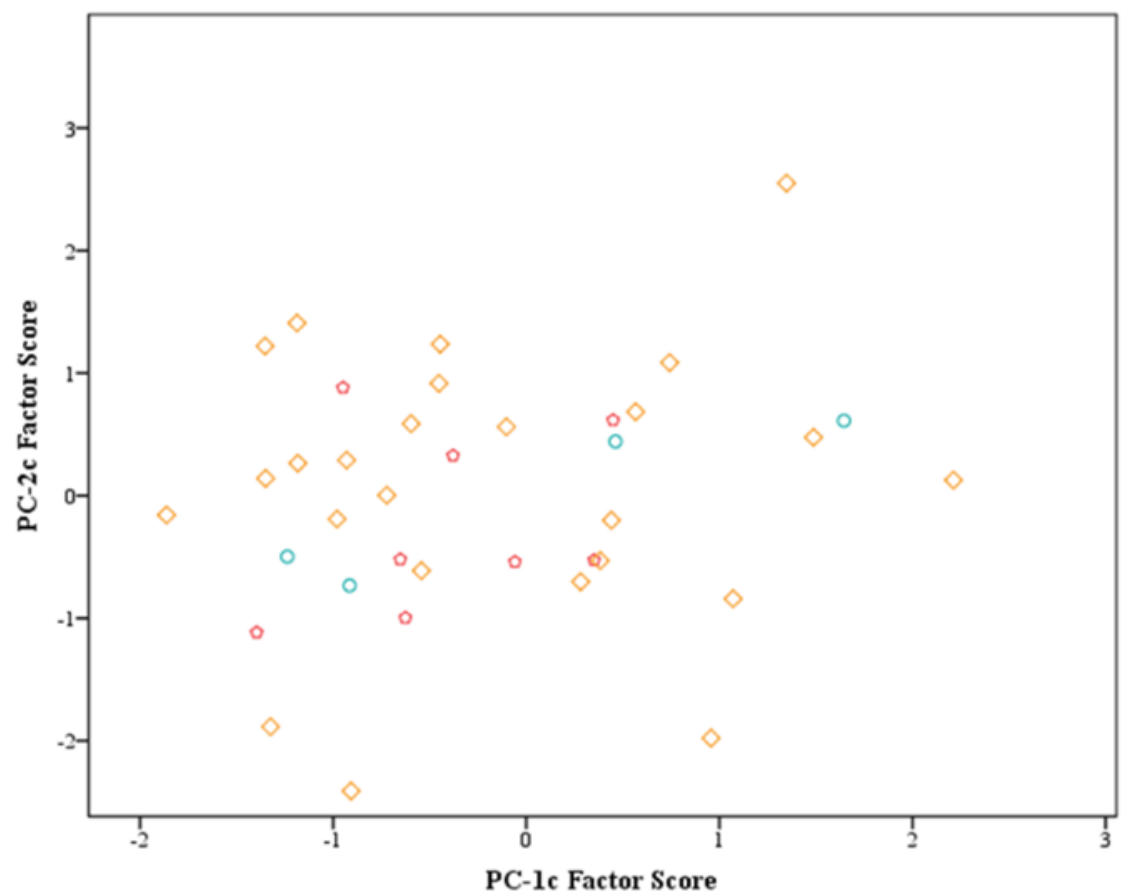

b) PC-1 vs. PC-3

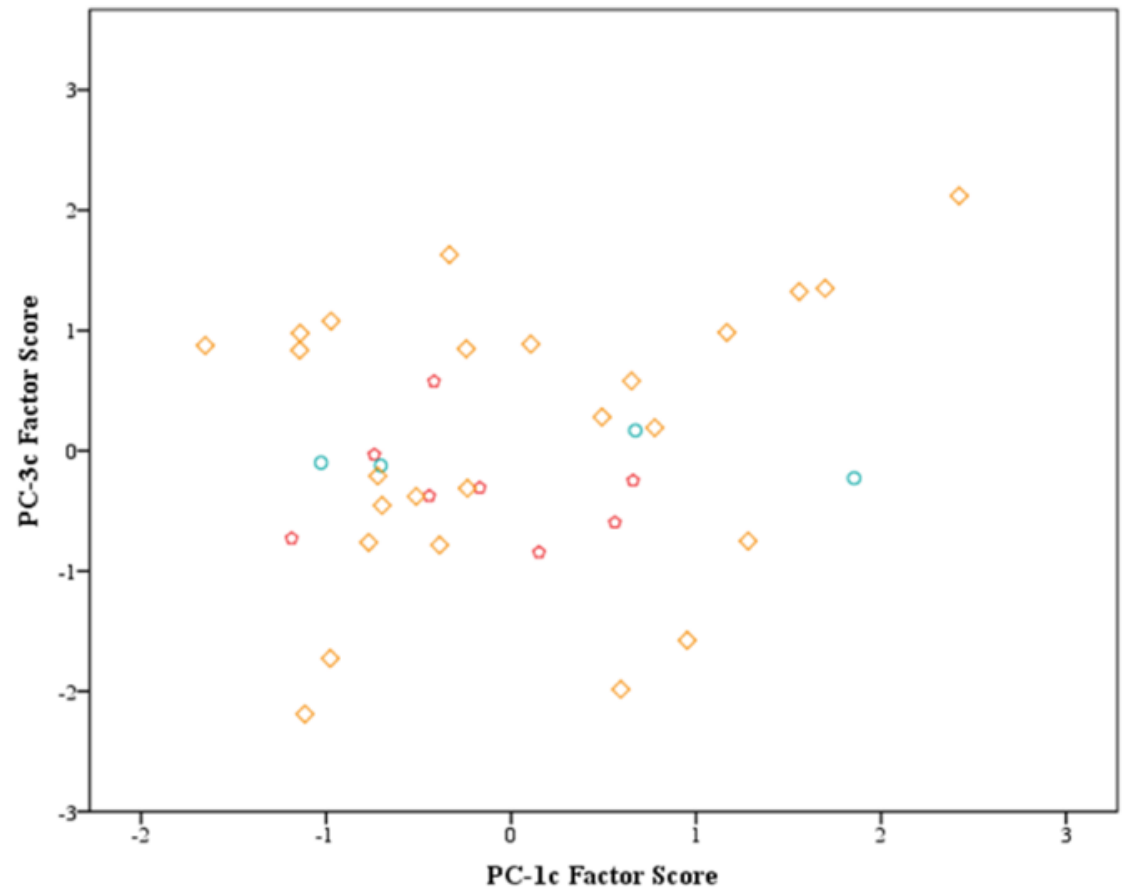

Feature Class
$\times$ Control
$\checkmark$ Houses
$\Delta$ Vegetation Anomaly
Food Storage Features
$\diamond$ Indeterminates

Figure B-1. PCA-Cult. Biplots of the first, second, and third principal components. 

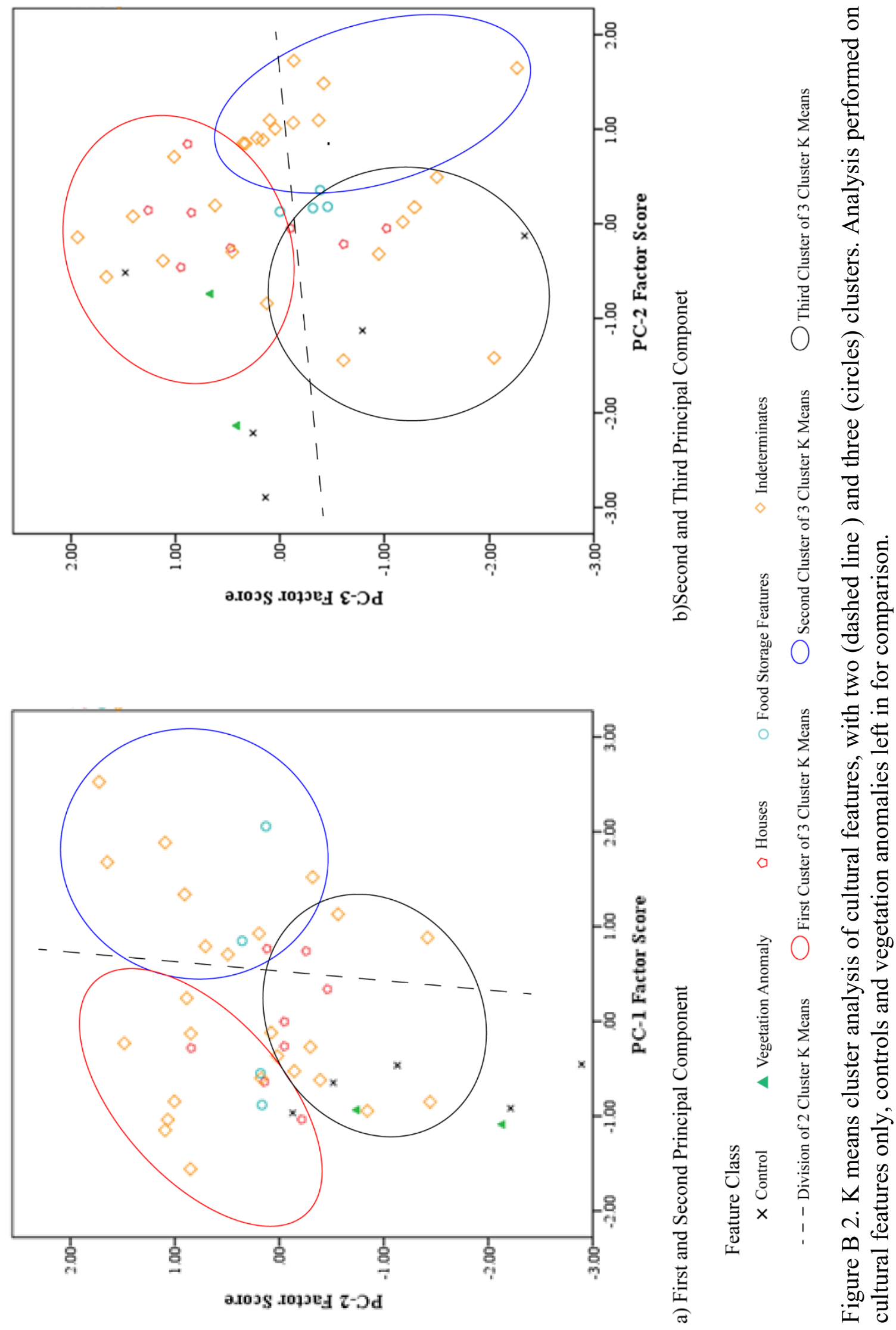